BANCA D'ITALIA

E U R O S I S T E M A

Temi di discussione

(Working Papers)

Modeling and forecasting macroeconomic downside risk

by Davide Delle Monache, Andrea De Polis and Ivan Petrella

$$
1324
$$





\section{BANCA D'ITALIA}

E U R O S I S T E M A

\section{Temi di discussione}

(Working Papers)

Modeling and forecasting macroeconomic downside risk

by Davide Delle Monache, Andrea De Polis and Ivan Petrella

Number 1324 - March 2021 
The papers published in the Temi di discussione series describe preliminary results and are made available to the public to encourage discussion and elicit comments.

The views expressed in the articles are those of the authors and do not involve the responsibility of the Bank.

Editorial Board: Federico Cingano, Marianna Riggi, Monica Andini, Audinga Baltrunaite, Marco Bottone, Davide Delle Monache, Sara Formai, Francesco Franceschi, Adriana Grasso, Salvatore lo Bello, Juho Taneli Makinen, Luca Metelli, Marco Savegnago.

Editorial Assistants: Alessandra Giammarco, Roberto Marano.

ISSN 1594-7939 (print)

ISSN 2281-3950 (online)

Printed by the Printing and Publishing Division of the Bank of Italy 


\title{
MODELING AND FORECASTING MACROECONOMIC DOWNSIDE RISK
}

\author{
by Davide Delle Monache*, Andrea De Polis** and Ivan Petrella**
}

\begin{abstract}
We document a substantial increase in downside risk to US economic growth over the last 30 years. By modelling secular trends and cyclical changes of the predictive density of GDP growth, we find an accelerating decline in the skewness of the conditional distributions, with significant, procyclical variations. Decreasing trend-skewness, which turned negative in the aftermath of the Great Recession, is associated with the long-run growth slowdown started in the early 2000s. Short-run skewness fluctuations imply negatively skewed predictive densities ahead of and during recessions, often anticipated by deteriorating financial conditions, while positively skewed distributions characterize expansions. The model delivers competitive out-of-sample (point, density and tail) forecasts, improving upon standard benchmarks, due to the strong signals of increasing downside risk provided by current financial conditions.
\end{abstract}

JEL Classification: C32, C51, C53, E44, G12.

Keywords: business cycle, financial conditions, downside risk, skewness, score driven models.

DOI: $10.32057 / 0 . T D .2021 .1324$

\section{Contents}

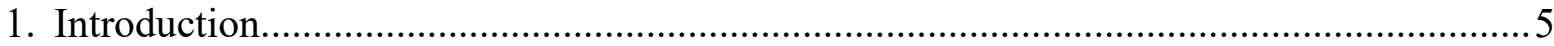

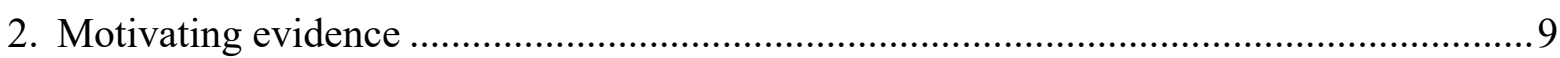

3. A time varying Skew-t model for GDP growth ........................................................... 11

3.1 Secular and cyclical variations of GDP growth's distribution ................................. 16

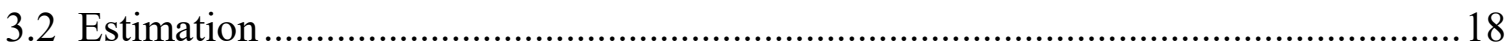

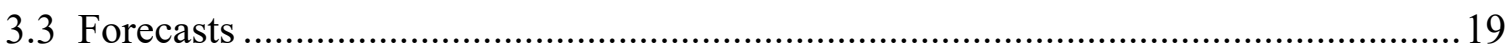

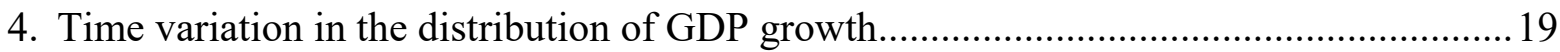

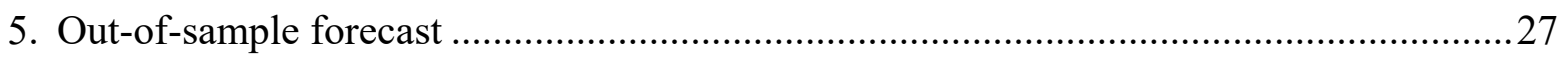

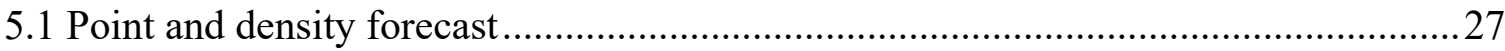

5.2 Downside risk predictions for the Great Recession.................................................. 31

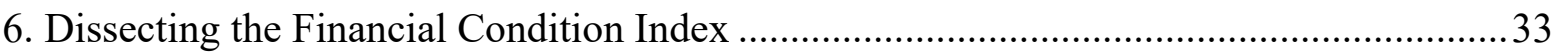

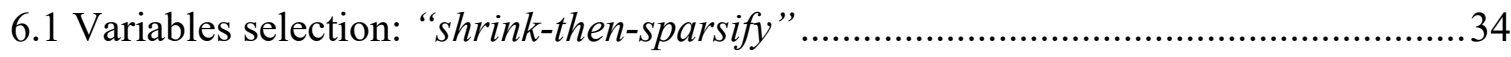

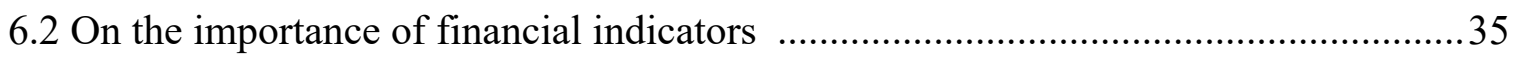

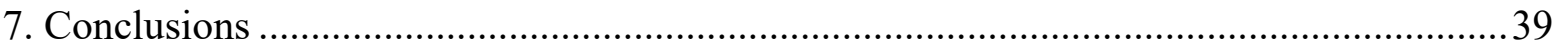

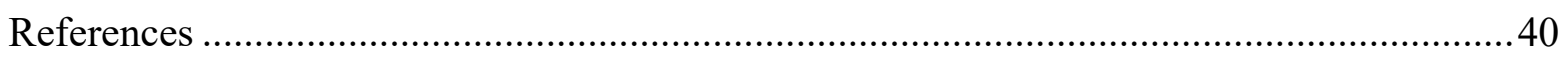

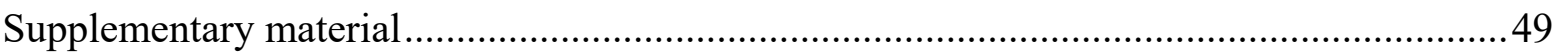

* Bank of Italy, ${ }^{* *}$ University of Warwick. 



\section{Introduction}

The Global Financial Crisis and the subsequent recession left policymakers with several new challenges. In a world of persistently sluggish growth, subject to infrequent but deep recessions, the idea of central bankers as 'risk managers' gained renewed popularity (see Cecchetti, 2008). Policy makers pursuing a 'plan for the worst, hope for the best' approach rely on downside risk measures to assess the distribution of risk around modal forecasts. Notably, Adrian et al. (2019) uncover a significant negative correlation between financial conditions and the lower quantiles of the distribution of future real economic growth, suggesting that financial conditions may provide a relevant signal of downside risk to economic activity. ${ }^{1}$ Gadea Rivas et al. (2020) highlight that increasing households and firms leverage posits a trade-off between deep recessions and prolonged expansions (see also Jensen et al., 2020). Yet, a number of recent contributions have called into question the presence of any (type of) asymmetry in business cycle fluctuations, and have suggested alternative ways of capturing time variation in downside risk (see, e.g., Brownlees and Souza, 2020; Carriero et al., 2020a).

Assessing the degree of asymmetry of business cycle fluctuations remains a challenging task. Nevertheless, failure in detecting unconditional asymmetry of GDP growth's distribution does not necessarily rule out the possibility that business cycle skewness is, at times, sizeable and significant. By investigating the properties of the score of the predictive likelihood of GDP growth, we provide novel evidence in support of the presence of conditional asymmetry. Hence, despite unconditional asymmetry over the full sample remains unsupported by data, conditional skewness, and thus downside risk to economic growth, feature significant variation over time. Starting from this result, we introduce a novel flexible methodology to characterize and forecast the conditional distribution of real economic growth with a parametric skewed Student-t (Skew-t) distribution with timevarying location, scale, and shape parameters. In order to fully capture the evolution of the predictive densities, our framework accommodates secular trends and cyclical components for each parameter, with the time variation being driven by the scaled score of the predictive likelihood function (Creal et al., 2013; Harvey, 2013), as well as financial

\footnotetext{
${ }^{1}$ Loria et al. (2019) show that contractionary shocks to technology, monetary policy, and financial conditions disproportionately increase downside risk to economic growth.
} 
indicators. The latter allow us explore to what extent downside risk to economic growth reflect imbalances arising in financial markets.

We document that the conditional distribution of GDP growth is characterized by procyclical skewness fluctuations around a declining trend-skewness. At the onset of downturns, business cycle swings exhibit significant negative skewness, while expansions are characterized by positively skewed distributions. Hence, the stark counter-cyclicality of GDP growth's volatility (see Jurado et al., 2015, among others) also reflects increasing downside volatility during recessions, not being entirely matched by upside volatility. On the other hand, long-run skewness has been decreasing over the last 30 years, partially accounting for the slowdown in long-run growth observed since the early 2000s (see, e.g., Cette et al., 2016; Antolin-Diaz et al., 2017), and turning to negative values in the aftermath of the Great Recession.

Several measures of financial stress have been identified as relevant indicators for predicting economic downturns. Among others, traditional spread measures (see, e.g., Rudebusch and Williams, 2009; Faust et al., 2013), credit and leverage growth (Drehmann et al., 2010; Jordà et al., 2013), as well as the leverage position of financial intermediaries (Adrian and Shin, 2008) received particular attention. Here, we show that the four subcomponents of the National Financial Condition Index (NFCI, Brave and Butters, 2012), capturing risk, credit, leverage and nonfinancial leverage developments, leads to substantial improvements in the fit of the model. The slow building up of nonfinancial leverage emerges as a key determinant of the scale of distribution, whereas skewness relates to all the subindices, in particular leverage of financial intermediaries and credit conditions. Hence, we document that financial deepening in the expansionary phase of the cycle is associated with positive GDP growth's skewness, whereas tightening of financial conditions consistently predict downside risk episodes. Furthermore, financial conditions significantly contribute to increasing the out-of-sample forecasting accuracy of our model, in particular during recessions. Our preferred specification delivers well calibrated predictive densities, improving upon competitive benchmarks in terms of point, density and tail forecasts, as well as leading to timely predictions of the odds of forthcoming recessions.

Although aggregate measures succeed in summarizing a large amount of data, concerns that information relevant for assessing risk can remain undetected persist (see, 
e.g., Galvão and Owyang, 2018; Carriero et al., 2020b). To address this question, we perform an out-of-sample variable selection exercise based on the 'shrink-then-sparsify' approach of Hahn and Carvalho (2015) using the full set of predictors feeding into the NFCI. ${ }^{2}$ Household debt outstanding emerges as a leading indicator of the build-up of downside risk throughout our sample. Fluctuations in the balance-sheet size of security broker-dealers as well as the mortgage-backed securities to treasury yield spread provide useful signals for gauging the severity of the downside risk during the Great Recession, highlighting the importance of the intermediary sector (Adrian and Shin, 2008) and the housing market (see, e.g., Gertler and Gilchrist, 2018). Processing the signal from a large panel of financial predictors leads to substantial improvements in medium term predictions, with sizable gains associated with the ability of the model to capture the increase in the downside risk ahead of the 2007-2009 recession. ${ }^{3}$

Our results highlight the importance of accounting for asymmetric business cycle fluctuations. These can emerge through nonlinearities in the transmission of Gaussian shocks (see, e.g., Fernández-Villaverde and Guerrón-Quintana, 2020a), or alternatively reflect conditionally skewed shocks hitting the economy (as in Bekaert and Engstrom, 2017; Salgado et al., 2019). The procyclical skewness dynamics we document is found to be associated with a dynamic correlation between the first and second moments, being positive in expansions, and turning negative in recessions (in line with the empirical evidence in Carriero et al., 2020a). This further reinforces the necessity of distinguishing between 'good' and 'bad' uncertainty, which can potentially impact economic activity in opposite directions (Segal et al., 2015). Our findings also emphasise the need to account for the nonlinear relationship between financial conditions and credit availability, and the distribution of GDP growth (see, e.g., Fève et al., 2019; Fernández-Villaverde et al., 2019) for policy monitoring (Adrian et al., 2020) and stabilization policy design (Gadea Rivas et al., 2020; Jordà et al., 2020). Lastly, we corroborate that modeling business cycle asymmetry within theoretical models entails capturing the fall in trend-

\footnotetext{
${ }^{2}$ Giannone et al. (2018) warn that sparsity can arise as an artefact of strong a priori beliefs. We approach sparsity within the purely data-driven framework of Ray and Bhattacharya (2018) which is robust to this concern, as also argued in Huber et al. (2020).

${ }^{3}$ The latter finding corroborates the evidence in Alessi et al. (2014), that the central banks' failure to predict the 2007-2009 downturn can be ascribed to their inability to read the signals from deteriorating financial conditions.
} 
skewness of economic fluctuations, and the associated increase of downside risk, over the last three decades (see, e.g., Jensen et al., 2020).

Related literature: This paper builds on the recent literature exploring the relationship between real economic activity and financial conditions (Jordà et al., 2013; Gertler and Gilchrist, 2018, among others). Giglio et al. (2016), Adrian et al. (2019) and Caldara et al. (2020) show that measures of systemic risk are more informative about future economic downturns, as they better predict lower quantiles of the conditional distribution of real output growth. ${ }^{4}$

In contrast to the two-step quantile approach of Adrian et al. (2019), which also requires a distribution to be fitted to the estimated quantiles, we propose a parametric Skew-t specification, for which we directly model the parameters, that provides great tractability and flexibility in accounting for the time variation of downside risk. We propose an observation-driven model to fit and forecast conditional mean, variance and skewness of GDP growth fluctuations. While models for time-varying asymmetry have already been introduced by Hansen (1994) and Harvey and Siddique (1999) with ad hoc laws of motion, we rely on the score-driven framework put forward by Creal et al. (2013) and Harvey (2013). This setting has proven to be particularly suitable for accommodating parameters' time variation under different distributional assumptions (Koopman et al., 2016). ${ }^{5}$ Moreover, building on the work of Harvey (2013, Section 2.6) and Schwaab et al. (2020), we introduce exogenous predictors in the updating equations of the time-varying parameters. To the best of our knowledge, we are the first to rely on Bayesian estimation methods within the score-driven setting. This allows us to jointly tackle parameters' proliferation and incorporate estimation uncertainty when producing forecasts. Specifically, the latter turns out to be useful in improving medium horizon density forecasts, in particular during recessions.

Our model allows for, but do not impose, skewness in GDP growth. Yet, we docu-

\footnotetext{
${ }^{4}$ De Nicolò and Lucchetta (2017) uphold the superior forecasting accuracy of factor-augmented quantile projections to predict economic growth tail risk. Busetti et al. (2020) use expectiles, as opposed to quantiles, to investigate the relationship between GDP growth and financial variables.

${ }^{5}$ Parameters' updating based on the score of the predictive likelihood always reduces the local Kullback-Leibler divergence between the true conditional density and the model-implied one, even under severe misspecification (Blasques et al., 2015).
} 
ment significant variation in the asymmetry of the conditional distribution. This delivers substantial gains in predicting downside risk developments over standard volatility models, whose competitiveness has recently been highlighted by Brownlees and Souza (2020). Plagborg-Møller et al. (2020) introduce a Skew-t model with time-varying parameters being linear functions of financial predictors and past GDP growth. Our framework nests their specification and provides a richer dynamic, able to capture smoother and sharper variations of the scale and shape parameters. In particular, we introduce persistence in the skewness of the distribution of GDP growth, in line with the term structure of the growth-at-risk displaying stronger asymmetry for the short- than for the mediumrun (Adrian et al., 2018), and consistent with the pronounced skewness displayed by the Survey of Professional Forecasters' short-term predictions (Ganics et al., 2020). Finally, unlike alternative approaches, we put forward a two-component specification for the time-varying parameters of the model, in the spirit of Engle and Lee (1999), to track both secular and cyclical changes in the underlying distribution of GDP growth. This allows the model to recover well-known stylized facts, such as the Great Moderation period (McConnell and Perez-Quiros, 2000; Stock and Watson, 2002) and the fall in long-run GDP growth, and to uncover an increasingly negatively skewed business cycle in the last part of the sample, which would remain undetected otherwise.

Structure: The remainder of the paper is organized as follows. Section 2 provides evidence of time-varying business cycle asymmetry. Section 3 presents the model, the estimation methodology and the forecasting procedure. Section 4 illustrates the characteristics of the conditional distribution of GDP growth, and how they relate to financial predictors. Section 5 reports the out-of-sample forecast and downside risk prediction evaluation. In Section 6 we investigate the predictive ability of the large set of financial indicators. Section 7 concludes.

\section{Motivating evidence}

Assessing the degree of skewness of GDP growth is notoriously challenging (Neftci, 1984; Morley and Piger, 2012). When measured over the 1973-2018 sample, we obtain a 
Table 1: Score-based tests for time variation

\begin{tabular}{|c|c|c|c|c|c|c|}
\hline & \multicolumn{3}{|c|}{$\begin{array}{l}\text { time-varying } \\
\text { location }\end{array}$} & \multicolumn{3}{|c|}{$\begin{array}{l}\text { time-varying } \\
\text { location \& } 8 \text { scale }\end{array}$} \\
\hline & $Q$ & $Q^{*}$ & $N$ & $Q$ & $Q^{*}$ & $N$ \\
\hline Scale ${ }^{2}$ & $70.28^{* * *}$ & $71.39^{* * *}$ & $1.95^{* * *}$ & & & \\
\hline Shape & $46.4^{* * *}$ & $47.13^{* * *}$ & $0.41^{*}$ & $21.44^{* * *}$ & $21.78^{* * *}$ & $0.78^{* * *}$ \\
\hline
\end{tabular}

Note: $Q$ is the portmanteau test, $Q^{*}$ is the Ljung-Box extension and $N$ corresponds to the Nyblom test. The lag length for the Portmanteau and Ljung-Box tests are selected following Escanciano and Lobato (2009). The first two tests are distributed as a $\chi^{2}$ with 1 degree of freedom, the Nyblom test statistics is instead distributed as a Cramer von-Mises distribution with 1 degree of freedom. ${ }^{*} p<10 \%,{ }^{* *} p<$ $5 \%,{ }^{* * *} p<1 \%$.

negative sample skewness of -0.42. Nevertheless, according to the Bai and Ng (2005) test, due to the low precision of this estimate over the full sample, one cannot reject the null of symmetry. However, the absence of skewness in the unconditional distribution does not necessarily imply the conditional distribution being symmetric as well (Carriero et al., 2020a). In fact, the difficulty of getting significant skewness estimates can potentially reflect the dynamic evolution of business cycles properties over time. Using Bai and $\mathrm{Ng}$ (2005)'s test over different rolling windows of 1 to 5 years, the test often rejects the null of symmetry, with periods of significant negative and positive skewness detected over the sample. The cyclical behaviour of the test statistics points out at substantial movements in the skewness of GDP growth, suggesting that prolonged expansions are, at times, characterized by significant positive skewness, while contractions are associated with significant negative skewness. ${ }^{6}$

In this Section, we report a number of tests for the presence of time-varying asymmetry. Harvey (2013, Section 2.5) highlights that the score of the conditional likelihood can be used to formally test for the time variation of parameters. As the score incorporates information about the level of time variation of the respective parameter, the Lagrange multiplier principle can be employed to construct appropriate test statistics (see also Calvori et al., 2017). Within this framework, testing for parameters' variation requires starting from a benchmark model, under the null of no time variation of the

\footnotetext{
${ }^{6}$ See Figure G1 in Appendix G, for a summary of these results.
} 
parameter(s) of interest. Here, we assume that GDP growth follows an AR(2) process with Skew-t innovations, with a shape parameter pinning down the degree of asymmetry. ${ }^{7}$ We test for the time variation of the shape parameter considering both the case of constant volatility and the more realistic case of time-varying volatility. Table 1 reports the statistics for the Portmanteau $(Q)$, Ljung-Box $\left(Q^{*}\right)$ and Nyblom (1989) $(N)$ tests. The null hypothesis of a constant shape parameter is strongly rejected, against the alternative of time variation. ${ }^{8}$ Note that the rejection of the Nyblom test, which under the alternative hypothesis implies that the parameter follows a martingale process, suggests that the shape parameter is likely to be highly persistent. Starting from this evidence, in the next Section we introduce a model where the conditional distribution of GDP growth features time-varying asymmetry.

\section{A time varying Skew-t model for GDP growth}

Let $y_{t}$ denote the annualized quarter-on-quarter GDP growth at time $t$. We assume its conditional distribution can be characterized by a Skew-t (Arellano-Valle et al., 2005; Gómez et al., 2007), with time-varying location $\mu_{t}$, scale $\sigma_{t}$, and shape $\varrho_{t}$ parameters, and constant degrees of freedom $\nu$. Specifically,

$$
y_{t}=\mu_{t}+\sigma_{t} \varepsilon_{t}, \quad \varepsilon_{t} \sim S k t_{\nu}\left(0,1, \varrho_{t}\right)
$$

with the degrees of freedom $\nu>3$, the scale parameter $\sigma_{t}>0$, and the asymmetry parameter $\varrho_{t} \in[-1,1]$, such that when it attains negative (positive) values, the distribution features positive (negative) skewness. The conditional log-likelihood function of the observation at time $t$ is:

$$
\ell_{t}=\log p\left(y_{t} \mid \theta, Y_{t-1}\right)=\log \mathcal{C}(\eta)-\frac{1}{2} \log \sigma_{t}^{2}-\frac{1+\eta}{2 \eta} \log \left[1+\frac{\eta \varepsilon_{t}^{2}}{\left(1-\operatorname{sgn}\left(\varepsilon_{t}\right) \varrho_{t}\right)^{2} \sigma_{t}^{2}}\right],
$$

\footnotetext{
${ }^{7}$ Horswell and Looney (1993) show that, when testing for skewness, omitting the presence of kurtosis might deliver misleading results. Repeating the tests with Skew-Normal innovations delivers similar evidence.

${ }^{8}$ Appendix A provides additional details on the specifics of the tests, as well as alternative specifications for the location and scale of GDP growth, confirming the robustness of these results.
} 
with $\eta=\frac{1}{\nu}$ being the inverse of the degrees of freedom, $\mathcal{C}(\eta)=\frac{\Gamma\left(\frac{1+\eta}{2 \eta}\right)}{\sqrt{\frac{\pi}{\eta}} \Gamma\left(\frac{1}{2 \eta}\right)}, \Gamma(\cdot)$ is the Gamma function, and $\operatorname{sgn}(\cdot)$ is the sign function. The vector $\theta$ collects all the static parameters, and $Y_{t-1}=\left\{y_{j}\right\}_{j=1}^{t-1}$ is the information set, up to time $t$. For $\varrho_{t}=0$ we have the symmetric Student-t distribution, for $\eta \rightarrow 0$ we retrieve the epsilon-Skew-Gaussian distribution of Mudholkar and Hutson (2000), whereas the distribution collapses to a Gaussian density when both condition hold. ${ }^{9}$ Thus, we allow for, but do not impose, asymmetric innovation terms.

Following the score-driven framework of Creal et al. (2013) and Harvey (2013), we postulate the driving force for the time-varying parameters to be the score of the predictive likelihood. Let $f_{t}$ collect the vector of time-varying parameters of interest:

$$
f_{t+1}=A f_{t}+B X_{t}+C s_{t}
$$

where $A$ contains autoregressive parameters governing the persistence of the updating, $B$ collects loadings on the explanatory variables $X_{t}$, and $C$ collects the score loadings adjusting the speed of the updating, given the prediction error. The scaled score, $s_{t}$, is defined as $s_{t}=\mathcal{S}_{t} \nabla_{t}$, where:

$$
\nabla_{t}=\frac{\partial \ell_{t}}{\partial f_{t}}, \quad \mathcal{S}_{t}=\mathcal{I}_{t}^{-\frac{1}{2}}=\mathbb{E}\left(-\frac{\partial^{2} \ell_{t}}{\partial f_{t} \partial f_{t}^{\prime}}\right)^{-\frac{1}{2}}
$$

with $\nabla_{t}$ being a vector of scores, namely the gradient of the likelihood function $\ell_{t}$ with respect to the dynamic parameters, while the scaling matrix $\mathcal{S}_{t}$ is proportional to the square root of the Moore-Penrose pseudo-inverse of the Information matrix, $\mathcal{I}_{t}$. The resulting scaled score is a martingale difference sequence with conditional variance equal to the identity matrix. Hence, the parameter updating is defined by the steepest ascent direction for improving the model's local fit. In fact, the direction and magnitude of the updating are dictated by the steepness and curvature of the likelihood function relative to the position of the parameters. Therefore, the resulting model belongs to

\footnotetext{
${ }^{9}$ As opposed to the Skew-t distribution of Azzalini and Capitanio (2003), adopted by Adrian et al. (2019), among others, in the context of GDP growth, the Skew-t distribution of Gomez et al. (2007) retrieve an information matrix which is always non-singular, and can thus be inverted, provided that $\left|\varrho_{t}\right|<1$.
} 
the observation-driven class, for which the trajectories of the time-varying parameters are perfectly predictable given past information and the log-likelihood function being available in closed form (Cox, 1981). The following Proposition provides the closed form expressions for the gradient and the associated information matrix.

Proposition 1. Given the model specification (1) and the likelihood in (2), the elements of the gradient $\nabla_{t}$, with respect to location, scale and asymmetry, are:

$$
\frac{\partial \ell_{t}}{\partial \mu_{t}}=\frac{1}{\sigma_{t}^{2}} w_{t} \varepsilon_{t}, \quad \frac{\partial \ell_{t}}{\partial \sigma_{t}^{2}}=\frac{1}{2 \sigma_{t}^{4}}\left(w_{t} \varepsilon_{t}^{2}-\sigma_{t}^{2}\right), \quad \frac{\partial \ell_{t}}{\partial \varrho_{t}}=-\frac{1}{\sigma_{t}^{2}} \frac{\operatorname{sgn}\left(\varepsilon_{t}\right)}{\left(1-\operatorname{sgn}\left(\varepsilon_{t}\right) \varrho t\right)} w_{t} \varepsilon_{t}^{2},
$$

where $w_{t}=\frac{(1+\eta)}{\left(1-\operatorname{sgn}\left(\varepsilon_{t}\right) \varrho_{t}\right)^{2}+\eta \zeta_{t}^{2}}$ and $\zeta_{t}$ denotes the standardized innovation, $\zeta_{t}=\frac{\varepsilon_{t}}{\sigma_{t}}$. The associated information matrix reads as follows:

$$
\mathcal{I}_{t}=\left[\begin{array}{ccc}
\frac{(1+\eta)}{(1+3 \eta)\left(1-\varrho_{t}^{2}\right) \sigma_{t}^{2}} & 0 & -\frac{4 c(1+\eta)}{\sigma_{t}\left(1-\varrho_{t}^{2}\right)(1+3 \eta)} \\
0 & \frac{1}{2(1+3 \eta) \sigma_{t}^{4}} & 0 \\
-\frac{4 c(1+\eta)}{\sigma_{t}\left(1-\varrho_{t}^{2}\right)(1+3 \eta)} & 0 & \frac{3(1+\eta)}{\left(1-\varrho_{t}^{2}\right)(1+3 \eta)}
\end{array}\right]
$$

Proof. See Appendix B.

Proposition 1 highlights the central role of re-weighting the standardized prediction error (and its square values) for updating of the time-varying parameters. Weights, $w_{t}$, penalize extreme standardized innovations depending on the thickness of the tails, as well as volatility and asymmetry, estimated conditional to time $t-1$. The top left panel of Figure 1 displays the weights associated to the prediction error, for alternative model parametrizations. In a Gaussian setting (black line), weights are constant and equal to unity, implying no discounting. On the other hand, when the asymmetry parameter is zero (red line), the weights display the classic outlier-discounting typical of the observation driven models with Student-t distributions (see, e.g. Harvey and Luati, 2014; Delle Monache and Petrella, 2017). When the distribution is positively (negatively) skewed, i.e. for $\varrho_{t}<0\left(\varrho_{t}>0\right)$, negative (positive) prediction errors, less likely in expectation, command a larger update of the parameters. This asymmetric treatment of the signal of the prediction error is more pronounced as the skewness of the distribution grows larger (i.e. $\left|\varrho_{t}\right| \rightarrow 1$ ). 
Weights

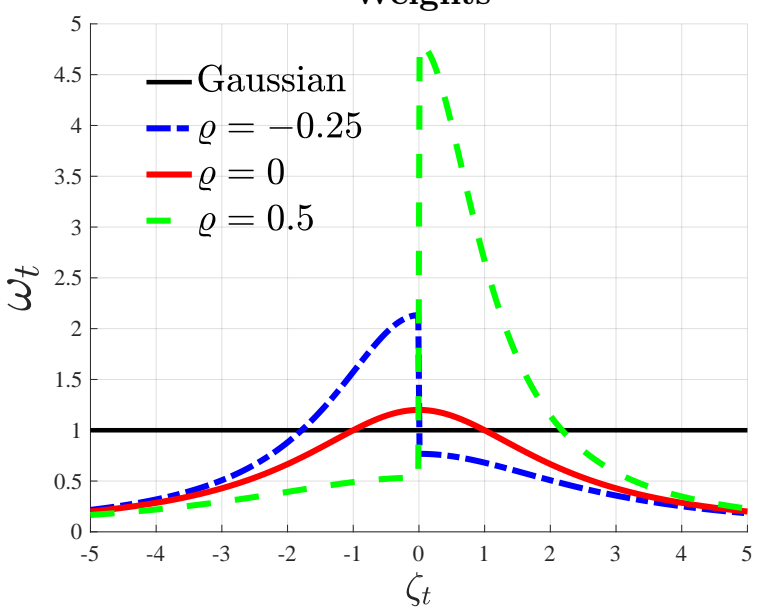

Scale

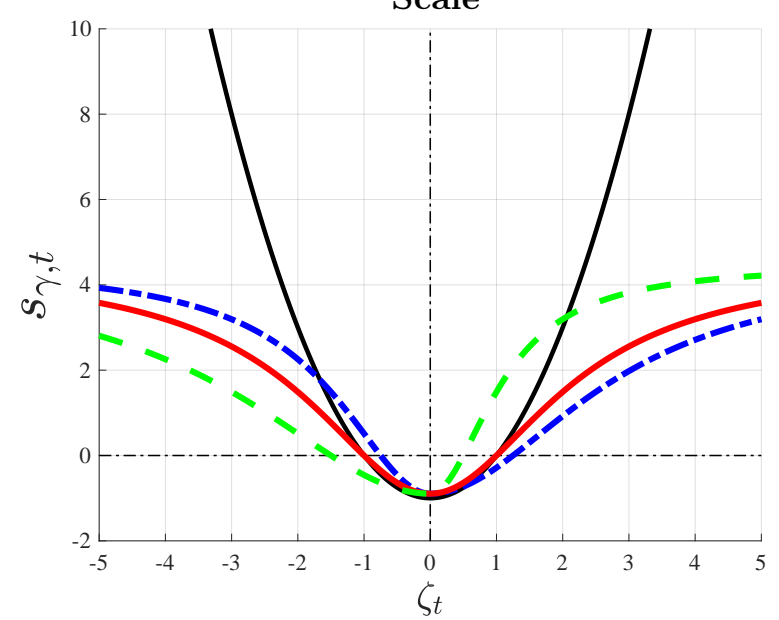

\section{Location}

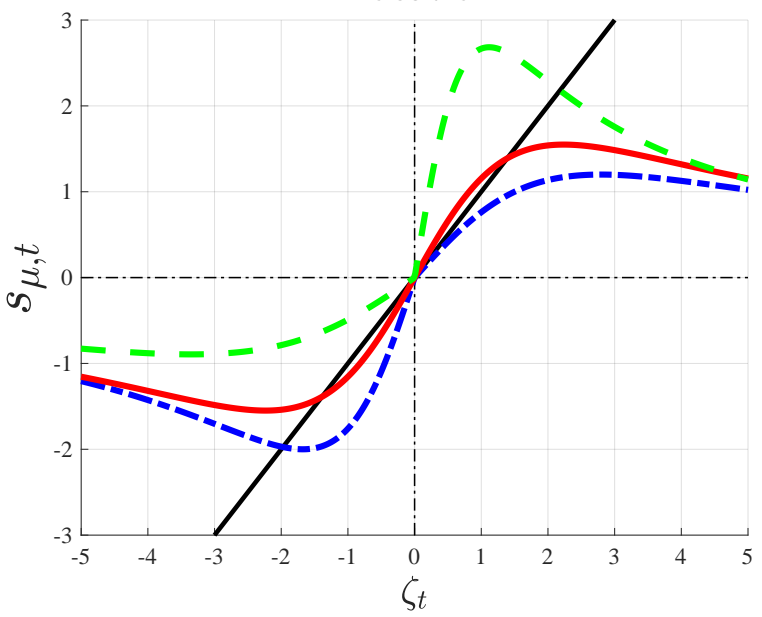

Shape

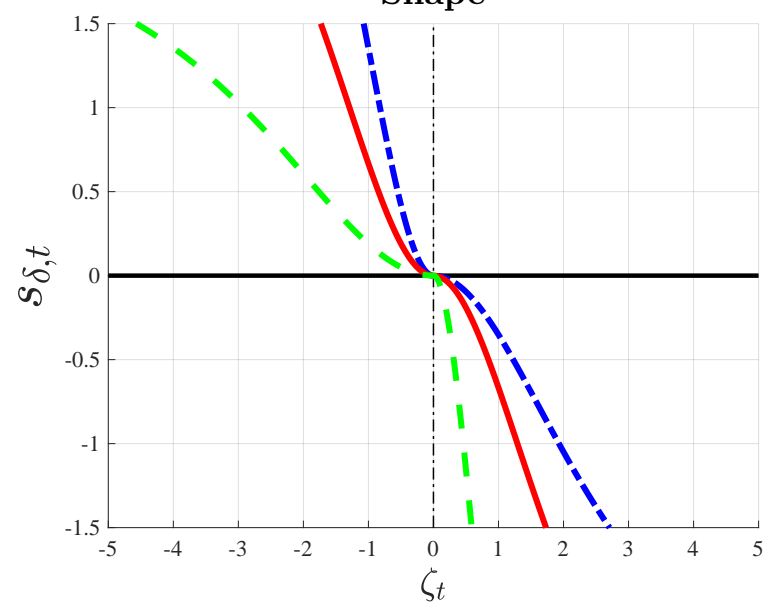

Figure 1: Prediction error and parameters' updating

Note: The figures plot the weighting scheme implied by the weights $\omega_{t}$, and the scaled scores, for different values of the prediction error $\varepsilon_{t}$. We consider three values of the asymmetry parameter: -0.5 (blue), 0 (red) and 0.7 (green). The Gaussian case is reported in black. The scale parameter is set to 1 , with 5 degrees of freedom.

In order to ensure the scale $\sigma_{t}$ to be positive and the shape $\varrho_{t}$ to lie within the unit circle, we apply time-invariant, invertible and differentiable "link functions" to these parameters. In practice, we model $\gamma_{t}=\log \left(\sigma_{t}\right)$ and $\delta_{t}=\operatorname{arctanh}\left(\varrho_{t}\right)$, so that the vector of time-varying parameters becomes $f_{t}=\left(\mu_{t}, \gamma_{t}, \delta_{t}\right)^{\prime}$. Moreover, we follow Lucas and Zhang (2016) and scale the score only using the diagonal elements of the information matrix. 
Therefore, the associated scaled score vector is

$$
s_{t}=\left(J_{t}^{\prime} \operatorname{diag}\left(\mathcal{I}_{t}\right) J_{t}\right)^{-\frac{1}{2}} J_{t}^{\prime} \nabla_{t}=\left[\begin{array}{c}
s_{\mu t} \\
s_{\gamma t} \\
s_{\delta t}
\end{array}\right]=\left[\begin{array}{c}
\sqrt{\frac{(1+3 \eta)\left(1-\varrho_{t}^{2}\right)}{(1+\eta)}} w_{t} \zeta_{t} \\
\sqrt{\frac{(1+3 \eta)}{2}\left(w_{t} \zeta_{t}^{2}-1\right)} \\
-\operatorname{sgn}\left(\varepsilon_{t}\right) \sqrt{\frac{\left(1+\operatorname{sgn}\left(\varepsilon_{t}\right) \varrho_{t}\right)(1+3 \eta)}{3\left(1-\operatorname{sgn}\left(\varepsilon_{t}\right) \varrho_{t}\right)(1+\eta)}} w_{t} \zeta_{t}^{2}
\end{array}\right],
$$

where $J_{t}=\frac{\partial\left(\mu_{t}, \sigma_{t}^{2}, \varrho t\right)}{\partial\left(\mu_{t}, \gamma_{t}, \delta_{t}\right)^{\prime}}$ is the Jacobian matrix associated to the link functions. ${ }^{10}$ Equation (7) highlights that the updating of the shape parameter is substantially different from the ad-hoc filters adopted by Hansen (1994) and Harvey and Siddique (1999), based on higher order powers of the prediction error.

The remainder of Figure 1 plots the scaled scores against the standardized innovations, for the location, scale and shape parameters, respectively. Negative prediction errors are associated with a negative update of the location and a positive update of the shape (i.e. the distribution becoming more left skewed). The opposite is true for positive prediction errors, whereas in both cases the scale is updated upward. For extreme values of the prediction errors, parameters' update becomes inelastic to the standardized innovations, as the scaled scores converge to their limiting values. Most importantly, the asymmetry of the distribution plays a key role in the translation of the standardized prediction error into a signal for the update of the distribution's parameters. For instance, when the distribution is left skewed (i.e. $\varrho_{t}>0$ ) a positive (negative) prediction error leads to a more (less) pronounced update for the parameters, while the opposite is true in the case of a positively skew distribution. This property of the updating function is a direct consequence of the stark asymmetry in the weights. In practice, the model is faster to update the asymmetry of the distribution when there is evidence for a change of sign. ${ }^{11}$ In our application, this allows the model to promptly detect shifts in the skewness of GDP growth around business cycle turning points.

\footnotetext{
${ }^{10}$ In Appendix B, we show that the score and Information matrix provided in Proposition 1 are still valid after applying the link functions.

${ }^{11}$ For instance, a large negative prediction error when the distribution is positive skewed will be perceived as strong signal that there has been a change in the shape of the distribution.
} 


\subsection{Secular and cyclical variation of GDP growth's distribution}

When modelling the conditional distribution of GDP growth, it is important to allow for both cyclical and secular movements of the central moments. Several papers have documented that over the sample under analysis GDP growth has experienced significant changes in the long run mean (see, e.g. Cette et al., 2016; Antolin-Diaz et al., 2017), as well as shifts in the volatility (McConnell and Perez-Quiros, 2000; Stock and Watson, 2002), and skewness of the distribution (Jensen et al., 2020) from the late 1980s. At the same time, Jurado et al. (2015) show that the volatility of GDP growth is countercyclical, while Giglio et al. (2016) and Adrian et al. (2019) argue that the skewness of the cycle falls sharply during recessions. To account for these features of the data, we postulate a two-component specification for the time-varying parameters, in the spirit of Engle and Lee (1999). We posit a random walk updating for the permanent components, where these are able to track both smooth variations and sudden breaks in the level of the parameters. Moreover, we allow a set of predictors, $X_{t}$, to have a transitory impact on the parameters of the distribution.

The location parameter is a linear combination of a trend component, $\bar{\mu}_{t}$, and a stationary component, $\tilde{\mu}_{t}$ :

$$
\begin{aligned}
\mu_{t+1} & =\bar{\mu}_{t+1}+\tilde{\mu}_{t+1}, \\
\bar{\mu}_{t+1} & =\bar{\mu}_{t}+\varsigma_{\mu} s_{\mu t}, \\
\tilde{\mu}_{t+1} & =\phi_{\mu, 1} \tilde{\mu}_{t}+\phi_{\mu, 2} \tilde{\mu}_{t-1}+\beta_{\mu}^{\prime} X_{t}+\kappa_{\mu} s_{\mu t},
\end{aligned}
$$

where the $\operatorname{AR}(2)$ specification for the cyclical component is able to recover the characteristic hump shaped impulse response of the data (see, e.g. Chauvet and Potter, 2013). Following Engle and Rangel (2008), we assume a multiplicative specification for the volatility, i.e. $\gamma_{t}=\log \left(\sigma_{t}\right)$ where:

$$
\begin{aligned}
\gamma_{t+1} & =\bar{\gamma}_{t+1}+\tilde{\gamma}_{t+1}, \\
\bar{\gamma}_{t+1} & =\bar{\gamma}_{t}+\varsigma_{\gamma} s_{\gamma t}, \\
\tilde{\gamma}_{t+1} & =\phi_{\gamma} \tilde{\gamma}_{t}+\beta_{\gamma}^{\prime} X_{t}+\kappa_{\gamma} s_{\gamma t} .
\end{aligned}
$$


Similarly, we posit an additive specification for the unrestricted shape parameter, $\delta_{t}=$ $\operatorname{arctanh}\left(\varrho_{t}\right)$ :

$$
\begin{aligned}
& \delta_{t+1}=\bar{\delta}_{t+1}+\tilde{\delta}_{t+1}, \\
& \bar{\delta}_{t+1}=\bar{\delta}_{t}+\varsigma_{\delta} s_{\delta t}, \\
& \tilde{\delta}_{t+1}=\phi_{\delta} \tilde{\delta}_{t}+\beta_{\delta}^{\prime} X_{t}+\kappa_{\delta} s_{\delta t},
\end{aligned}
$$

that implies $\varrho_{t}=\tanh \left(\bar{\delta}_{t}+\tilde{\delta}_{t}\right)$. Therefore, the resulting vector of time-varying parameters is equal to $f_{t}=\left(\bar{\mu}_{t}, \tilde{\mu}_{t}, \bar{\gamma}_{t}, \tilde{\gamma}_{t}, \bar{\delta}_{t}, \tilde{\delta}_{t}\right)^{\prime}$, whose law of motion is described by a restricted specification of equation (3), as we show in Appendix B.

Plagborg-Møller et al. (2020) consider a time-varying Skew-t specification for GDP growth and specify the time-varying parameters (location, log-scale and shape) as a linear function of the set of predictors. In our framework, a specification similar to theirs can be retrieved setting $\left\{\varsigma_{\mu}, \phi_{\mu, 1}, \phi_{\mu, 2}, \kappa_{\mu}, \varsigma_{\gamma}, \phi_{\gamma}, \kappa_{\gamma}, \varsigma_{\delta}, \phi_{\delta}, \kappa_{\delta}\right\}=0$. In this case, the sole source of parameters' variation stems from the dynamics of the predictors, which generates substantial variability in the underlying parameters, and thus uncertainty around the estimates. In contrast, our specification allows for both secular and transitory shifts in the parameters, where the autoregressive structure of the cyclical components makes them functions of discounted values of all past predictors and scores (where these latter are themselves nonlinear functions of past data). Specifically,

$$
\begin{aligned}
\mu_{t+1} & =\bar{\mu}_{t+1}+\sum_{j=0}^{t-1} \psi_{\mu, j}\left(\beta_{\mu}^{\prime} X_{t-j}+\kappa_{\mu} s_{\mu t-j}\right) \\
\gamma_{t+1} & =\bar{\gamma}_{t+1}+\sum_{j=0}^{t-1} \phi_{\gamma}^{j}\left(\beta_{\gamma}^{\prime} X_{t-j}+\kappa_{\gamma} s_{\gamma t-j}\right), \\
\delta_{t+1} & =\bar{\delta}_{t+1}+\sum_{j=0}^{t-1} \phi_{\delta}^{j}\left(\beta_{\delta}^{\prime} X_{t-j}+\kappa_{\delta} s_{\delta t-j}\right)
\end{aligned}
$$

where $\psi_{\mu, j}$ is a convolution of the autoregressive parameters $\phi_{\mu, 1}$ and $\phi_{\mu, 2}$, which decays to zero for $j \rightarrow \infty$, and the long-run components are proportional to the cumulative sum of past scores. As a result, the time-varying parameters we estimate are smoother and 
less affected by the noise of data. ${ }^{12}$

\subsection{Estimation}

The parameters of the model and the associated conditional distribution of GDP growth are estimated using Bayesian methods. Maximum likelihood estimates are used to initialize an adaptive Random-Walk Metropolis-Hastings (ARWMH) algorithm (Haario et al., 1999). Credible sets for both static and time-varying parameters are obtained from the empirical distribution functions arising from the resampling.

We set Minnesota-type Normal priors for the AR coefficients of the cyclical parameters, centered around high persistence values. For the location's AR parameters, we also introduce a prior on the sum of coefficients, in line with Doan et al. (1984) and Sims and Zha (1998). We assume Normal priors for the loadings associated to the predictors. These coefficients are centered around zero, with tight scales in order to avoid overfitting of the parameters, in the fashion of $L_{2}$ (Ridge) regularization. The prior distribution of the score loadings are inverse gamma, as we expect these parameters to be positive. Lastly, we assume an inverse gamma prior for $\eta$.

Appendix D provides an extensive description of the sampling algorithm as well as the details on the exact prior specification for the parameters. Furthermore, Appendix E investigates the small sample properties of the model through a Monte Carlo analysis. When the distribution is symmetric throughout the entire sample, the model correctly estimates a null shape parameter, with limited variability. Therefore, time variation in the location and scale is not confounded for time variation of the asymmetry, even when the former are correlated. Conversely, the model appropriately tracks shifts in the asymmetry of the distribution when this is a feature of the simulated data. Moreover, the two-component specification properly disentangles long- and short-lived fluctuations of the shape parameter.

\footnotetext{
${ }^{12}$ In addition, our framework allows for non-linearities through the non-linear mapping of the predictors into the scaled scores, and the non-linear link functions applied to the restricted parameters. This, as discussed in the previous Section, provides an automatic down-weighting of the extreme fluctuations in the data. In Appendix $\mathrm{C}$ we highlight that these additional features of the model turns out to be important to recover salient features of the distribution of GDP growth, such as the Great Moderation, and significant cyclical variation in the conditional skewness.
} 


\section{$3.3 \quad$ Forecasts}

For any draw of the model parameters, $\theta$, the last step of the the observation driven filter (3) provides the optimal one-step-ahead prediction of the parameters of interest (Cox, 1981). These values can then be used to retrieve the one-step-ahead prediction density for GDP growth, $p\left(y_{T+1} \mid \theta\right)=s k t_{\nu}\left(f_{T+1}(\theta)\right)$, which allows us to draw the forecast of interest as $p\left(y_{T+1}\right)=\int p\left(y_{T+1} \mid \theta\right) d \theta$.

For multiple-steps forecasts additional complications arise from the necessity to sample the score, and the dependence of the forecasts on the predicted values of the conditioning variables. In Section 5, we produce forecasts keeping the conditioning variables fixed to their last observations, akin to assuming a random walk specification for their law of motion. ${ }^{13}$ As for the the score vector, we follow Koopman et al. (2018) and adopt a "bootcasting" algorithm to sample multiple $h-1$ dimensional vectors of the scores from the (scaled) score vector obtained in the estimation, thus avoiding any assumption on the distribution of the score. Therefore, for a given (bootstraped) draw of the score, and assuming $X_{T+h}=X_{T}$, the score filter (3) can be used to obtain $f_{T+h}$, and thus compute $p\left(y_{T+h} \mid \theta, X_{T+h}=X_{T}\right)$. The $h$-step ahead forecast reads $p\left(y_{T+h}\right)=\int p\left(y_{T+h} \mid \theta, X_{T+h}=\right.$ $\left.X_{T}\right) d \theta$.

\section{Time variation in the distribution of GDP growth}

Our model allows to study the characteristics of the conditional distribution of GDP growth. We place particular emphasis on the asymmetry (skewness) parameter, as we seek to provide a timely and accurate description of the downside risk to GDP growth. We use US quarterly data over the period 1973Q1 to 2018Q4 on real economic activity and financial conditions, as proxied by the NFCI and its four subindices, tracking developments in the credit, risk, leverage and non-financial leverage markets (Brave and Butters, 2012). While the risk and credit components closely track the dynamics of the

\footnotetext{
${ }^{13}$ Therefore, taking advantage of the fact that the underlying predictors in our applications are persistent enough, holding them fixed over the forecast window results in small loss of overall predicting ability. As an alternative, one could feed predictions for the explanatory variables into the model, as in Hasenzagl et al. (2020). Owning to the persistence of the underlying data, the latter approach produces results very similar to the one reported here.
} 
Table 2: Deviance Information Criterion for alternative specifications

\begin{tabular}{lcc}
\hline \hline \multicolumn{1}{c}{ Model } & DIC & DIC Rec \\
\hline Gaussian AR(2) + GARCH(1,1) & 4.926 & 2.580 \\
One-Component Skew-t Model & 4.595 & 2.442 \\
One-Component Skew-t Model with NFCI & 4.518 & 2.378 \\
One-Component Skew-t Model with 4DFI & 4.510 & 2.390 \\
Two-Component Skew-t Model & 4.462 & 2.419 \\
Two-Component Skew-t Model with NFCI & 4.363 & 2.354 \\
Two-Component Skew-t Model with 4DFI & 4.367 & 2.347 \\
\hline \hline
\end{tabular}

Note: The table reports the Deviance Information Criterion of Spiegelhalter et al. (2002) for 7 different models: a Gaussian $\operatorname{AR}(2)$ model with $\operatorname{GARCH}(1,1)$ volatility; time-varying parameters Skew-t with time-invariant long-run components, includes lags of the NFCI, and the four disaggregated financial indices. The last three models allow for time-varying long-run components. In the column $D I C^{R e c}$ we evaluate the DIC measure during recession periods.

NFCI, the leverage indicator, as well as the nonfinancial leverage (NFL) index, provide important additional information. In particular, the NFL is often regarded as an "early warning" signal for economic downturns (Mian and Sufi, 2010), and it clearly leads the (HP-filtered) credit-to-GDP ratio, which is itself considered a leading measure of financial distress (Drehmann et al., 2010; Jordà et al., 2017). ${ }^{14}$ In all cases we use two lags of the predictors.

Table 2 investigates the goodness of fit of several specifications using the Deviance Information Criterion (DIC, Spiegelhalter et al., 2002). The baseline model, featuring both low frequency and cyclical fluctuations in all the parameters, improves upon a simple Gaussian model with time-varying volatility as well as compared to a simpler meanreverting specification of the time-varying parameters. In particular, the large improvement with respect to the GARCH model further underlines the relevance of time-varying business cycle skewness. Adding financial predictors further improves the sharpness of the cyclical component, and delivers lower DIC scores. The four disaggregated financial indicators slightly worsen the fit when evaluated over the full sample, yet they improve the performance of the model around turning points, with DIC scores reducing from 2.354 to 2.347 , during recessions. ${ }^{15}$ Based on these results, we now focus on the baseline

\footnotetext{
${ }^{14}$ See Appendix $\mathrm{F}$ for further discussion on the data.

${ }^{15}$ In Section 5, we will show that the specification used in the current Section is associated with substantial improvements over the one that only includes the NFCI, or the one that does not feature any
} 
Expected Value

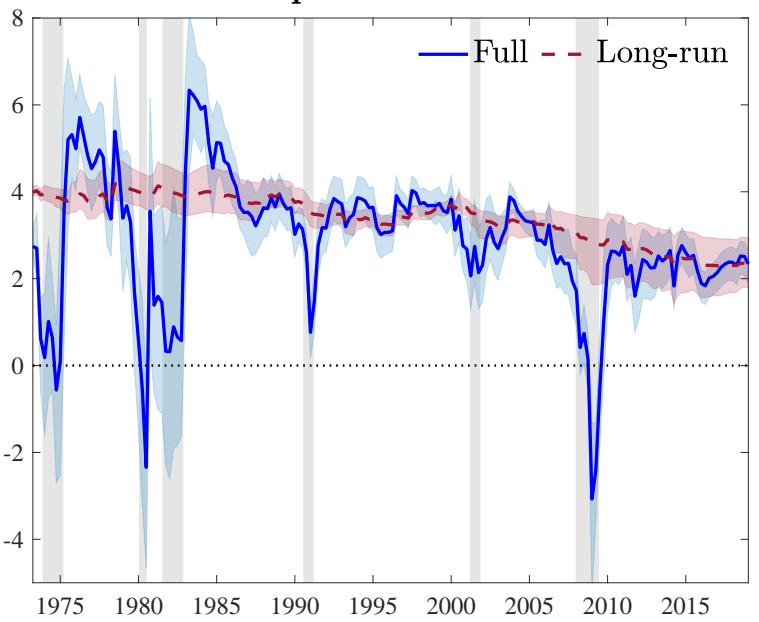

Skewness

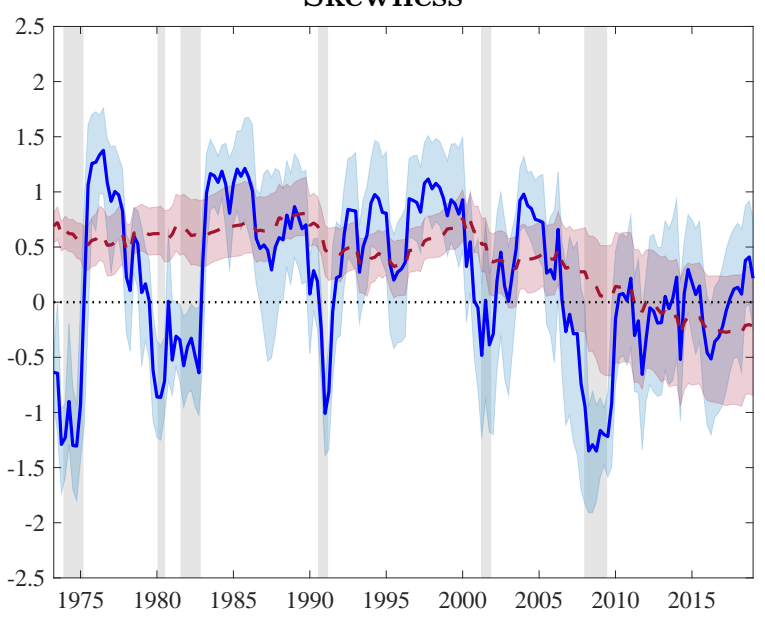

Standard Deviation

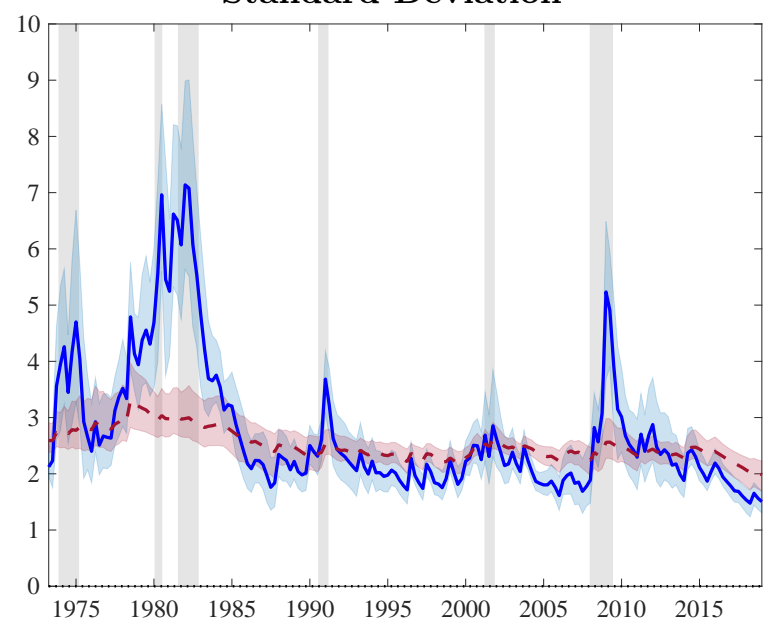

Density

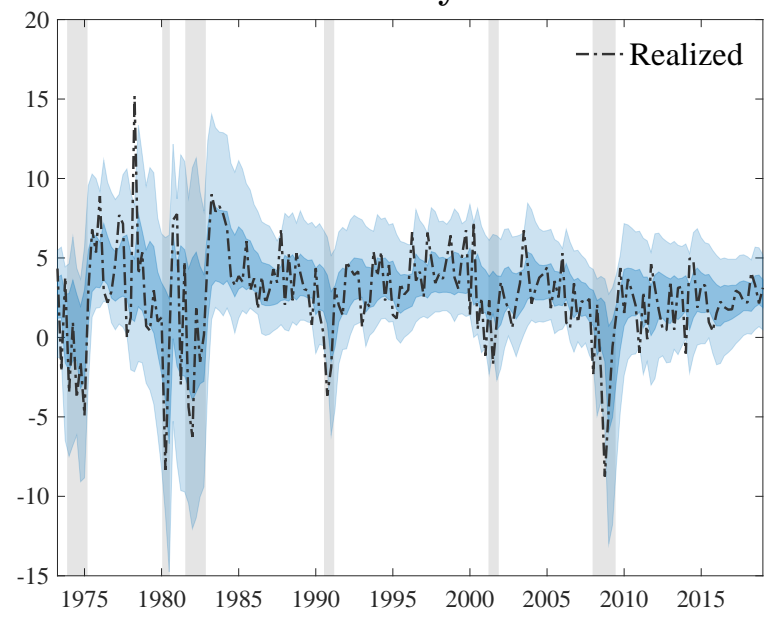

Figure 2: Time-varying moments and density

Note: The plots illustrate the estimated time-varying moments (blue), along with the long-run components, in red, and $95 \%$ confidence bands. The bottom right panel plots the conditional density (i.e. interquartile range and $5^{\text {th }}$ and $95^{\text {th }}$ quantile), along with realizations (dashed, black) of GDP growth. Shaded bands represent NBER recessions.

specification including all the four subindices of the NFCI.

Figure 2 reports the time-varying moments of the distribution of GDP growth, together with the implied density. The mean moves along the business cycle and displays sharp contractions during recessions. Volatility features a marked countercyclical behaviour, with peaks occurring during recessions, whereas skewness is distinctively procyclical. While the sample skewness value of -0.42 is mainly due to the large drawdowns occurring at the onset of recessions, sharp rebounds of the coefficient towards positive financial indicator as a predictor of the distribution of GDP growth. 
values accompany economic recoveries. Interestingly, skewness tends to decrease in anticipation of recessions, a feature which we show to be related to the information contained in the financial indicators affecting the shape of the conditional distribution.

On the same charts, we also report in red the low-frequency component of each of the moments. That is, the moments of the distribution which would prevail in the absence of cyclical variations of the model's parameters. The model neatly captures a fall in long-run growth, with the expected value falling from roughly $4 \%$ in the 1970 s, to roughly $2.3 \%$ over the sample, in line with the evidence in Antolin-Diaz et al. (2017). The model also captures the substantial decline in variance, starting from the mid-1980s. The Great Moderation (GM) is reflected by the long-run volatility being revised downward by roughly $30 \%$. According to the decomposition in Figure 2, the high volatility during the 1970s and 1980s is to a large extent due to cyclical factors. In the most recent times, such low trend levels suggest that the GM period might not be over (Gadea et al., 2018). Similarly, long-run skewness displays a downward trend starting in the late 1980s, markedly falling in the post-2000 sample. As a result, business cycle fluctuations are characterized by decreasing, but positive, trend-skewness until the onset of the financial crisis in 2007. In the aftermath of the subsequent recession, this long-term trend turns to negative values, implying negatively skewed long-run conditional distributions.

Overall, the conditional distribution of GDP growth features mild positive skew over expansions, whereas downside risk clearly dominates (ahead of, and) during downturns. Notwithstanding increasing volatility, during recessions we observe marked downward movements in the lower quantiles of the distribution, not being matched by increases in the higher quantiles. ${ }^{16}$

Expected value and variance decomposition The estimated model suggests that conditional skewness fluctuations are a prominent feature of the predictive distribution of GDP growth. Here, we illustrate how these shifts affect the central moments of the distribution, besides shaping the behavior of the tails. In particular, the Skew-t model allows

\footnotetext{
${ }^{16}$ In contrast, when the model is estimated imposing a Gaussian conditional distribution, the widely documented countercyclicality of GDP growth (see, e.g. Jurado et al., 2015) implies that higher and lower quantiles of the distribution move in opposite direction, so that the fall in the expected value is necessarily met by a fall in the location.
} 
to easily isolate the contributions of the variation in the asymmetry of the distribution as follows: ${ }^{17}$

$$
\begin{aligned}
\mathbb{E}\left(y_{t} \mid Y_{t-1}\right) & =\mu_{t}-g(\eta) \sigma_{t} \varrho_{t}, & & g(\eta)=\frac{4 \mathcal{C}(\eta)}{1-\eta}, \\
\operatorname{Var}\left(y_{t} \mid Y_{t-1}\right) & =\sigma_{t}^{2}\left(\frac{1}{1-2 \eta}+h(\eta) \varrho_{t}^{2}\right), & h(\eta) & =\frac{3}{1-2 \eta}-g(\eta)^{2},
\end{aligned}
$$

The expected value and variance are equal to the location and scale of a standard Studentt distribution with $\nu=\frac{1}{\eta}$ degrees of freedom, plus a component which is a function of the shape parameter of the Skew-t density. This latter is magnified by larger values of $\sigma_{t}$, for the expected value, while it disappears for both moments when $\varrho_{t}$ is equal to 0 . Figure 4 isolates the contribution of the asymmetry for both the first and second moment.

The expected value decomposition highlights how the location parameter (red line, left panel) is remarkably stable over the sample, while most of the fluctuations reflect shifts in the shape of the distribution, with expansions characterized by positive skewness and contractions associated with negative skewness. Interestingly, the contribution of the asymmetry for positive expected values becomes more muted during the Great Moderation, whereas the negative drag from the asymmetry remains of substantial importance during recessions. In contrast, the effect of the shape parameter on the second moment is less pervasive. Nevertheless, it accounts for a non-trivial share of the increase in variance during recessions, as recently documented by Salgado et al. (2019) in the cross-section of firms, for several countries.

Equations (20)-(21) also highlight another interesting property of the model. The procyclical variation in the skewness is reflected into a time-varying correlation between the mean and the volatility of GDP growth. While the expected value is always negatively affected by shifts of the shape parameter (i.e. $\frac{\partial \mathbb{E}\left(y_{t} \mid Y_{t-1}\right)}{\partial \varrho_{t}}<0, \forall \varrho_{t}, \eta$ ), an increase of the the latter is associated with an increase in the variance when the distribution is negatively skewed (i.e. for $\varrho_{t}>0$ ), and it decrease the variance when the distribution is positively skewed (i.e. for $\left.\varrho_{t}<0\right) .{ }^{18}$ Therefore, the procyclicality in skewness is reflected

\footnotetext{
${ }^{17}$ Although an expression for the skewness is not available in closed form, a Taylor expansion of the skewness function attributes almost all of the variation to movements of the shape parameter, while relatively remaining insensitive to location and scale.

${ }^{18} \mathrm{In}$ fact, $\frac{\partial \operatorname{Var}\left(y_{t} \mid Y_{t-1}\right)}{\partial \varrho_{t}}=2 h(\eta) \sigma_{t}^{2} \varrho_{t}$, and since $h(\eta)>0$ for $\nu>3$, the shift in the variance will be
} 


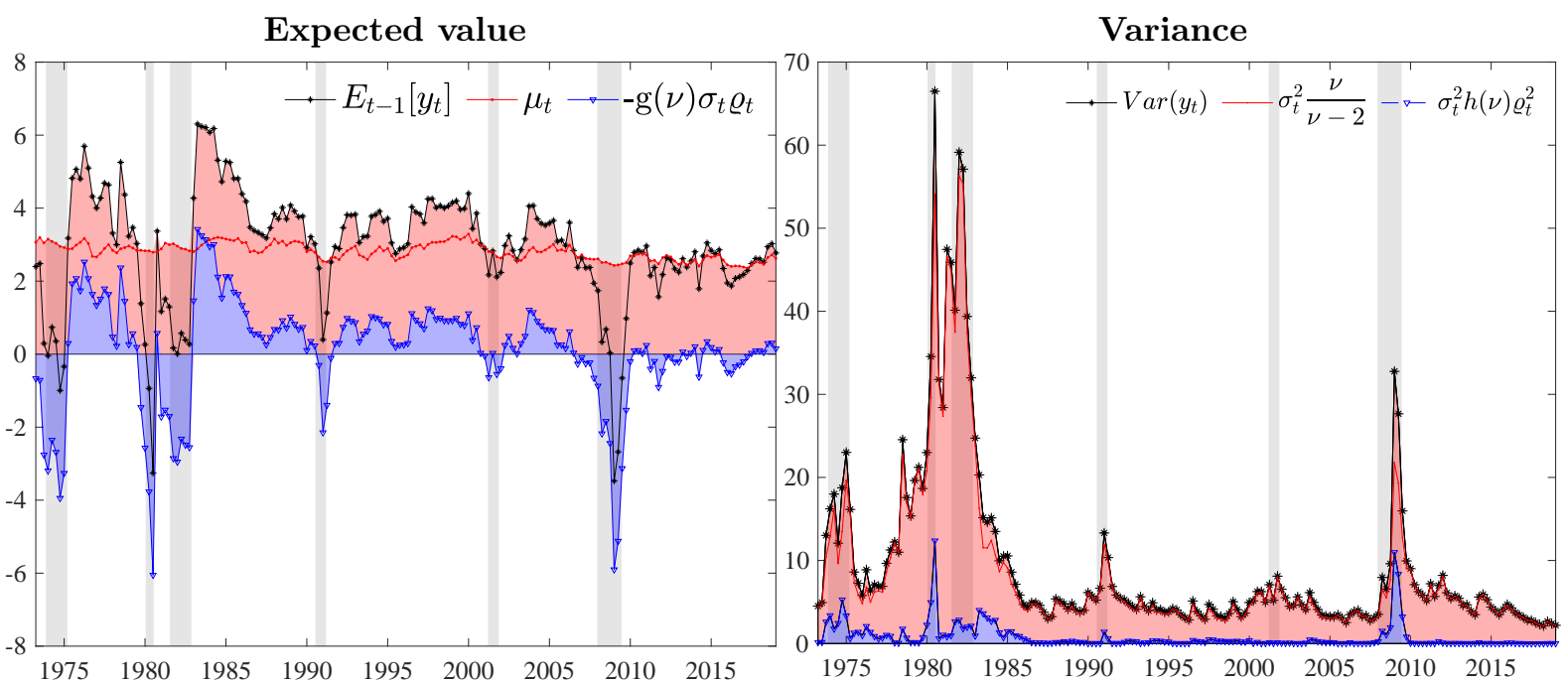

Figure 3: Expected value and variance decomposition

Note: The plot shows the decomposition of the expected value and variance of GDP growth. We report in red the contribution of the moment estimator (e.g. location and scale), whereas the blue area identifies the contribution of higher order moments. Central moments (black lines) are computed as per Equation (20)-(21). Shaded bands represent NBER recessions.

into a procyclicality in the correlation between mean and variance, which is in line with findings in Carriero et al. (2020a). These nonlinearities in the interaction between uncertainty and aggregate economic activity are consistent with findings in Segal et al. (2015), which highlight how "positive uncertainty" (i.e. volatility in the procyclical phases of the business cycle) tends to be associated with positive expected growth, whereas this correlation turns negative during contractionary phases of the cycle. ${ }^{19}$

Accounting for the fall in long-run growth. The upper left panel of Figure 2 shows that the model picks up a substantial fall in the underlying long-run GDP growth. Following the expected value decomposition in Equation (20), we can assess to what extent shifts in long-run growth that we observe over the sample reflect a reassessment of (long-run) risk in GDP growth. Starting in the late 1980s, the distribution of GDP growth featured decreasing positive skewness. This increase in downside risk maps into a decline of the long-run growth, as shown in Figure 4, so that roughly two thirds of the slowdown reflect a reassessment of risk. Notably, the long-run component displays a of the same sign as the level of the shape parameter (thus opposite sign to the level of the conditional skewness).

${ }^{19}$ The possibility that increases in uncertainty leads to expanding economic activity in a DSGE environment is further highlighted in Fernández-Villaverde and Guerrón-Quintana (2020b). 


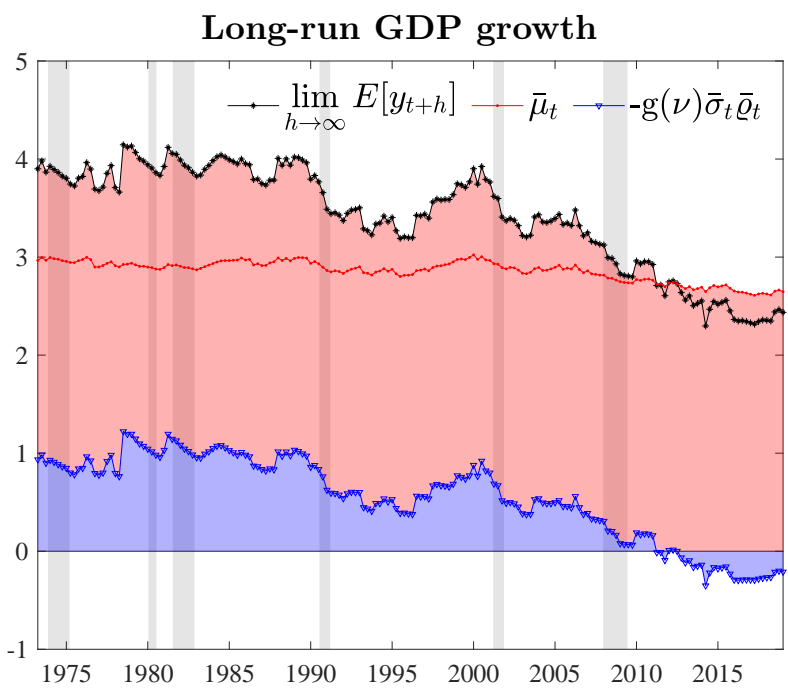

Figure 4: Long-run GDP growth

Note: The plot shows the decomposition of the long-run expected value (black lines), akin to taking $\lim _{h \rightarrow \infty} \mathbb{E}\left[y_{t+h}\right]$. We report in red the contribution of the long-run location component $\bar{\mu}_{t}$, whereas the blue area identifies the contribution of higher order moments. $\bar{\sigma}_{t}$ and $\bar{\varrho}_{t}$ refers to the secular components of scale and shape, respectively. Shaded bands represent NBER recessions.

pronounced left tail starting from the Great Recession, thus becoming a negative drag to the long-term growth. Moreover, notice that the downward trend in long-run growth is temporarily reversed in correspondence of the IT productivity boom of the mid-1990s, when long-run growth is revised upward by roughly $0.5 \%$. Interestingly, we find that this upward revision reflects, to a large extent, a shift in the risk of the upside, rather than the central tendency, of GDP growth's distributions.

How important are financial predictors? To gauge the contribution of financial indicators to the overall variation of these parameters, we exploit the the moving average representation of the cyclical components in Equations (18) and (19). In Figure 5, we decompose $\tilde{\gamma}_{t}$ and $\tilde{\delta}_{t}$ into a "score-driven" component $\left(\kappa_{\gamma} \sum_{j=0}^{t-1} \phi_{\gamma}^{j} s_{\gamma t-j}\right.$ and $\kappa_{\delta} \sum_{j=0}^{t-1} \phi_{\delta}^{j} s_{\delta t-j}$, respectively) and a component reflecting the share of variation driven by the predictors $\left(\beta_{\gamma}^{\prime} \sum_{j=0}^{t-1} \phi_{\gamma}^{j} X_{t-j}\right.$ and $\beta_{\delta}^{\prime} \sum_{j=0}^{t-1} \phi_{\delta}^{j} X_{t-j}$, respectively), for which we highlight the contribution of each financial index. This decomposition highlights the upside of looser financial conditions (see, Gadea Rivas et al., 2020), which are associated with lower than average volatility, and distributions that feature mildly positive skewness. NFL is by far the largest contributor to the variation in the scale parameter, followed by the leverage indicator, whereas both credit and risk play a limited role. On the contrary, indicators 

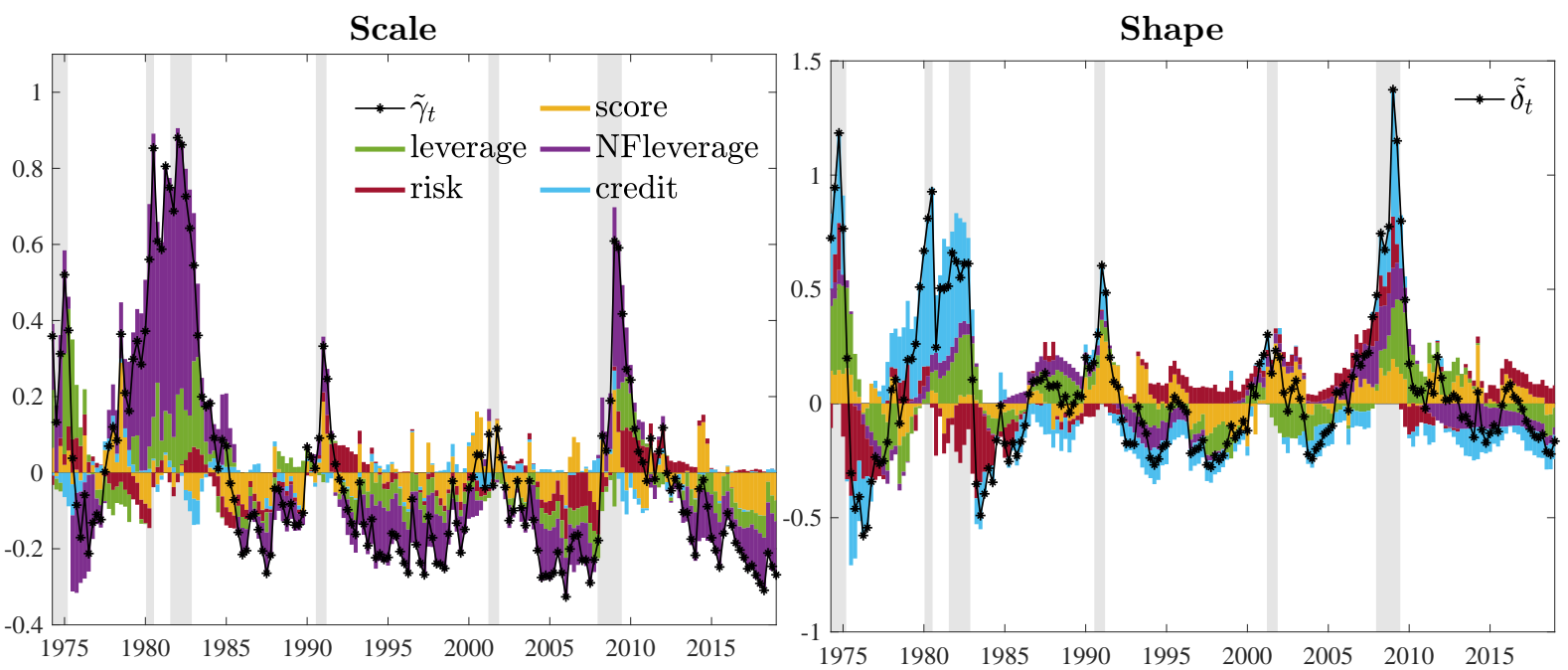

Figure 5: Predictive financial conditions

Note: The figures plot the decomposition of the "untransformed" short-term parameters (in black) into a "Score-driven" (yellow) and a "Predictor-driven" component, for which we highlight all the subcomponents. Shaded bands represent NBER recessions.

heterogeneously affect the shape parameter. Specifically, during the severe recessions of the early 1980s and 2008, the marked increase of the parameter reflects the increasing of imbalances in the financial markets. Focusing on the latest financial crisis, leverage and NFL indicators greatly contribute to the increase in negative asymmetry of the predictive distribution, consistently with the leverage-cycle narrative of Mian and Sufi (2010) and Jordà et al. (2013). Similarly, the credit index is of paramount importance both in the pre-crisis and crisis period: lower credit spreads before the crash impaired a sharp increase of the asymmetry parameter, while as the crisis exploded their higher values pushed the parameter towards further positive values, as argued by Krishnamurthy and Muir (2017). Risk and NLF tend to positively feed into the dynamics ahead of recessions (see, e.g. Bekaert and Hoerova, 2014; Hasenzagl et al., 2020, respectively), while credit and leverage indices contribute to determine the amount of asymmetry recessions are characterized by. Interestingly, the contribution of financial indicators is muted during the dot-com recession, in line with the weak link between this recession and financial predictors, as highlighted by Stock and Watson (2003). 


\section{Out-of-sample evaluation}

We further explore the importance of taking into account downside risk time variation, and its relation to financial variables, within an out-of-sample exercise. We evaluate the forecasting performance of the model over the period 1993Q1-2018Q4, at the one-quarter and one-year horizon. In the latter case, the results are reported in terms cumulated output growth over the next four quarters. Forecasts are obtained from real-time GDP vintages and evaluated using the latest available release.

We assess the point forecast accuracy via the mean square forecast error (MSFE). Density forecasts accuracy is evaluated via the predictive log-score and quantile scores. The latter, put forward by Gneiting and Ranjan (2011), read as $w Q S_{t+h}=\int_{0}^{1} Q S(\alpha) \omega(\alpha) d \alpha$, where $\alpha$ represents the quantiles, $Q S(\alpha)=2\left(I\left(y_{t+h}<F^{-1}(\alpha)\right)-\alpha\right)\left(F^{-1}(\alpha)-y_{t+h}\right)$, with $F^{-1}(\alpha)$ being the empirical quantile function of the density forecast, and $\omega(\alpha)$ is a weighting function. We consider two version of this measure: i) the Continuously Ranked Probability Score (CRPS), which assigns equal weight to each quantile of the empirical distribution function (Gneiting and Raftery, 2007), arising for $\omega(\alpha)=1$, and ii) a scoring rule with $\omega(\alpha)=(1-\alpha)^{2}$ that assigns higher weights to the lower quantiles of the distribution function, thus emphasising the accuracy in predicting the left tail of the distribution. Similarly, when we evaluate the calibration of the predictive densities by means of the probability integral transforms (PITs) (Diebold et al., 1998), we explicitly consider the calibration of the the left side of the distribution. Last, we investigate the use of the model in producing measures of downside risk and predicting recessions.

\subsection{Point and density forecasts}

Asymmetry and the value of financial predictors. As a first step into our analysis, we aim at evaluating the importance of accounting for the skewness of the distribution of GDP growth, as well as assessing whether conditioning on financial predictors leads to forecast improvements. Brownlees and Souza (2020) show that GARCH models based on symmetric distributions deliver competitive out-of-sample forecasts for GDP growth-atrisk. Therefore, we compare our specifications against a Gaussian autoregressive model 
Table 3: Forecasting performance

\begin{tabular}{|c|c|c|c|c|c|c|}
\hline & Skt & $\begin{array}{c}S k t \\
N F C I\end{array}$ & $\begin{array}{c}S k t \\
4 D F I\end{array}$ & Skt & $\begin{array}{c}S k t \\
N F C I\end{array}$ & $\begin{array}{c}S k t \\
4 D F I\end{array}$ \\
\hline & & & \multicolumn{2}{|c|}{ One-quarter ahead } & & \\
\hline & & MSFE & & & $-\log S$ & \\
\hline Full & $\underset{(0.021)}{\mathbf{0 . 8 2 7}}$ & $\begin{array}{c}\mathbf{0 . 7 6 9} \\
(0.025)\end{array}$ & $\begin{array}{c}\mathbf{0 . 7 7 7} \\
(0.054)\end{array}$ & $\begin{array}{l}0.106 \\
(0.139)\end{array}$ & $\underset{(0.066)}{\mathbf{0 . 1 5 4}}$ & $\begin{array}{l}0.105 \\
(0.203)\end{array}$ \\
\hline Rec. & $\begin{array}{c}\mathbf{0 . 7 6 4} \\
(0.038)\end{array}$ & $\begin{array}{c}\mathbf{0 . 6 7 4} \\
(0.057)\end{array}$ & $\begin{array}{c}\mathbf{0 . 6 5 1} \\
(0.067)\end{array}$ & $\begin{array}{l}0.408 \\
(0.101)\end{array}$ & $\begin{array}{l}0.539 \\
(0.102)\end{array}$ & $\begin{array}{c}\mathbf{0 . 5 4 5} \\
(0.088)\end{array}$ \\
\hline \multirow[t]{2}{*}{$\mathrm{GFC}$} & $\begin{array}{l}0.767 \\
(0.129)\end{array}$ & $\begin{array}{l}0.621 \\
(0.107)\end{array}$ & $\begin{array}{c}\mathbf{0 . 5 6 9} \\
(0.085)\end{array}$ & $\begin{array}{l}0.581 \\
(0.244)\end{array}$ & $\begin{array}{l}0.897 \\
(0.142)\end{array}$ & $\begin{array}{l}0.955 \\
(0.103)\end{array}$ \\
\hline & & CRPS & & & - wQS & \\
\hline Full & $\begin{array}{c}\mathbf{0 . 9 1 6} \\
(0.029)\end{array}$ & $\underset{(0.019)}{\mathbf{0 . 8 9 0}}$ & $\begin{array}{c}\mathbf{0 . 9 0 3} \\
(0.075)\end{array}$ & $\begin{array}{l}0.910 \\
(0.121)\end{array}$ & $\underset{(0.056)}{\mathbf{0 . 8 7 0}}$ & $\begin{array}{l}0.888 \\
(0.124)\end{array}$ \\
\hline Rec. & $\mathbf{0 . 8 4 1}$ & $\begin{array}{c}\mathbf{0 . 7 9 1} \\
(0.045)\end{array}$ & $\mathbf{0 . 7 7 5}$ & $\begin{array}{c}\mathbf{0 . 7 9 6} \\
(0.031)\end{array}$ & $\mathbf{0 . 7 3 2}$ & $\begin{array}{c}\mathbf{0 . 7 1 9} \\
(0.049)\end{array}$ \\
\hline \multirow[t]{2}{*}{ GFC } & $\begin{array}{l}0.825 \\
(0.117)\end{array}$ & $\begin{array}{c}\mathbf{0 . 7 2 0} \\
(0.088)\end{array}$ & $\begin{array}{c}\mathbf{0 . 6 6 6} \\
(0.057)\end{array}$ & $\begin{array}{l}0.798 \\
(0.156)\end{array}$ & $\begin{array}{l}0.679 \\
(0.142)\end{array}$ & $\begin{array}{c}\mathbf{0 . 6 4 2} \\
(0.096)\end{array}$ \\
\hline & & & \multicolumn{2}{|c|}{ - One-year ahead } & & \\
\hline Full & $\begin{array}{c}\mathbf{0 . 7 5 9} \\
(0.046)\end{array}$ & $\begin{array}{c}\mathbf{0 . 6 6 0} \\
(0.052)\end{array}$ & $\begin{array}{l}0.667 \\
(0.162)\end{array}$ & $\begin{array}{l}0.179 \\
(0.208)\end{array}$ & $\underset{(0.008)}{\mathbf{0 . 3 0 6}}$ & $\begin{array}{c}\mathbf{0 . 2 6 5} \\
(0.096)\end{array}$ \\
\hline Rec. & $\begin{array}{c}\mathbf{0 . 8 5 3} \\
(0.035)\end{array}$ & $\begin{array}{c}\mathbf{0 . 7 1 5} \\
(0.064)\end{array}$ & $\begin{array}{c}\mathbf{0 . 6 7 1} \\
(0.003)\end{array}$ & $\begin{array}{l}0.346 \\
(0.437)\end{array}$ & $\begin{array}{c}\mathbf{0 . 6 5 2} \\
(0.007)\end{array}$ & $\begin{array}{c}\mathbf{0 . 7 1 3} \\
(0.007)\end{array}$ \\
\hline \multirow[t]{2}{*}{ GFC } & $\underset{(0.019)}{\mathbf{0 . 8 6 6}}$ & $\underset{(0.036)}{\mathbf{0 . 6 9 0}}$ & $\underset{(0.002)}{\mathbf{0 . 5 8 3}}$ & $\begin{array}{l}0.072 \\
(0.300)\end{array}$ & $\underset{(0.000)}{\mathbf{0 . 9 1 1}}$ & $\begin{array}{c}1.192 \\
(0.000)\end{array}$ \\
\hline & & CRPS & & & - wQS & \\
\hline Full & $\begin{array}{c}\mathbf{0 . 8 7 8} \\
(0.023)\end{array}$ & $\underset{(0.009)}{\mathbf{0 . 8 4 1}}$ & $\underset{(0.045)}{\mathbf{0 . 8 4 6}}$ & $\begin{array}{c}\mathbf{0 . 8 3 7} \\
(0.044)\end{array}$ & $\underset{(0.039)}{\mathbf{0 . 7 7 0}}$ & $\begin{array}{l}0.774 \\
(0.153)\end{array}$ \\
\hline Rec. & $\begin{array}{c}\mathbf{0 . 8 7 1} \\
(0.009)\end{array}$ & $\begin{array}{c}\mathbf{0 . 8 2 1} \\
(0.028)\end{array}$ & $\begin{array}{c}\mathbf{0 . 7 8 9} \\
(0.008)\end{array}$ & $\begin{array}{c}\mathbf{0 . 7 9 6} \\
(0.001)\end{array}$ & $\underset{(0.008)}{\mathbf{0 . 7 3 1}}$ & $\begin{array}{c}\mathbf{0 . 6 8 2} \\
(0.001)\end{array}$ \\
\hline GFC & $\begin{array}{l}\mathbf{0 . 8 6 4} \\
(0.004)\end{array}$ & $\begin{array}{c}\mathbf{0 . 7 9 3} \\
(0.015)\end{array}$ & $\begin{array}{c}\mathbf{0 . 7 3 4} \\
(0.003)\end{array}$ & $\begin{array}{c}\mathbf{0 . 8 0 7} \\
(0.000)\end{array}$ & $\begin{array}{c}\mathbf{0 . 7 0 0} \\
(0.018)\end{array}$ & $\begin{array}{r}\mathbf{0 . 5 9 7} \\
(0.001)\end{array}$ \\
\hline
\end{tabular}

Note: The table reports the average forecast metrics relative to the Gaussian model. We use ratios for the MSFE, CRSP and wQS, and differences for the logS. Ratios smaller than 1, and positive values of the log-score differences indicate that the column-specific model performs better than the Gaussian benchmark. The p-value for Giacomini and White (2006) test are in parentheses. Values in bold are significant at the $10 \%$ level; gray shaded cells highlight the best score.

with GARCH innovations. ${ }^{20}$ Table 3 reports the predictive performance of alternative Skew-t models against the Gaussian benchmark, for one-quarter and one-year ahead predictions. In particular, we produce forecasts from (a) a Skew-t model without any financial predictor, (b) a Skew-t model that includes as predictor only the NFCI and (c) our baseline Skew-t model, including the four disaggregate financial indices (4DFI). For all the measures, we report ratios with respect to the Gaussian benchmark, except for the $\log$-score $(\log S)$ for which we report differences. Values in parentheses report the

\footnotetext{
${ }^{20}$ When innovations are Gaussian the score-driven volatility is akin to a GARCH model for the volatility (see. e.g. Creal et al., 2013; Harvey, 2013).
} 
Table 4: Forecast performance with respect to Adrian et al. (2019)

\begin{tabular}{|c|c|c|c|c|c|c|c|c|}
\hline & \multicolumn{4}{|c|}{ One-quarter ahead } & \multicolumn{4}{|c|}{ One-year ahead } \\
\hline & MSFE & $\log S$ & CRPS & wQS & MSFE & $\log S$ & CRPS & wQS \\
\hline Full & $\begin{array}{l}0.977 \\
(0.775)\end{array}$ & $\begin{array}{l}0.031 \\
(0.623)\end{array}$ & $\begin{array}{l}0.975 \\
(0.774)\end{array}$ & $\begin{array}{l}0.986 \\
(0.943)\end{array}$ & $\begin{array}{l}0.873 \\
(0.625)\end{array}$ & $\begin{array}{l}0.113 \\
(0.151)\end{array}$ & $\begin{array}{l}0.964 \\
(0.654)\end{array}$ & $\begin{array}{l}0.962 \\
(0.481)\end{array}$ \\
\hline Rec. & $\begin{array}{l}0.970 \\
(0.799)\end{array}$ & $\begin{array}{l}0.120 \\
(0.248)\end{array}$ & $\underset{(0.077)}{\mathbf{0 . 9 4 6}}$ & $\begin{array}{l}0.930 \\
(0.236)\end{array}$ & $\begin{array}{l}0.772 \\
(0.329)\end{array}$ & $\begin{array}{l}0.212 \\
(0.131)\end{array}$ & $\underset{(0.002)}{\mathbf{0 . 7 7 9}}$ & $\begin{array}{l}0.833 \\
(0.278)\end{array}$ \\
\hline GFC & $\begin{array}{l}0.965 \\
(0.936)\end{array}$ & $\begin{array}{l}0.274 \\
(0.334)\end{array}$ & $\begin{array}{c}\mathbf{0 . 9 0 7} \\
(0.096)\end{array}$ & $\begin{array}{l}0.917 \\
(0.538)\end{array}$ & $\begin{array}{c}\mathbf{0 . 6 5 2} \\
(0.000)\end{array}$ & $\underset{(0.000)}{\mathbf{0 . 8 0 2}}$ & $\underset{(0.000)}{\mathbf{0 . 6 9 8}}$ & $\underset{(0.000)}{\mathbf{0 . 6 9 2}}$ \\
\hline
\end{tabular}

Note: The table reports the average forecast metrics from the $S k t-4 D F I$ model relative to Adrian et al. (2019). We use ratios for the MSFE, CRSP and wQS, and differences for the logS. Ratios smaller than 1 , and positive values of the log-score differences indicate that the Skt $4 D F I$ model performs better than Adrian et al. (2019). The p-value for Giacomini and White (2006) test are in parentheses. Values in bold are significant at the $10 \%$ level; gray shaded cells highlight the best score.

p-values of the Giacomini and White (2006) test for conditional predictive accuracy. We compare the performance of the models for the entire out-of-sample period, as well as for the two recessions (Rec.) in our sample, and the Global Financial Crisis (GFC). ${ }^{21}$ Simply introducing fat tails and asymmetry improves the forecast accuracy of the model with respect to the benchmark Gaussian specification. However, further predictive accuracy is gained when conditioning on financial information. Using the four subcomponents leads to additional gains during recessions. This is true for both the one-quarter and one-year ahead forecasts, for which the improvements are in generally larger, irrespective of the loss function. The gains over the benchmark Gaussian model are quite substantial, for instance, the baseline Skt-4DFI model produces roughly 25\% (35\%) improvement in MSFE, and 10\% (15\%) and 12\% (23\%) improvements in the CRPS and wQS, respectively, for the one-quarter (one-year) ahead forecasts. The gains become even larger if one focuses on recessions, or just the 2007-2009 recession.

Comparison with Adrian et al. (2019) In Table 4 we report the comparison of the baseline specification against the model of Adrian et al. (2019). ${ }^{22}$ Also in this case, the

\footnotetext{
${ }^{21}$ Within our evaluation sample the two recession occur from 2000Q1 to 2002Q4, and from $2007 \mathrm{Q} 1$ to 2009Q4. Test statistics for the Recessions and the GFC periods are to be taken as guidelines given the considered small sample.

${ }^{22}$ For comparability, we follow exactly the procedure of Adrian et al. (2019), using the replication codes accompanying their paper, but re-estimating the model using real-time vintages of GDP growth.
} 
Table 5: Density calibration tests

\begin{tabular}{|c|c|c|c|c|c|c|}
\hline \multirow[b]{3}{*}{ Dist. } & $A R(2)$ & $A B G$ & $\begin{array}{c}S k t \\
4 D F I\end{array}$ & $A R(2)$ & $A B G$ & $\begin{array}{c}S k t \\
4 D F I\end{array}$ \\
\hline & \multicolumn{3}{|c|}{ One-quarter ahead } & \multicolumn{3}{|c|}{ One-year ahead } \\
\hline & 0.561 & 1.401 & 0.167 & 1.688 & 1.524 & 0.414 \\
\hline Left tail & 0.510 & 0.567 & 0.195 & 3.244 & 2.295 & 0.782 \\
\hline
\end{tabular}

Note: The table reports the test statistics for the Rossi and Sekhposyan (2019) tests, based on the Cramér-von Mises type tests. The left tail score is computed over the support [0,0.25]. Values in bold indicate the rejection of the null hypothesis of correct specification of the density forecast at the $10 \%$ confidence level. Critical values are obtained by 1000 bootstrap simulations. Gray shaded cells indicate the lowest value of the statistic.

baseline model specification is associated with better point and density forecasts, and with significant values arising especially in the recession subperiods.

In particular, it is worth noticing that the forecast gains that we document during recessions stem from the adaptiveness of the score filter. The shape parameter we estimate promptly reacts to turning points, thus implying timely fluctuations of the skewness of the predictive distributions. As a consequence, forecast densities are characterized by longer left tails during recessions as compared to those implied by the Skew-t model of Adrian et al. (2019).

Density calibration Table 5 evaluates the calibration of the density forecasts looking at the properties of the PITs. In particular, we report the test statistic of Rossi and Sekhposyan (2019) for the Gaussian AR(2) model, the model of Adrian et al. (2019) $(A B G)$, and our Skew-t model with the four disaggregated financial indices. The test rejects the null hypothesis that the cumulative distribution function of the PIT lies within the $10 \%$ critical value bands for both the Gaussian benchmark and for the model of Adrian et al. (2019), for the one-quarter and one-year ahead forecasts. Whereas, the null is not rejected for our model, neither for the calibration of the entire density, nor for the 'left tail' of the distribution.

How important is parameters' uncertainty? To answer this question we produce forecasts from our baseline model fixing the parameters to the (recursively re-estimated) modal estimates, and we compare their performance with the baseline model's (which 
integrate over the estimated parameters). We find that density forecasts, especially over the medium horizon, are positively affected by the presence of parameters' uncertainty. In particular, explicitly accounting for parameters uncertainty leads to sizable gains in terms of log-scores and weighted quantile scores, in particular during recessions. Moreover, forecasts produced with the modal estimates of the model are found to understate downside risk, in particular for one year ahead forecasts. ${ }^{23}$

\subsection{Downside risk predictions for the Great Recession}

We now turn to the assessment of downside risk predictions, placing particular focus on the ability of the model to anticipate the build up in downside risk ahead of the 2008 financial crisis, and its reduction during the subsequent recovery. Measures such as Value at Risk (VaR), as well as the Expected Shortfall (ES) are readily obtained within our framework. $E S_{t+h}^{\alpha}=\alpha^{-1} \int_{0}^{\alpha} V a R_{t+h \mid t}^{a} d a$ describes the expected growth level for $y_{t+h}<V a R_{t+h}^{\alpha}$, corresponding to the $(100 \alpha)^{\text {th }}$ percentile of the h-step ahead predictive distribution, whereas the Expected Longrise $\left(E L_{t+h}^{1-\alpha}=\alpha^{-1} \int_{1-\alpha}^{1} V a R_{t+h \mid t}^{a} d a\right)$ is the upper counterpart of the ES. The left hand panel of Figure 6 contrasts the $5 \%$ expected shortfall and the $95 \%$ expected longrise for the Gaussian model, the Skew-t model without financial predictors and our baseline model.

The Gaussian model fails to capture the building-up of risk ahead of the latest recession, predicting an expected shortfall around zero as the economy enters the recession. In addition, assuming a symmetric distribution implies that falls in the ES are often associated with peaks in the EL, as clearly visible during the latest recession, where the minimum ES corresponds to the maximum EL in 2009Q2. On the other hand, allowing for Skew-t innovations alleviates both problems, delivers more conservative risk measures with less erratic longrise figures, and anticipate the build-up of downside risk ahead of the recession. Conditioning the forecasts on the available subindices of financial conditions increases the timeliness of the prediction of risk, due to the prompt discounting of financial overheating. The prediction of the ES falls to roughly $-5 \%$ in the first quarter of the recessions, and decreases consistently until the first quarter of recovery, as indicated by a sharp upward revision. Moreover, within the recession, the model delivers a downwarding

\footnotetext{
${ }^{23}$ These results are reported in Tables G9 and G10, in Appendix G.
} 

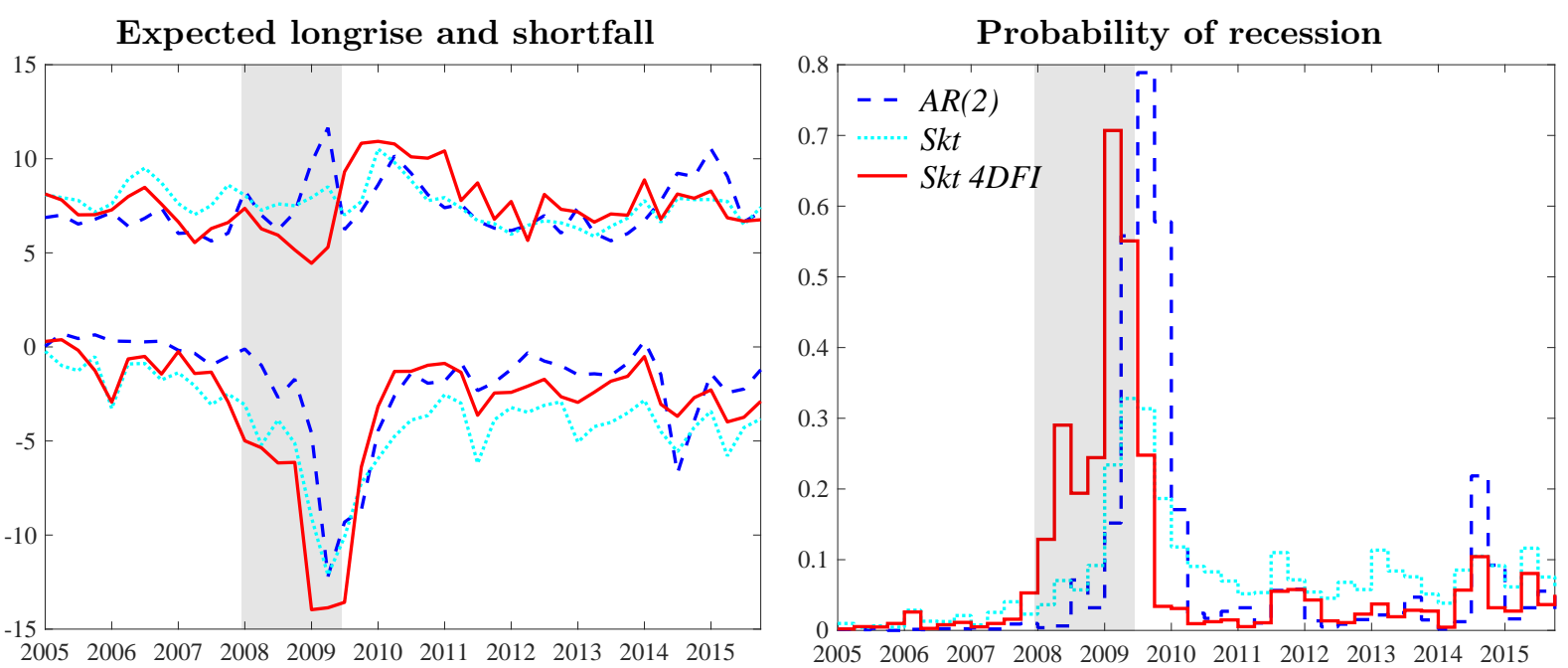

Figure 6: Expected Shortfall and Expected Longrise

Note: We report the ES and EL for $\alpha=0.05$. Shaded bands represent NBER recessions.

longrise, predicting modest gains even for the most optimistic scenario. The longrise is sharply revised upward already for the first post-trough quarter.

Brownlees and Souza (2020) argue that GARCH forecasts provide competitive results for the dynamics of the lower quantiles. On the contrary, our class of Skew-t models deliver substantial gains in assessing the downside risk. Evaluating ES accuracy using the score metric proposed by Taylor (2019) highlights that the baseline model produces gains of up to $80 \%$ with respect to the Gaussian model, and $25 \%$ with respect to the Skew-t model with no predictors, for the one-quarter ahead forecast during the crisis period; even larger gains are found for the one-year ahead forecast. ${ }^{24}$

Last, we investigate the ability of the model to predict recessions. The NBER Business Cycle Dating Committee (BCDC) defines a recession as "...] a significant decline in activity spread across the economy, lasting more than a few months [...]". Within our forecast distributions of GDP growth up to a one year horizon, we retrieve the probability of observing any two consecutive negative forecasts for the next four quarters. The right panel of Figure 6 highlights that combining the information on financial conditions and allowing for asymmetry in the forecast densities produces a realistic assessment of recession risk. The implied probability of recession stars picking up earlier as compared

\footnotetext{
${ }^{24}$ Using different scores, such as the Fissler et al. (2016) loss function, or the tick loss function for the $5 \%$ VaR proposed by Giacomini and Komunjer (2005) we document similar gains. The full set of results is available in Table G11, in Appendix G.
} 
to the other measures, warning against an imminent output contraction. Moreover, the probability of observing a recession within the forthcoming year recedes sharply when the recession ends and is already below $5 \%$ just a quarter after the end of the recession, as dated by the BCDC. In contrast, the Gaussian model, as well as the Skew-t model without conditioning information, starts to produce a reasonable probability of recession only toward the end of the recession period, and they continue to perceive a substantial treat of recession many quarters after the formal end of it. We evaluate the ability of the model to time recessions over the sample 1993-2018, using the Brier score. Deviating from the Gaussian assumption provides gains of more than 30\%, whereas additional gains, of around 10\%, can be directly ascribed to the inclusion of financial predictors. Overall, these results uncover a significant contribution from financial conditions to the prediction of downside risk to growth, both in terms of magnitude and timing.

\section{Dissecting the Financial Condition Index}

In the previous Section, we have highlighted that financial conditions are important predictors of the distribution of GDP growth. At this stage, a natural question is to what extent the predictive power of the model can be further improved considering the entire panel of data that feeds into the NFCI, and what are the indicators useful to predict downside risk.

To address this question, we consider the full set of 105 (smoothed) indicators of financial activity that constitute the NFCI. Specifically, to obtain predictors in pseudoreal-time, we assume that a time $t$, the set of predictors corresponds to the quarterly average of the financial indicators from the third week of the previous quarter to the second week of the current quarter. This approach mimics the information set available to the econometrician who produces real-time forecasts, and avoids dealing with overlapping quarters. As indicators enter the predictors' set at different points in time, for each time $t$, we only consider predictors available for at least four years. This implies that the first forecast produced in 1992Q4 includes less than 50\% of the 105 financial indices. As predictors' availability steadily increases over the sample, forecasts of the 2001 recession include $70 \%$ of the total predictors, while forecasts of the 2007-2009 recession exploit $85 \%$ 
of the full set of indicators.

\subsection{Variables selection: "shrink-then-sparsify"}

A potential concern of this exercise lies in the steep increase in the number of parameters our model needs to accommodate. When all indicators (and their lags) are included at the same time, the model features more than 600 coefficients. We tackle this dimensionality problem through a "shrink-then-sparsify" strategy (see Hahn and Carvalho, 2015). ${ }^{25}$ Specifically, the shrinkage of the predictor loadings is induced by means of hierarchical priors and, in particular, we rely on the Horseshoe (HS) prior specification of Carvalho et al. (2010): $b^{j} \sim \mathcal{N}\left(0, \lambda^{j} \tau\right)$, where the hyperparameters $\lambda^{j}$ and $\tau$ control the local (coefficient specific) and the global shrinkage, respectively. Therefore, $\lambda^{j} \sim \operatorname{HC}^{+}(0,1)$ and $\tau \sim H C^{+}(0,1)$, where $H C^{+}(0,1)$ denotes the standard Half-Cauchy distribution. Unlike other common shrinkage priors (e.g. Ridge, Lasso), the HS priors are free of exogenous inputs, implying a fully adaptive shrinkage procedure. We add a second sparsification step to reduce the estimation uncertainty arising from the near-zero shrinkage coefficients. We approach sparsification through the Signal Adaptive Variable Selector (SAVS) algorithm of Ray and Bhattacharya (2018). This data-driven procedure specifies the sparsification tuning parameter as $m_{j}=\left|\hat{b}_{j}\right|^{-2}$ such that each of the $j$ variables receives a penalization "ranked in inverse-squared order of magnitude of the corresponding coefficient" (Ray and Bhattacharya, 2018). The sparsified coefficients are computed as

$$
b_{j}^{*}=\operatorname{sgn}\left(\hat{b}_{j}\right)\left\|X_{j}\right\|^{-2} \max \left\{\left|\hat{b}_{j}\right| \cdot\left\|X_{j}\right\|^{2}-m_{j}, 0\right\},
$$

where $\|\cdot\|$ represents the Euclidean norm of the vector $X_{j}$. We apply the sparsification step for each draw of the MCMC algorithm to further account for model uncertainty. As noted by Huber et al. (2020), this procedure is akin to the idea of Bayesian model averaging.

\footnotetext{
${ }^{25}$ Further details on this approach are provided in Section D.2 of Appendix D.
} 


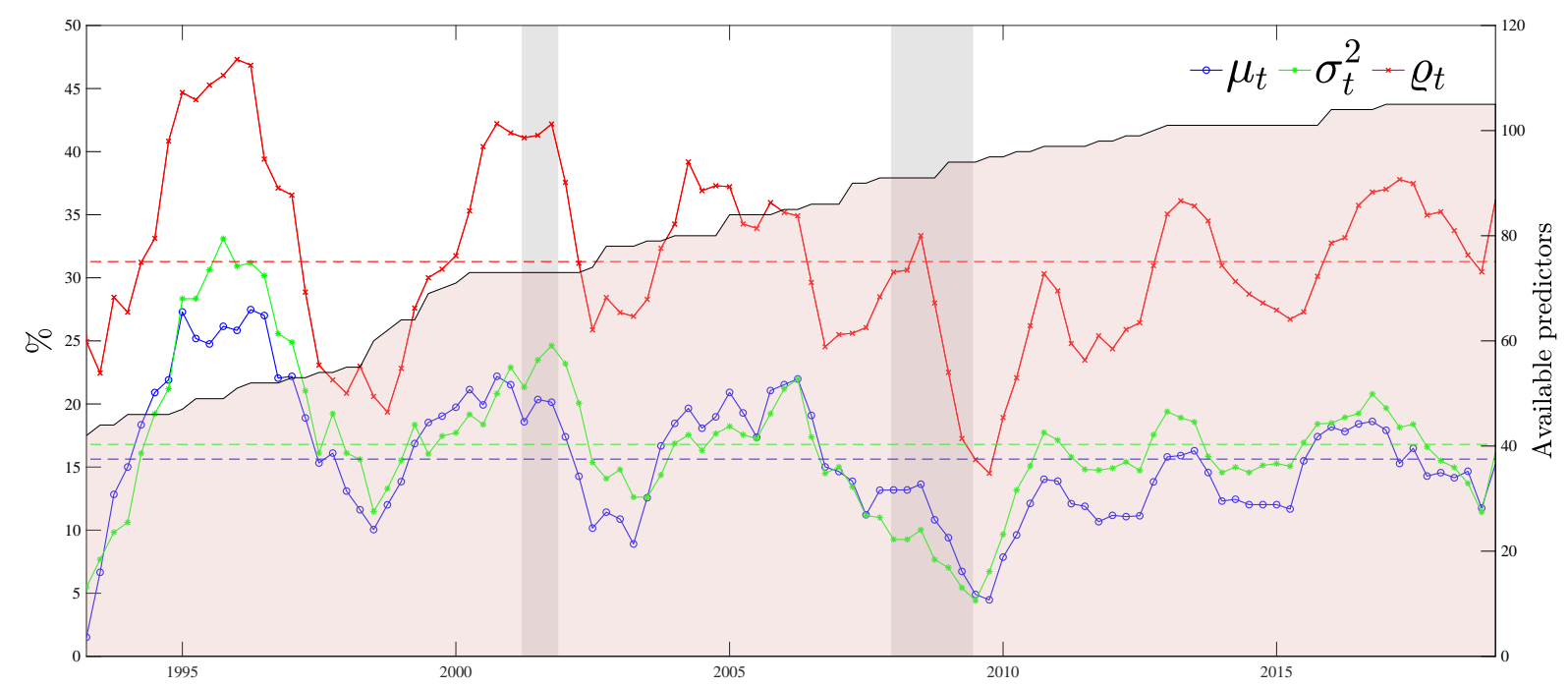

Figure 7: Percentage of predictors for the time-varying parameters over time

Note: For each period, the percentage of predictors corresponds to the number of financial indicators that receive a non-zero loading after the SAVS algorithm has been applied, over the available amount. Shaded bands represent NBER recessions.

\subsection{On the importance of financial indicators}

The sparsification strategy is highly effective in reducing the number of coefficients we need to estimate when producing forecasts from a large panel of financial indicators. Figure 7 plots the evolution over time of the number of financial indicators available that are selected as predictors for each of the three time varying parameters. These values are computed as the number of predictors that receive a non-zero loading after the SAVS algorithm has been applied to the shrinkage parameters. ${ }^{26}$ The number of selected coefficients remains steady over time, in spite of the higher number of indicators that become available over the sample. Interestingly, the number of predictors the model selects are on average twice as many for the shape parameter than for the location and scale (roughly $31 \%$ vs. $15 \%$ and $16 \%$ of the available predictors). This highlights the importance of predicting the asymmetry of the distribution, to appropriately reflect the underlying uncertainty in GDP growth. Moreover, the number of predictors of the shape parameters increases ahead of the financial crisis, roughly around the time when the model starts to predict an increasing downside risk in the one-year ahead forecast. Thus, the information in the financial indicators maps into substantial gains in prediction accuracy (as highlighted in Table 6).

\footnotetext{
${ }^{26}$ Data has been smoothed using a 2-years moving average filter for comparison purposes.
} 
The upper panel of Figure 8 reports ten predictors for which the average posterior probability of inclusion is the highest, for the scale and shape parameters. Overall, leverage and credit indicators are the most relevant categories of predictors. In particular, corporate equity issuances (STKGR) and household leverage (HH) show up as the most important predictors of the asymmetry of the distribution, whereas commercial property prices $(\mathrm{CPH})$ and the 10-2 year Treasury spread are relevant predictors for the scale. ${ }^{27}$ The predictors that are selected do not remain constant over time. The lower panel of Figure 8 reports the most relevant predictors during the Great Recession. In this case, risk indicators play a more relevant role also in predicting the shape of the distribution. The financial roots of the crisis are reflected in the selected variable. The amount of traded security of the broker-dealers over GDP (SBD) and the mortgage backed securities/10year Treasury yield spread (CTMBS) provide useful to gauge the increasing downside risk associated with the GFC outburst. The roots of the GFC are found in the role of real-estate, as indicated by the presence of housing prices, for the scale, and of the CTMBS variable, for the shape, as well as highlighting the importance of the shadow banking sector (as highlighted by Adrian and Shin, 2008).

Evaluated over the full sample, using a large dataset produces forecasts (point and density) which are in line with the baseline model using the 4 major subindices of the NFCI (Table 6). In this case, we observe gains for the one-quarter ahead density forecasts, in particular for the left tail of the distribution, where we report gains of up to $15 \%$ compared to the model of Adrian et al. (2019). The gains become more substantial for one-year head predictions. We document $10 \%$ to $20 \%$ improvements in point forecast during the Great recession. As for left tail of the density, gains reach up to almost $50 \%$ with respect to Adrian et al. (2019). These results further underline the importance of accounting for broader and detailed financial information sets, when predicting the distribution of GDP growth, and the relative downside risk, in particular for mediumterm horizon.

\footnotetext{
${ }^{27}$ In Appendix $G$ we report the predictors for the location. However, it is worth noting that their importance is limited. We also report the full ranking of the predictors for the three parameters.
} 


\section{Full sample}

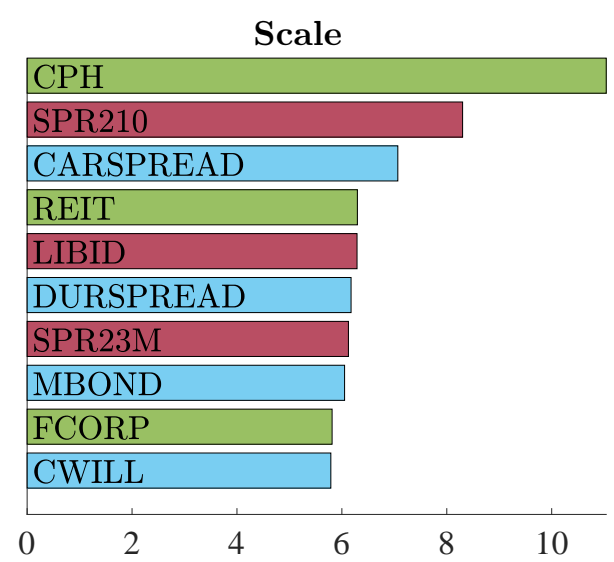

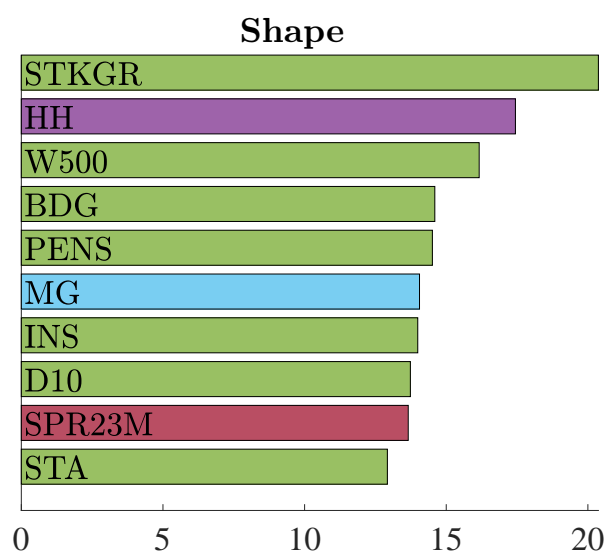

\section{GFC sample}

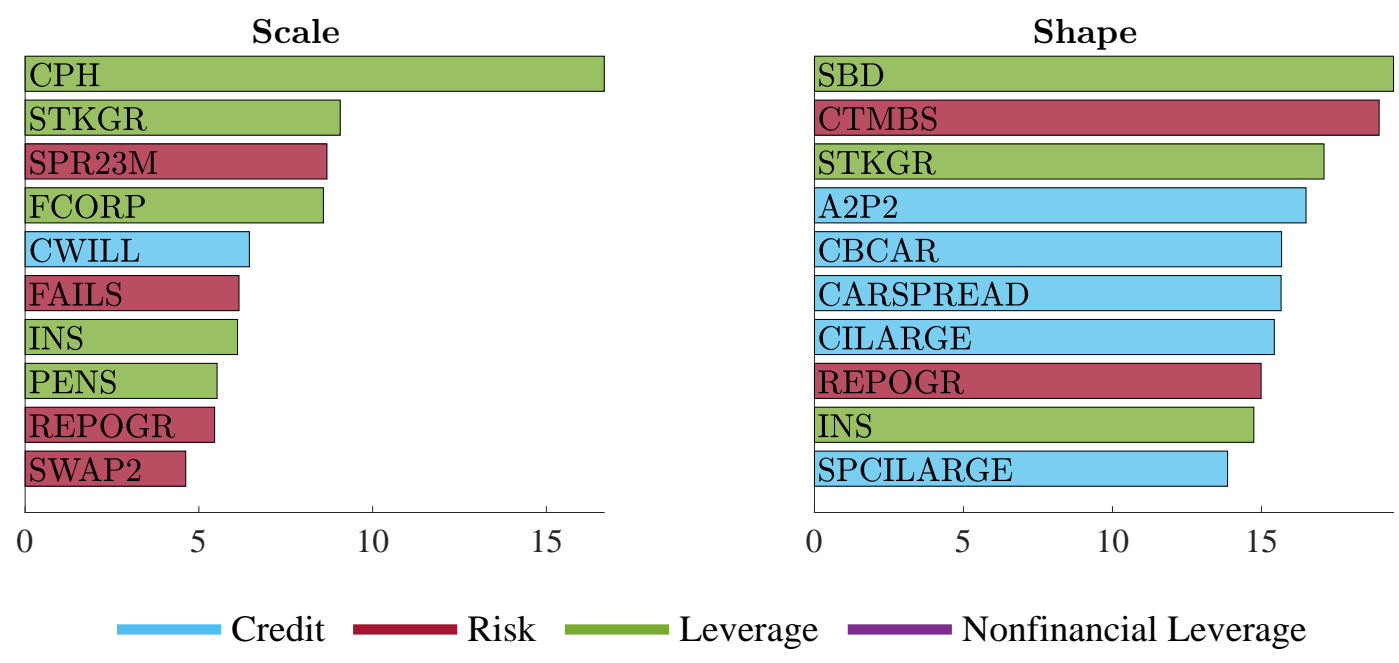

Figure 8: Top 10 predictors for $\sigma_{t}$ and $\varrho_{t}$

Note: The bar plots report the top 10 predictors for each parameter. The $x$-axis reports average posterior probability of inclusion, expressed in percentage terms. 
Table 6: Forecast performance - Large data model

\begin{tabular}{|c|c|c|c|c|c|c|c|c|}
\hline \multirow[b]{4}{*}{ Full } & \multicolumn{4}{|c|}{ One-quarter ahead } & \multicolumn{4}{|c|}{ One-year ahead } \\
\hline & $A B G$ & $\begin{array}{c}S k t \\
4 D F I\end{array}$ & $A B G$ & $\begin{array}{c}S k t \\
4 D F I\end{array}$ & $A B G$ & $\begin{array}{c}S k t \\
4 D F I\end{array}$ & $A B G$ & $\begin{array}{c}S k t \\
4 D F I\end{array}$ \\
\hline & \multicolumn{2}{|c|}{ MSFE } & \multicolumn{2}{|c|}{$-\log \mathrm{S}$} & \multicolumn{2}{|c|}{ MSFE } & \multicolumn{2}{|c|}{$\log \mathrm{S}$} \\
\hline & $\begin{array}{l}1.022 \\
(0.254)\end{array}$ & $\begin{array}{l}1.047 \\
(0.335)\end{array}$ & $\underset{(0.100)}{-\mathbf{0 . 0 1 5}}$ & $\begin{array}{c}-0.047 \\
(0.985)\end{array}$ & $\begin{array}{l}0.789 \\
(0.583)\end{array}$ & $\begin{array}{l}0.904 \\
(0.165)\end{array}$ & $\begin{array}{l}0.089 \\
(0.350)\end{array}$ & $\begin{array}{c}-0.024 \\
(0.644)\end{array}$ \\
\hline Rec. & $\begin{array}{c}\mathbf{0 . 9 3 7} \\
(0.090)\end{array}$ & $\underset{(0.002)}{\mathbf{0 . 9 4 9}}$ & $\underset{(0.078)}{\mathbf{0 . 2 0 3}}$ & $\begin{array}{l}0.116 \\
(0.128)\end{array}$ & $\begin{array}{l}0.570 \\
(0.104)\end{array}$ & $\begin{array}{c}\mathbf{0 . 7 3 9} \\
(0.067)\end{array}$ & $\begin{array}{c}\mathbf{0 . 6 3 8} \\
(0.014)\end{array}$ & $\underset{(0.017)}{\mathbf{0 . 4 2 6}}$ \\
\hline \multirow[t]{2}{*}{ GFC } & $\underset{(0.090)}{\mathbf{0 . 9 6 9}}$ & $\underset{(0.022)}{1.036}$ & $\underset{(0.002)}{\mathbf{0 . 3 7 9}}$ & $\underset{(0.004)}{\mathbf{0 . 0 3 1}}$ & $\underset{(0.096)}{\mathbf{0 . 5 0 1}}$ & $\underset{(0.001)}{\mathbf{0 . 7 6 8}}$ & $\underset{(0.000)}{1.152}$ & $\underset{(0.000)}{\mathbf{0 . 3 5 0}}$ \\
\hline & \multicolumn{2}{|c|}{ CRPS } & \multicolumn{2}{|c|}{ wQS } & \multicolumn{2}{|c|}{ CRPS } & \multicolumn{2}{|c|}{ - wQS } \\
\hline Full & $\begin{array}{l}1.019 \\
(0.133)\end{array}$ & $\begin{array}{l}1.045 \\
(0.801)\end{array}$ & $\begin{array}{l}1.035 \\
(0.386)\end{array}$ & $\begin{array}{l}1.050 \\
(0.564)\end{array}$ & $\begin{array}{l}0.978 \\
(0.693)\end{array}$ & $\begin{array}{l}1.015 \\
(0.892)\end{array}$ & $\begin{array}{l}0.930 \\
(0.863)\end{array}$ & $\begin{array}{l}0.967 \\
(0.760)\end{array}$ \\
\hline Rec. & $\begin{array}{l}0.915 \\
(0.135)\end{array}$ & $\underset{(0.005)}{\mathbf{0 . 9 6 0}}$ & $\underset{(0.075)}{\mathbf{0 . 8 6 6}}$ & $\underset{(0.035)}{\mathbf{0 . 9 4 0}}$ & $\begin{array}{l}0.746 \\
(0.238)\end{array}$ & $\begin{array}{c}\mathbf{0 . 9 5 8} \\
(0.013)\end{array}$ & $\begin{array}{c}\mathbf{0 . 6 3 9} \\
(0.077)\end{array}$ & $\underset{(0.033)}{\mathbf{0 . 7 6 7}}$ \\
\hline GFC & $\begin{array}{l}0.888 \\
(0.103)\end{array}$ & $\begin{array}{l}\mathbf{1 . 0 2 7} \\
(0.000)\end{array}$ & $\underset{(0.045)}{\mathbf{0 . 8 5 1}}$ & $\underset{(0.075)}{\mathbf{0 . 9 9 0}}$ & $\begin{array}{l}0.652 \\
(0.302)\end{array}$ & $\underset{(0.000)}{\mathbf{0 . 9 3 4}}$ & $\underset{(0.018)}{\mathbf{0 . 5 4 0}}$ & $\begin{array}{c}\mathbf{0 . 7 7 9} \\
(0.000)\end{array}$ \\
\hline
\end{tabular}

Note: The table reports the large data model's average forecast metrics relative to the column-specific model. We use ratios for the MSFE, CRSP and wQS, and differences for the logS. Ratios smaller than 1, and positive values of the log-score differences indicate that the large data model performs better than the column-specific benchmark. The p-value for Giacomini and White (2006) test are in parentheses. Values in bold are significant at the $10 \%$ level; gray shaded cells highlight the best score. 


\section{Conclusions}

The severity of the latest financial crisis and the ensuing recession has spurred the interest of both academics and practitioners in developing models that allow us to better understand and predict downside risk to economic growth. In this paper, we introduce a class of parametric models to fully characterize the conditional distribution of GDP growth. The flexibility of our approach allows us to inspect the dynamics and the drivers of the parameters relating to the level, uncertainty and asymmetry of business cycle fluctuations. Procyclical asymmetry is a strong feature of the data, with business cycle fluctuations characterized by positive skewness in expansions and negative skewness in recessions. As a result, the correlation between the mean and the variance of the conditional distribution varies over business cycle phases, turning negative during recessions. These features become even more prominent after we allow measures of financial conditions to drive time variation in the parameters. When financial markets are overheating, future economic growth becomes more uncertain, not only due to increasing risk, but also due to deepening negative skewness of the predictive distributions. Leverage and credit are important signals when assessing downside risk in GDP growth. In particular, non financial leverage measures anticipate a fall in economic growth, driving the rising negative asymmetry of the 2007-2009 recession.

Secular changes in the moments of the conditional distribution highlight that the statistical properties of economic growth have changed dramatically over the last 50 years in response to permanent shocks. Moreover, we find that, since the 2008 recession, the unconditional distribution of GDP growth displays a marked negative skewness, indicating that the slow recovery observed over the last 10 years stands on very weak ground, and that well before the COVID-19 crisis there were visible signs of downside risk in economic activity.

From a policymaking perspective, our results point to the paramount importance of nonlinearities and non-Gaussianity in capturing the dynamics of downside risk to economic growth, and in improving predictions. Conditioning on large financial information sets delivers sharper forecasts, which accurately characterize the left tail of the predictive distribution, both on short-and medium-term projections. 


\section{References}

Adrian, T., N. Boyarchenko, and D. Giannone (2019): "Vulnerable Growth," American Economic Review, 109, 1263-89.

Adrian, T., F. Duarte, N. Liang, And P. Zabczyk (2020): "NKV: A New Keynesian Model with Vulnerability," AEA Papers and Proceedings, 110, 470-76.

Adrian, T., F. Grinberg, N. Liang, And S. Malik (2018): "The Term Structure of Growth-at-Risk," Discussion Papers 13349, Centre for Economic Policy Research.

Adrian, T. AND H. S. ShIn (2008): "Financial intermediaries, financial stability and monetary policy," Proceedings - Economic Policy Symposium - Jackson Hole, 287-334.

Alessi, L., E. Ghysels, L. Onorante, R. Peach, And S. Potter (2014): "Central bank macroeconomic forecasting during the global financial crisis: the european central bank and federal reserve bank of new york experiences," Journal of Business $\&$ Economic Statistics, 32, 483-500.

Antolin-Diaz, J., T. Drechsel, And I. Petrella (2017): "Tracking the slowdown in long-run GDP growth," Review of Economics and Statistics, 99, 343-356.

Arellano-Valle, R. B., H. W. Gómez, and F. A. Quintana (2005): "Statistical inference for a general class of asymmetric distributions," Journal of Statistical Planning and Inference, 128, 427-443.

Azzalini, A. AND A. CAPitanio (2003): "Distributions generated by perturbation of symmetry with emphasis on a multivariate skew t-distribution," Journal of the Royal Statistical Society: Series B (Statistical Methodology), 65, 367-389.

BAI, J. AND S. NG (2005): "Tests for skewness, kurtosis, and normality for time series data," Journal of Business 83 Economic Statistics, 23, 49-60.

Bekaert, G. And E. Engstrom (2017): "Asset Return Dynamics under Habits and Bad Environment-Good Environment Fundamentals," Journal of Political Economy, $125,713-760$. 
Bekaert, G. And M. Hoerova (2014): "The VIX, the variance premium and stock market volatility," Journal of Econometrics, 183, 181-192.

Blasques, F., S. J. Koopman, and A. LuCas (2015): "Information-theoretic optimality of observation-driven time series models for continuous responses," Biometrika, $102,325-343$.

Brave, S. And R. A. Butters (2012): "Diagnosing the Financial System: Financial Conditions and Financial Stress," International Journal of Central Banking, 8, 191239.

Brownlees, C. And A. B. Souza (2020): "Backtesting Global Growth-at-Risk," Journal of Monetary Economics, Forthcoming.

Busetti, F., M. Caivano, D. Delle Monache, And C. Pacella (2020): "The time-varying risk of italian GDP," Temi di discussione (Economic working papers) 1288, Bank of Italy.

Caldara, D., D. Cascaldi-Garcia, P. Cuba-Borda, And F. Loria (2020): "Understanding Growth-at-Risk: A Markov-Switching Approach," Unpublished manuscript.

Calvori, F., D. Creal, S. J. Koopman, and A. Lucas (2017): "Testing for parameter instability across different modeling frameworks," Journal of Financial Econometrics, 15, 223-246.

Carriero, A., T. E. Clark, And M. Marcellino (2020a): "Capturing Macroeconomic Tail Risks with Bayesian Vector Autoregressions," Working Paper 20-02, Federal Reserve Bank of Cleveland.

- (2020b): "Nowcasting Tail Risks to Economic Activity with Many Indicators," Working Papers WP 20-13, Federal Reserve Bank of Cleveland.

Carvalho, C. M., N. G. Polson, And J. G. Scott (2010): "The horseshoe estimator for sparse signals," Biometrika, 97, 465-480. 
Cecchetti, S. G. (2008): "Measuring the Macroeconomic Risks Posed by Asset Price Booms," in Asset Prices and Monetary Policy, University of Chicago Press, NBER Chapters, 9-43.

Cette, G., J. Fernald, And B. Mojon (2016): "The pre-Great Recession slowdown in productivity," European Economic Review, 88, 3-20.

Chauvet, M. And S. PotTer (2013): "Forecasting output," in Handbook of Economic Forecasting, Elsevier, vol. 2, 141-194.

Cox, D. R. (1981): "Statistical analysis of time series: Some recent developments," Scandinavian Journal of Statistics, 93-115.

Creal, D., S. J. Koopman, And A. Lucas (2013): "Generalized autoregressive score models with applications," Journal of Applied Econometrics, 28, 777-795.

De Nicolò, G. And M. Lucchetta (2017): "Forecasting tail risks," Journal of Applied Econometrics, 32, 159-170.

Delle Monache, D. And I. Petrella (2017): "Adaptive models and heavy tails with an application to inflation forecasting," International Journal of Forecasting, 33, $482-501$.

Diebold, F. X., T. A. Gunther, And A. Tay (1998): "Evaluating density forecasts, with Applications to Financial Risk Management," International Economic Review, 39, $863-883$.

DoAn, T., R. LitTerman, And C. Sims (1984): "Forecasting and conditional projection using realistic prior distributions," Econometric Reviews, 3, 1-100.

Drehmann, M., C. E. Borio, L. Gambacorta, G. Jimenez, and C. Trucharte (2010): "Countercyclical capital buffers: exploring options," Working Paper 317, Bank for International Settlement.

ENGLE, R. F. AND G. LeE (1999): "A permanent and transitory component model of stock return volatility," in Causality, and Forecasting: A Festschrift in Honor of Clive 
W. J. Granger, ed. by R. F. Engle and H. White, Oxford: Oxford University Press, chap. 20, 475-497.

Engle, R. F. And J. G. RAngel (2008): "The spline-GARCH model for low-frequency volatility and its global macroeconomic causes," The Review of Financial Studies, 21, $1187-1222$.

Escanciano, J. C. AND I. N. Lobato (2009): "An automatic portmanteau test for serial correlation," Journal of Econometrics, 151, 140-149.

Faust, J., S. Gilchrist, J. H. Wright, And E. ZakrajŠSeK (2013): "Credit spreads as predictors of real-time economic activity: a Bayesian model-averaging approach," Review of Economics and Statistics, 95, 1501-1519.

Fernández-Villaverde， J. And P. Guerrón-Quintana (2020a): "Estimating DSGE Models: Recent Advances and Future Challenges," NBER Working Papers 27715, National Bureau of Economic Research.

(2020b): "Uncertainty Shocks and Business Cycle Research," Review of Economic Dynamics, 37, 118-166.

Fernández-Villaverde, J., S. Hurtado, And G. Nuño (2019): "Financial Frictions and the Wealth Distribution," NBER Working Papers 26302, National Bureau of Economic Research.

Fissler, T., J. F. Ziegel, And T. Gneiting (2016): "Expected shortfall is jointly elicitable with value-at-risk: implications for backtesting." Risk.net (www. risk. net/ $2439862)$.

Fève, P., P. Garcia Sanchez, A. Moura, and O. Pierrard (2019): "Costly default and asymetric real business cycles," TSE Working Papers 19-1048, Toulouse School of Economics.

Gadea, M. D., A. Gómez-Loscos, And G. PÉrez-Quirós (2018): "Great Moderation and Great Recession: From plain sailing to stormy seas?" International Economic Review, 59, 2297-2321. 
Gadea Rivas, M. D., L. Laeven, And G. Pérez-Quirós (2020): "Growth-and-Risk Trade-off," CEPR Discussion Papers 14492.

GAlvão, A. B. AND M. T. OWYANG (2018): "Financial stress regimes and the macroeconomy," Journal of Money, Credit and Banking, 50, 1479-1505.

Ganics, G., B. Rossi, And T. Sekhposyan (2020): "From Fixed-event to Fixedhorizon Density Forecasts: Obtaining Measures of Multi-horizon Uncertainty from Survey Density Forecasts," CEPR Discussion Papers 14267, Centre for Economic Policy Research.

Gertler, M. And S. Gilchrist (2018): "What happened: Financial factors in the great recession," Journal of Economic Perspectives, 32, 3-30.

Giacomini, R. And I. Komunjer (2005): "Evaluation and combination of conditional quantile forecasts," Journal of Business \& Economic Statistics, 23, 416-431.

Giacomini, R. And H. White (2006): "Tests of conditional predictive ability," Econometrica, 74, 1545-1578.

Giannone, D., M. Lenza, And G. E. Primiceri (2018): "Economic predictions with big data: The illusion of sparsity," Staff Report 847, Federal Reserve Bank of New York.

Giglio, S., B. Kelly, And S. Pruitt (2016): "Systemic risk and the macroeconomy: An empirical evaluation," Journal of Financial Economics, 119, 457-471.

Gneiting, T. And A. E. RAftery (2007): "Strictly proper scoring rules, prediction, and estimation," Journal of the American Statistical Association, 102, 359-378.

Gneiting, T. And R. Ranjan (2011): "Comparing density forecasts using thresholdand quantile-weighted scoring rules," Journal of Business $\&$ Economic Statistics, 29, $411-422$.

Gómez, H. W., F. J. Torres, And H. Bolfarine (2007): "Large-sample inference for the epsilon-skew-t distribution," Communications in Statistics-Theory and Methods, $36,73-81$. 
HAARio, H., E. SAKSman, AND J. TAMminen (1999): "Adaptive proposal distribution for random walk Metropolis algorithm," Computational Statistics, 14, 375-396.

Hahn, P. R. And C. M. Carvalho (2015): "Decoupling shrinkage and selection in Bayesian linear models: a posterior summary perspective," Journal of the American Statistical Association, 110, 435-448.

Hansen, B. E. (1994): "Autoregressive Conditional Density Estimation," International Economic Review, 35, 705-730.

Harvey, A. And A. Luati (2014): "Filtering With Heavy Tails," Journal of the American Statistical Association, 109, 1112-1122.

HARvey, A. C. (2013): Dynamic models for volatility and heavy tails: with applications to financial and economic time series, vol. 52, Cambridge University Press.

Harvey, C. R. And A. Siddique (1999): "Autoregressive conditional skewness," Journal of Financial and Quantitative Analysis, 34, 465-487.

Hasenzagl, T., L. Reichlin, And G. Ricco (2020): "Financial Variables as Predictors of Real Growth Vulnerability," Discussion Paper DP14322, CEPR.

Horswell, R. And S. LoOney (1993): "Diagnostic limitations of skewness coefficients in assessing departures from univariate and multivariate normality: Diagnostic limitations of skewness coefficients," Communications in statistics-simulation and computation, 22, 437-459.

Huber, F., G. Koop, And L. Onorante (2020): "Inducing Sparsity and Shrinkage in Time-Varying Parameter Models," Journal of Business \& Economic Statistics, Forthcoming.

Jensen, H., I. Petrella, S. H. Ravn, And E. Santoro (2020): "Leverage and Deepening Business-Cycle Skewness," American Economic Journal: Macroeconomics, $12,245-81$.

Jordà, Ò., M. Schularick, And A. M. TAYlor (2013): "When credit bites back," Journal of Money, Credit and Banking, 45, 3-28. 
(2017): "Macrofinancial history and the new business cycle facts," NBER Macroeconomics Annual Report, 31, 213-263.

JordÀ, Ò., M. Schularick, AND A. M. TAYlor (2020): "Disasters Everywhere: The Costs of Business Cycles Reconsidered," NBER Working Papers 26962, National Bureau of Economic Research.

Jurado, K., S. C. Ludvigson, And S. NG (2015): "Measuring uncertainty," American Economic Review, 105, 1177-1216.

Koopman, S. J., A. Lucas, And M. Scharth (2016): "Predicting time-varying parameters with parameter-driven and observation-driven models," Review of Economics and Statistics, 98, 97-110.

Koopman, S. J., A. LuCAs, And M. Zamojski (2018): "Dynamic term structure models with score-driven time-varying parameters: estimation and forecasting," Working Papers 258, Narodowy Bank Polski.

Krishnamurthy, A. And T. Muir (2017): "How credit cycles across a financial crisis," Working Paper 23850, National Bureau of Economic Research.

Loria, F., C. Matthes, And D. Zhang (2019): "Assessing macroeconomic tail risk," Working Papers WP 19-10, FRB Richmond Working Paper.

LuCAS, A. AND X. Zhang (2016): "Score-driven exponentially weighted moving averages and Value-at-Risk forecasting," International Journal of Forecasting, 32, 293-302.

McConnell, M. M. And G. Perez-Quiros (2000): "Output fluctuations in the United States: What has changed since the early 1980's?" American Economic Review, 90, 1464-1476.

Mian, A. And A. Sufi (2010): "Household Leverage and the Recession of 2007-09," IMF Economic Review, 58, 74-117.

Morley, J. And J. Piger (2012): "The asymmetric business cycle," Review of Economics and Statistics, 94, 208-221. 
Mudholkar, G. S. And A. D. Hutson (2000): "The epsilon-skew-normal distribution for analyzing near-normal data," Journal of Statistical Planning and Inference, 83, 291309.

Neftci, S. N. (1984): "Are economic time series asymmetric over the business cycle?" Journal of Political Economy, 92, 307-328.

NyBlom, J. (1989): "Testing for the constancy of parameters over time," Journal of the American Statistical Association, 84, 223-230.

Plagborg-Møller, M., L. Reichlin, G. Ricco, and T. Hasenzagl (2020): "When is Growth at Risk?" Conference draft, Brooking Paper on Economic Activity.

Ray, P. And A. Bhattacharya (2018): "Signal Adaptive Variable Selector for the Horseshoe Prior," arXiv preprint arXiv:1810.09004.

Rossi, B. And T. SEkHPOSyan (2019): "Alternative tests for correct specification of conditional predictive densities," Journal of Econometrics, 208, 638-657.

Rudebusch, G. D. And J. C. Williams (2009): "Forecasting Recessions: The Puzzle of the Enduring Power of the Yield Curve," Journal of Business $\& 5$ Economic Statistics, 27, 492-503.

Salgado, S., F. Guvenen, And N. Bloom (2019): "Skewed business cycles," Working Paper 26565, National Bureau of Economic Research.

SchwaAB, B., X. Zhang, And A. LuCAS (2020): "Modeling extreme events: timevarying extreme tail shape," Tinbergen Institute Discussion Papers 20-076/III.

Segal, G., I. Shaliastovich, And A. Yaron (2015): "Good and bad uncertainty: Macroeconomic and financial market implications," Journal of Financial Economics, 117, 369-397.

Sims, C. A. AND T. Zha (1998): "Bayesian methods for dynamic multivariate models," International Economic Review, 949-968. 
Spiegelhalter, D. J., N. G. Best, B. P. Carlin, and A. Van Der Linde (2002): "Bayesian measures of model complexity and fit," Journal of the Royal Statistical Society: Series B (Statistical Methodology), 64, 583-639.

Stock, J. H. And M. W. Watson (2002): "Has the business cycle changed and why?" NBER Macroeconomics Annual Report, 17, 159-218.

(2003): "How did leading indicator forecasts perform during the 2001 recession?" FRB Richmond Economic Quarterly, 89, 71-90.

TAYLOR, J. W. (2019): "Forecasting value at risk and expected shortfall using a semiparametric approach based on the asymmetric Laplace distribution," Journal of Business E Economic Statistics, 37, 121-133. 
MODELING AND FORECASTING
MACROECONOMIC DOWNSIDE RISK:

SUPPLEMENTARY MATERIAL 


\section{A Score-driven setting}

Assume that the variable $y_{t}$ is generated by the observation density $\mathcal{D}\left(\theta, f_{t}\right)$, with $\theta$ collecting the static parameters of the distribution. The score-driven setting postulates the dynamics of the time-varying parameters, $f_{t}$, being:

$$
f_{t+1}=\varpi+\sum_{i=0}^{p-1} \alpha_{i} s_{t-i}+\sum_{j=0}^{q-1} \beta_{j} f_{t-j}
$$

which we refer to as $G A S(p, q)$ dynamics. ${ }^{28}$ The scaled score $s_{t}$ is a non-linear function of past observations and past parameters' values. For $\ell_{t}=\log \mathcal{D}\left(\theta, f_{t}\right)$, we define:

$$
s_{t}=\mathcal{S}_{t} \nabla_{t}, \quad \nabla_{t}=\frac{\partial \ell_{t}}{\partial f_{t}}, \quad \mathcal{S}_{t}=\mathcal{I}_{t}^{-\frac{1}{2}}=-\mathbb{E}\left(\frac{\partial^{2} \ell_{t}}{\partial f_{t} \partial f_{t}^{\prime}}\right)^{-\frac{1}{2}}
$$

where $\nabla_{t}$ corresponds to the gradient vector of the log-likelihood function, $\ell_{t}$, and the scaling matrix $\mathcal{S}_{t-1}$ is proportional to the square-root generalized inverse of the Information matrix $\mathcal{I}_{t-1} \cdot{ }^{29}$ Within this framework, the parameters are updated in the direction of the steepest ascent, in order to maximize the local fit of the model.

\section{A.1 Score-based tests for time varying asymmetry}

In Section 2 we exploited properties of the score function to motivate the modeling of time-varying parameters. The Lagrange multiplier principle can be employed to formally test for the time variation of the parameter of interest (Harvey, 2013, Section 2.5). ${ }^{30}$ When the conditional distribution is available in closed form, we can use the score of the log-likelihood function with respect to the parameter under consideration to investigate its autocorrelation properties. In fact, the score incorporates information about the level of time variation of the respective parameter, and local power arguments indicate that the resulting test can be expected to be more powerful as the unconditional parameter moves away from zero. This is not the case with the standard moment-based portmanteau test,

\footnotetext{
${ }^{28}$ Creal et al. (2013) refer to the Generalized Autoregressive Score (GAS) model, while Harvey (2013) names it Dynamics Conditional Score (DCS) model. We stick to the former notation throughout this appendix.

${ }^{29}$ Refer to Creal et al. (2013) for additional details on this choice.

${ }^{30} \mathrm{~A}$ similar testing approach is put forward by Calvori et al. (2017).
} 
which simply uses the cross-product of standardized residuals (see, e.g. Bollerslev, 1990).

Given the law of motion in Equation (A1), and provided $\left\{\left|\beta_{j}\right|<1\right\}_{j=0}^{q-1}$, we can recover the (infinite) moving average representation of the filter:

$$
f_{t+1}=\varpi^{*}+\sum_{i=0}^{\infty} \psi_{i} s_{t-i}
$$

equivalent to a $G A S(\infty, 0)$, with $\varpi^{*}=\frac{\varpi}{\left(1-\beta_{1}-\beta_{2}-\ldots-\beta_{q-1}\right)}$. Tests can then be carried out using the score's autocorrelation function, $r_{s}(\tau)$.

Assume the conditional distribution of $y_{t}$ being the Skew-t of Gómez et al. (2007), $y_{t} \mid Y_{t-1} \sim \operatorname{skt}_{\nu}\left(\mu_{t}, \gamma, \delta\right)$, with log-likelihood

$$
\begin{aligned}
\ell_{t}\left(y_{t} \mid \theta, Y_{t-1}\right) & =\log \mathcal{C}(\eta)-\frac{1}{2} \log \sigma^{2}-\frac{1+\eta}{2 \eta} \log \left[1+\frac{\eta \varepsilon_{t}^{2}}{\left(1-\operatorname{sgn}\left(\varepsilon_{t}\right) \varrho\right)^{2} \sigma^{2}}\right], \\
\log \mathcal{C}(\eta) & =\log \Gamma\left(\frac{\eta+1}{2 \eta}\right)-\log \Gamma\left(\frac{1}{2 \eta}\right)-\frac{1}{2} \log \left(\frac{1}{\eta}\right)-\frac{1}{2} \log \pi
\end{aligned}
$$

where $\Gamma(\cdot)$ is the Gamma function, $\operatorname{sgn}($.$) is the sign function, and \eta=1 / \nu$ is the inverse of the degrees of freedom. To ensure positive scale and bounded shape, we model $\gamma=\log \sigma$, $\delta=\operatorname{arctanh}(\varrho)$, and the score vector with respect to $\mu, \gamma$, and $\delta$ (scaled by inverse square root of information matrix as described later in details) will be equal to:

$$
\left[\begin{array}{c}
s_{\mu, t} \\
s_{\gamma, t} \\
s_{\delta, t}
\end{array}\right]=\sqrt{\frac{(1+3 \eta)}{(1+\eta)}}\left[\begin{array}{c}
\sqrt{\left(1-\varrho^{2}\right)} w_{t} \zeta_{t} \\
\sqrt{\frac{(1+\eta)}{2}}\left(w_{t} \zeta_{t}^{2}-1\right) \\
-\sqrt{\frac{\left(1-\varrho^{2}\right)}{3}} \frac{\operatorname{sgn}\left(\varepsilon_{t}\right)}{\left(1-\operatorname{sgn}\left(\varepsilon_{t}\right) \varrho\right)} w_{t} \zeta_{t}^{2}
\end{array}\right],
$$

where

$$
w_{t}=\frac{(1+\eta)}{\left(1-\operatorname{sgn}\left(\varepsilon_{t}\right) \varrho\right)^{2}+\eta \zeta_{t}^{2}}, \quad \zeta_{t}=\frac{\varepsilon_{t}}{\sigma} .
$$

The scores in Equation (A4) can thus be used to test for the presence of time variation of the parameters. First, we fix the scale and shape parameters to their maximum likelihood estimates, $\hat{\gamma}$ and $\hat{\delta}$, respectively, and let $\mu_{t}$ being the only time-varying parameter. Then, using the estimated parameters we recover the time series of of the scores $s_{\gamma}$ and $s_{\delta}$, which we use to carry out the tests. Specifically, following Harvey and Thiele (2016), 
which apply this methodology to test against the time variation of correlations, we employ three different test specifications: the Portmanteau test, $Q$, the Ljung-Box test, $Q^{*}$, and the Nyblom (1989) test. For all these test, the optimal lag-length is selected following the methodology of Escanciano and Lobato (2009).

We apply the testing procedure to three different specifications for the dynamics of $\mu_{t}:$

S1: $\mu_{t}=0$ and $y_{t} \sim A R(2)$ with skew-t innovations $\operatorname{skt}_{\nu}(0, \sigma, \varrho)$ (see Section 2).

S2: $\mu_{t} \sim G A S(1,1)$ with a unit $\operatorname{root}(\mathrm{RW}) ;$

S3: $\mu_{t} \sim R W+G A S(1,2)$ with stationary roots;

For each case, we consider a specification with constant $\gamma=\log \sigma$, and another with time-varying $\gamma_{t}=\log \sigma_{t}$, following a non-stationary $G A S(1,1)$ process. Tests' results, using data on GDP growth from 1971 to 2018, are reported in Table 1 (Section 2) for S1, while Table A1 reports the results for S2 and S3. For all the cases and specifications we reject the null hypothesis of constant shape at the $1 \%$ confidence level, for $Q$ and $Q^{*}$. Similarly, the Nyblom specification rejects the null, but the test provide less precise evidence. While the first two tests leave the alternative hypothesis unspecified, the latter tests for parameter constancy, against a random walk law of motion. Therefore, we ascribe such low precision to the stationary nature of the scale parameter. ${ }^{31}$

\footnotetext{
${ }^{31}$ Harvey and Streibel (1998) argue that the Nyblom (1989) test can be used to test against stationary, but highly persistent, alternative hypotheses.
} 
Table A1: Score-based tests for time variation

\begin{tabular}{|c|c|c|c|c|c|c|}
\hline & \multicolumn{3}{|c|}{$\begin{array}{l}\text { time-varying } \\
\text { location }\end{array}$} & \multicolumn{3}{|c|}{$\begin{array}{l}\text { time-varying } \\
\text { location } \& \text { \& scale }\end{array}$} \\
\hline & $Q$ & $Q^{*}$ & $N$ & $Q$ & $Q^{*}$ & $N$ \\
\hline Scale ${ }^{2}$ & $82.97^{* * *}$ & $84.27^{* * *}$ & $2.09^{* * *}$ & & & \\
\hline Shape & $44.30^{* * *}$ & $45.00^{* * *}$ & $0.46^{*}$ & $11.30^{* * *}$ & $11.48^{* * *}$ & $0.58^{* *}$ \\
\hline Scale ${ }^{2}$ & $70.12^{* * *}$ & $71.22^{* * *}$ & $1.91^{* * *}$ & & & \\
\hline Shape & $46.95^{* * *}$ & $47.68^{* * *}$ & $0.41^{*}$ & $10.76^{* * *}$ & $10.93^{* * *}$ & $0.97^{* * *}$ \\
\hline
\end{tabular}

Note: $Q$ is the portmanteau test, $Q^{*}$ is the Ljung-Box extension and $N$ corresponds to the Nyblom test. The lag length for the Portmanteau and Ljung-Box tests are selected following Escanciano and Lobato (2009). The first two tests are distributed as a $\chi^{2}$ with 1 degree of freedom, the Nyblom test statistics is distributed as a Cramer von-Mises distribution with 1 degree of freedom. ${ }^{*} p<10 \%,{ }^{* *} p<5 \%,{ }^{* * *} p<$ $1 \%$.

\section{B Derivation of the score-driven Skew-t model}

In this appendix we derive provide details on the scaled scores for the Skew-t distribution of Gómez et al. (2007), the use of the link functions and the matrix representation of the model.

\section{B.1 Scaled scores}

Differentiating the log-likelihood function in Equation (A3) with respect to location, scale and asymmetry we obtain the gradient vector $\nabla_{t}=\left[\frac{\partial \ell_{t}}{\partial \mu_{t}}, \frac{\partial \ell_{t}}{\partial \sigma_{t}^{2}}, \frac{\partial \ell_{t}}{\partial \varrho t}\right]^{\prime}$, with elements:

$$
\begin{aligned}
\frac{\partial \ell_{t}}{\partial \mu_{t}} & =\frac{1}{\sigma_{t}^{2}}\left[\frac{(1+\eta) \sigma_{t}^{2} \varepsilon_{t}}{\left(1-\operatorname{sgn}\left(\varepsilon_{t}\right) \varrho_{t}\right)^{2} \sigma_{t}^{2}+\eta \varepsilon_{t}^{2}}\right]=\frac{1}{\sigma_{t}^{2}} w_{t} \varepsilon_{t}, \\
\frac{\partial \ell_{t}}{\partial \sigma_{t}^{2}} & =\frac{1}{2 \sigma_{t}^{2}}\left[\frac{(1+\eta) \varepsilon_{t}^{2}}{\left.\left(1-\operatorname{sgn}\left(\varepsilon_{t}\right) \varrho_{t}\right)\right)^{2} \sigma_{t}^{2}+\eta \varepsilon_{t}^{2}}-1\right]=\frac{1}{2 \sigma_{t}^{4}}\left(w_{t} \varepsilon_{t}^{2}-\sigma_{t}^{2}\right), \\
\frac{\partial \ell_{t}}{\partial \varrho_{t}} & =-\frac{\operatorname{sgn}\left(\varepsilon_{t}\right)}{\left(1-\operatorname{sgn}\left(\varepsilon_{t}\right) \varrho_{t}\right)} \frac{(1+\eta)}{\left.\left(1-\operatorname{sgn}\left(\varepsilon_{t}\right) \varrho_{t}\right)\right)^{2} \sigma_{t}^{2}+\eta \varepsilon_{t}^{2}} \varepsilon_{t}^{2}=-\frac{1}{\sigma_{t}^{2}} \frac{\operatorname{sgn}\left(\varepsilon_{t}\right)}{\left(1-\operatorname{sgn}\left(\varepsilon_{t}\right) \varrho_{t}\right)} w_{t} \varepsilon_{t}^{2},
\end{aligned}
$$


where

$$
w_{t}=\frac{(1+\eta)}{\left(1-\operatorname{sgn}\left(\varepsilon_{t}\right) \varrho_{t}\right)^{2}+\eta \zeta_{t}^{2}}
$$

and $\zeta_{t}=\frac{\varepsilon_{t}}{\sigma_{t}}$ is the standardized innovations.

The Fisher information matrix is computed as the expected values of outer product of the gradient vector, for a fixed number of degrees of freedom:

$$
\mathcal{I}_{t \mid t-1}=\mathbb{E}_{t-1}\left[\nabla_{t} \nabla_{t}^{\prime}\right]=\left[\begin{array}{ccc}
\frac{(1+\eta)}{(1+3 \eta)\left(1-\varrho_{t}^{2}\right) \sigma_{t}^{2}} & 0 & -\frac{4 c(1+\eta)}{\sigma_{t}\left(1-\varrho_{t}^{2}\right)(1+3 \eta)} \\
0 & \frac{1}{2(1+3 \eta) \sigma_{t}^{4}} & 0 \\
-\frac{4 c(1+\eta)}{\sigma_{t}\left(1-\varrho_{t}^{2}\right)(1+3 \eta)} & 0 & \frac{3(1+\eta)}{\left(1-\varrho_{t}^{2}\right)(1+3 \eta)}
\end{array}\right]
$$

Given we model $\gamma_{t}=\ln \sigma_{t}$ and $\delta_{t}=\operatorname{arctanh}\left(\varrho_{t}\right)$, for the chain rule we have:

$$
\frac{\partial \ell_{t}}{\partial \gamma_{t}}=\frac{\partial \ell_{t}}{\partial \sigma_{t}^{2}} \frac{\partial \sigma_{t}^{2}}{\partial \gamma_{t}}, \quad \frac{\partial \ell_{t}}{\partial \delta_{t}}=\frac{\partial \ell_{t}}{\partial \varrho_{t}} \frac{\partial \varrho_{t}}{\partial \delta_{t}}
$$

where $\frac{\partial \sigma_{t}^{2}}{\partial \gamma_{t}}=2 \sigma_{t}^{2}$ and $\frac{\partial \varrho_{t}}{\partial \delta_{t}}=\left(1-\varrho_{t}^{2}\right)$. We can thus define the vector of interest as $f_{t}=\left(\mu_{t}, \gamma_{t}, \delta_{t}\right)^{\prime}$ with the associated Jacobian matrix

$$
J_{t}=\frac{\partial\left(\mu_{t}, \sigma_{t}^{2}, \varrho_{t}\right)}{\partial f_{t}^{\prime}}=\left[\begin{array}{ccc}
1 & 0 & 0 \\
0 & 2 \sigma_{t}^{2} & 0 \\
0 & 0 & 1-\varrho_{t}^{2}
\end{array}\right]
$$

As such the scaled score reads:

$$
\mathbf{s}_{t}=\left(J_{t}^{\prime} \operatorname{diag}\left(\mathcal{I}_{t}\right) J_{t}\right)^{-\frac{1}{2}} J_{t}^{\prime} \nabla_{t}=\left[\begin{array}{c}
s_{\mu t} \\
s_{\sigma t} \\
s_{\varrho t}
\end{array}\right]=\left[\begin{array}{c}
\sqrt{\frac{(1+3 \eta)\left(1-\varrho_{t}^{2}\right)}{(1+\eta)}} w_{t} \varepsilon_{t} \\
\sqrt{\frac{(1+3 \eta)}{2}}\left(w_{t} \zeta_{t}^{2}-1\right) \\
-\operatorname{sgn}\left(\varepsilon_{t}\right) \sqrt{\frac{\left(1+\operatorname{sgn}\left(\varepsilon_{t}\right) \varrho_{t}\right)(1+3 \eta)}{3\left(1-\operatorname{sgn}\left(\varepsilon_{t}\right) \varrho_{t}\right)(1+\eta)}} w_{t} \zeta_{t}^{2}
\end{array}\right] .
$$

To prevent numerical instability, it is often the case to replace the scaling matrix $\dot{\mathcal{S}}_{t}=$ $\left(J_{t}^{\prime} \operatorname{diag}\left(\mathcal{I}_{t}\right) J_{t}\right)^{-\frac{1}{2}}$ with its smoothed estimator, $\ddot{\mathcal{S}}_{t}=(1-\lambda) \ddot{\mathcal{S}}_{t-1}+\lambda \dot{\mathcal{S}}_{t}, 0<\lambda<1$. 


\section{B.2 Transformed parameters' scores}

Here we provide a proof of the equivalence between the the score vector arising from the restriction imposed on the scale and shape parameters and that arising by imposing constraints on the two-component specification. We will drop the time subscript for the sake of clarity.

Proof. Let consider $\gamma=\log \sigma$ being the $\log$-scale, it follows that $\sigma=\exp \gamma$, and the gradient is

$$
\frac{\partial \ell}{\partial \gamma}=\frac{\partial \ell}{\partial \sigma^{2}} \frac{\partial \sigma^{2}}{\partial \gamma}=\frac{\partial \ell}{\partial \sigma^{2}} 2 \sigma^{2}
$$

Let now consider the multiplicative two-component counterpart $\sigma=\bar{\sigma} \tilde{\sigma}$, such that $\gamma=$ $\log \sigma=\log \bar{\sigma}+\log \tilde{\sigma}=\bar{\gamma}+\tilde{\gamma}$. The gradient with respect to the first component reads

$$
\frac{\partial \ell}{\partial \bar{\gamma}}=\frac{\partial \ell}{\partial \sigma^{2}} \frac{\partial \sigma^{2}}{\partial \gamma} \frac{\partial \gamma}{\partial \bar{\gamma}}=\frac{\partial \ell}{\partial \sigma^{2}} 2 \sigma^{2}
$$

The same applies for the second component.

Proof. For the shape parameter $\varrho=\tanh \delta$, we model $\delta=\operatorname{arctanh} \varrho$ and the gradient is

$$
\frac{\partial \ell}{\partial \delta}=\frac{\partial \ell}{\partial \varrho} \frac{\partial \varrho}{\partial \delta}=\frac{\partial \ell}{\partial \varrho}\left(1-\varrho^{2}\right)
$$

Consider the two-component counterpart $\delta=(\bar{\delta}+\tilde{\delta})$, so that $\varrho=\tanh (\bar{\delta}+\tilde{\delta})$, it is easy to see that that

$$
\frac{\partial \ell}{\partial \bar{\delta}}=\frac{\partial \ell}{\partial \varrho} \frac{\partial \varrho}{\partial \delta} \frac{\partial \delta}{\partial \bar{\delta}}=\frac{\partial \ell}{\partial \varrho}\left(1-\varrho^{2}\right)
$$

The same applies for the second component.

\section{B.3 Matrix representation}

Given the vector of time-varying parameters, $f_{t}$, we can express the score-driven law of motion of Equation (3) in matrix form. 


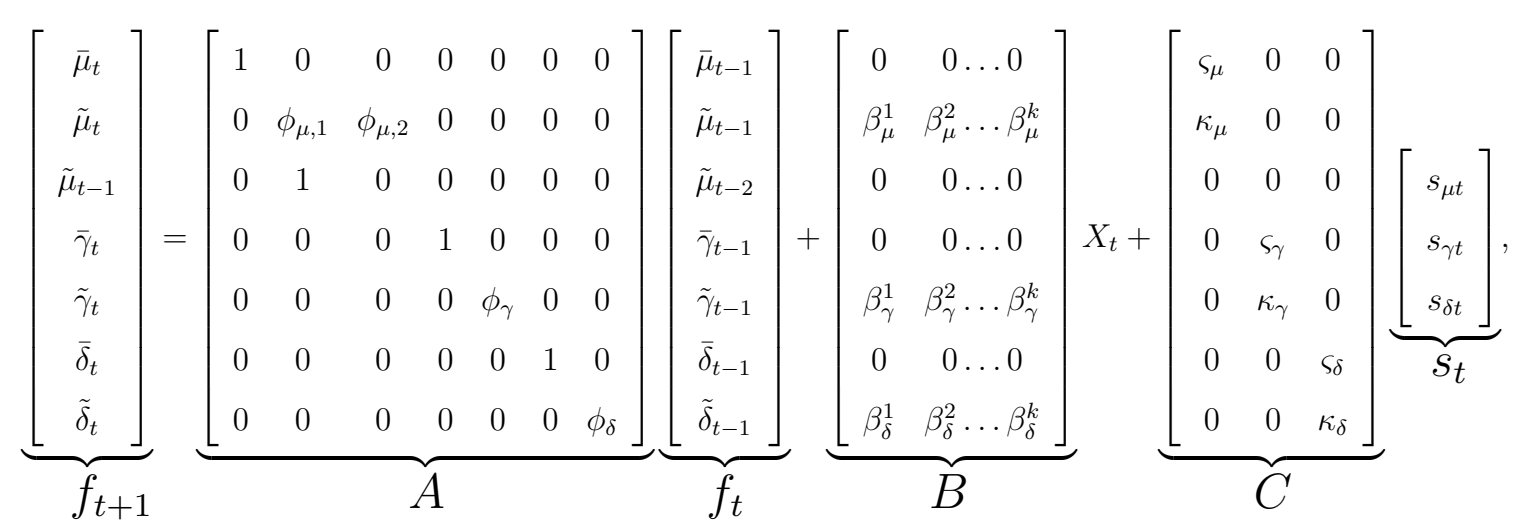

with $X_{t}$ being a k-dimensional vector of predictors, at time $t$. 


\section{On the importance of dynamic conditional moments}

In this Section, we consider a restricted specification of the model in line with the work of Plagborg-Møller et al. (2020). As noted in Section 3, when the autoregressive features of the model is dropped out, and the information content of past prediction errors (condensed into the score) is ignored, the model collapses to a parametric model for the distribution of GDP growth akin to the one in Plagborg-Møller et al. (2020). ${ }^{32}$ Specifically, setting $\varsigma_{\mu}=\phi_{\mu, 1}=\phi_{\mu, 2}=\kappa_{\mu}=\varsigma_{\gamma}=\phi_{\gamma}=\kappa_{\gamma}=\varsigma_{\delta}=\phi_{\delta}=\kappa_{\delta}=0$, we obtain

$$
\begin{aligned}
\mu_{t+1} & =\bar{\mu}+\beta_{\mu}^{\prime} X_{t}, \\
\gamma_{t+1} & =\bar{\gamma}+\beta_{\gamma}^{\prime} X_{t}, \\
\delta_{t+1} & =\bar{\delta}+\beta_{\delta}^{\prime} X_{t}
\end{aligned}
$$

so that the parameters' laws of motion become linear functions of predictors only.

We estimate the model above using as predictors the 4 disaggregated components of the NFCI, as well as the factors used in Plagborg-Møller et al. (2020) (including in both cases lagged values of GDP growth). Table C2 reports the Deviance Information Criterion associated to these two specifications. Our baseline model strongly outperforms the two restricted specifications, both over the whole sample and during recessions. Figure C1 reports the estimated volatility and skewness from the baseline model (in blue) and the restricted specification (in red). For comparability purposes, both models are estimated using the disaggregated components of the NFCI as predictors. ${ }^{33}$ The results of the restricted specification are broadly in line with those reported by Plagborg-Møller et al. (2020). The estimated skewness from their model is cyclical but displays large uncertainty, so that the $90 \%$ confidence bands only rarely excludes the zero. Moreover, the simplified specification of the time-varying model does not display the well-known reduction of the volatility occurred during the Great Moderation period.

Overall, comparing the restricted model to the baseline specification highlights the benefits associated with a richer framework, including the score of the predictive likelihood, long-run components, and persistent cyclical variations. In terms of volatility

\footnotetext{
${ }^{32}$ Note that Plagborg-Møller et al. (2020) consider the Skew-t of Azzalini and Capitanio (2003).

${ }^{33}$ The mean GDP growth extracted from the two models displays less noticeable differences.
} 
Table C2: Deviance Information Criterion

\begin{tabular}{lcc}
\hline \hline \multicolumn{1}{c}{ Model } & DIC & DIC Rec \\
\hline Skt 4DFI & 4.367 & 2.347 \\
Plagborg-Møller et al. (2020) with 4DFI & 4.589 & 2.387 \\
Plagborg-Møller et al. (2020) Financial Factor & 4.503 & 2.376 \\
\hline \hline
\end{tabular}

Note: The table reports the Deviance Information Criterion of Spiegelhalter et al. (2002) for the Skt $-4 D F I$ specification, and the nested version of Plagborg-Møller et al. (2020), with the four disaggregated financial indices and with the global and financial factors. In the column $D I C^{R e c}$ we evaluate the DIC measure during recession periods.

estimates, the presence of long-run components, as well as the addition of the score (which for the volatility is a function of the squared prediction errors) as signal for the updating, turn out to be of key importance to track the well-established stylized fact of a substantial decline in volatility from the mid-1980s (McConnell and Perez-Quiros, 2000; Stock and Watson, 2002). Persistent cyclical components, on the other hand, allow the model to recover significant variations of the skewness coefficients. This is not surprising, as the unrestricted model implies that the time variation in the parameters reflects current and past discounted variation of the predictors (as well as the information in the scaled score). This implies that high frequency noisy variations of the predictors are averaged out when incorporated into the time-varying dynamics. Moreover, while the skewness from both models set on similar levels at the beginning of the sample and during the 1990s, the asymmetry implied by the restricted specification becomes lower over the mid 1980s, while attaining higher values after the Global Financial Crisis. This pattern supports the addition of secular components, able to track the declining trend of business cycle skewness, as documented by Jensen et al. (2020).

Furthermore, we investigate to what extent our results are affected by the different choice of financial predictors. Re-estimating our baseline model using the two factors employed by Plagborg-Møller et al. (2020), we recover very similar time-varying second and third moments to the one reported for our baseline specification. Volatility displays a clear countercyclical dynamics, as well as a sharp fall in the mid-1980s. Skewness exhibits pronounced cyclical variation, with recessions characterized by negatively skewed conditional distributions, and expansions associated with positively skewed distributions. 

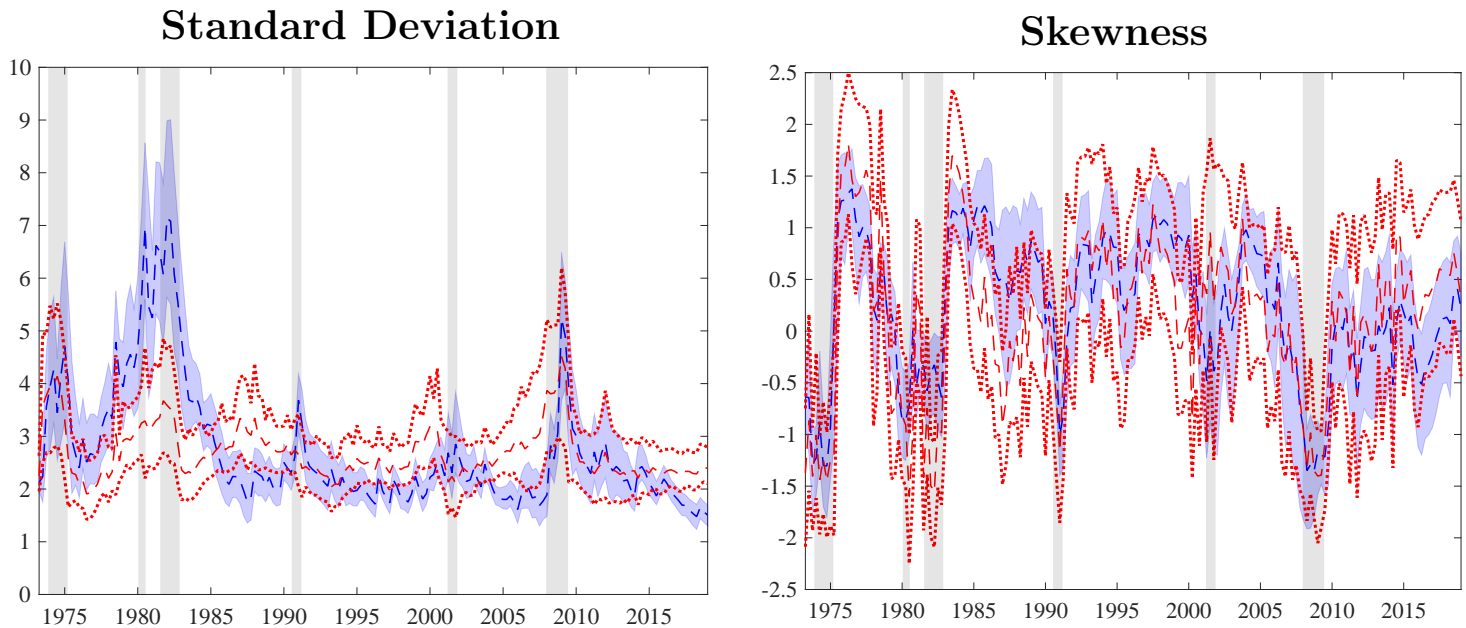

Figure C1: Time-varying moments: Skt 4DFI vs. Plagborg-Møller et al. (2020)

Note: The plots illustrate the estimated time-varying volatility (left panel) and skewness (right panel) with $95 \%$ confidence bands. Results for the $S k t-4 D F I$ are reported in blue, while red lines report results for the nested version of Plagborg-Møller et al. (2020)'s model. Shaded bands represent NBER recessions.

Again, one should not be surprised by these broad similarities. The inclusion of the scaled score as a driver of the time-varying parameters introduces a self-correction mechanism to the model, which allows the parameters to closely track the most pronounced features of the data, regardless of the predictors included in the model. In terms of DIC, the baseline specification with the disaggregated components of the NFCI continues to be preferred with respect to the alternative factors included by Plagborg-Møller et al. (2020).

\section{Bayesian estimation}

In this section we outline the Bayesian approach for the estimation of the models. We estimate the vector of static parameters $\theta$, and the time-varying parameters $f_{t}$, through the following steps:

(i ) Estimate $\theta^{*}$ via ML and initialize the sampling algorithm with $\theta^{*}$

(ii ) Sample $\theta$ and $f_{t}$ with the Adaptive Random-Walk Metropolis-Hastings (AR$\mathrm{WMH})$

(iii) Compute the statistics of interest as the percentiles of the empirical distribution function.

In the following subsections, we detail the prior specifications and the ARWMH algorithm. 


\section{D.1 Prior specification}

Starting from Equations 9 - 16, let $\phi$ be a generic first-lag partial autocorrelation, while $\varsigma$ and $\kappa$ being generic score loadings for the long-run and short-run equations, respectively. Let $\beta_{i} \in B$, be a generic predictor loading for the parameter $i, i=\mu, \sigma, \varrho$, and let $\eta$ be the inverse of the Skew-t degrees of freedom. Prior specifications for these parameters read:

$$
\begin{aligned}
& \phi \sim N I D\left(\mu_{\phi}, \sigma_{\phi}\right) \cdot I_{(\phi \in \Phi)} ; \\
& \beta_{i} \sim N I D\left(\mu_{\beta}, \sigma_{\beta}^{i}\right), i=\mu, \sigma, \varrho ; \\
& \varsigma, \kappa \sim \mathcal{G}^{-1}\left(a_{j}, b_{j}\right), j=\varsigma, \kappa ; \\
& \eta \sim \mathcal{G}^{-1}\left(a_{\eta}, b_{\eta}\right) \cdot I_{(\eta \in H)} .
\end{aligned}
$$

Prior specification D1 sets the prior distribution for the first autroregressive parameters: we target high persistence, with $\mu_{\phi} \lesssim 1$, with a standard tightness of $\sigma_{\mu}=0.2$, in line with Bayesian Vector Autoregressive models (see, e.g., Doan et al., 1984; Sims and Zha, 1998). We restrict the prior distribution to only span the stationary region, $\Phi$, by truncating the support, which gives rise to an improper prior distribution as in Cogley and Sargent (2005). Predictor loadings are drawn from a Normal distribution with $\mu_{\beta}=0$, and standard deviations $\sigma_{\beta}$ are set to small values of 0.05, 0.2 and 0.1 for the location, scale and shape parameters, respectively. These priors aim at preventing model overfitting, applying an $L_{2}$ regularization, akin to the shrinkage induced by a Ridge-type regression. We set inverse gamma priors for the score loadings, such that they reflect the a priori expectation of small, but positive coefficients, in line with the properties of the score-driven filters (for further discussion, see Blasques et al., 2014). We set $a_{\varsigma}=a_{\kappa}=4$, and $b_{\varsigma}=3$ and $b_{\kappa}=10$, to reflect the properties of the long- and the short-run components. Eventually, we use an inverse gamma prior for $\eta$, the inverse of the degrees of freedom parameter, with $a_{\eta}=2$ and $b_{\eta}=10$. In line with Juárez and Steel (2010), these values allow the distribution to explore a wide range of feasible values, with a mean of 20 and a median of 10. In order to ensure the existence of, at least, the first three moments, we restrict the support to the $H=[0,0.33]$ set. 
We also target the stationarity of the cyclical component of the location through a prior on the sum of the autoregressive coefficients (Sims and Zha, 1998). Let $\phi^{S}$ be the sum of two generic autoregressive coefficients, $\phi^{S}=\phi^{1}+\phi^{2}$, we assume

$$
\phi^{S} \sim \mathcal{N}\left(\mu_{\phi^{S}}, \sigma_{\phi^{S}}\right) \cdot I_{\left(\phi^{S} \in \Phi\right)},
$$

with $\mu_{\phi^{2}} \lesssim 1$ and and $\sigma_{\phi}^{s}=0.2$.

\section{D.2 Horseshoe priors and SAVS}

Consider the regression model:

$$
y_{t}=b^{\prime} X_{t}+e_{t}, \quad e_{t} \sim \operatorname{iid}\left(0, \sigma_{e}^{2} I_{p}\right)
$$

the Horseshoe (HS) priors of (Carvalho et al., 2010) posit Ridge-type priors for the coefficients: $b^{j} \sim \mathcal{N}\left(0, \lambda^{j} \tau\right)$, where the hyperparameters $\lambda^{j}$ and $\tau$ control the local (coefficient specific) and the global shrinkage, respectively. We follow the original paper in setting the hyperpriors as: ${ }^{34}$

$$
\lambda^{j} \sim H C^{+}(0,1), \quad \tau \sim H C^{+}(0,1)
$$

where $H C^{+}(0,1)$ denotes the standard Half-Cauchy distributions with density function

$$
p(z)=\frac{2}{\pi\left(1+z^{2}\right)}, \quad z \in \mathbb{R}^{+} .
$$

Unlike other common shrinkage priors (e.g. Ridge, Lasso), the HS priors is free of exogenous inputs, implying a fully adaptive shrinkage procedure.

Known pitfalls of shrinkage operators account for parameters not being exactly set to zero (e.g. Ridge), thus increasing parameter uncertainty, or weak selection performances when predictors are correlated (e.g. Lasso). A common remedy to the first pathology is

\footnotetext{
${ }^{34}$ Makalic and Schmidt (2015) exploit the link between the scale mixture of Inverse Gamma distributions to approximate the Half-Cauchy distributions to propose a tractable framework for posterior simulation via Gibbs sampling. However, this hierarchy features twice as may parameters (auxiliary variables) compared to the original specification.
} 
the sparsification of the near-zero elements. Let $p$ be the number of possible predictors, the sparsification problem can be cast as:

$$
b^{*}=\underset{b}{\operatorname{argmin}}\left[\frac{1}{2}\|X \hat{b}-X b\|_{2}^{2}+\sum_{j=1}^{p} m_{j}\left|b_{j}\right|\right],
$$

where the sparse coefficients $b^{*}$ are obtained minimizing the Euclidean distance between $X b$ and the model fit obtained from the shrinkage operator. Additional penalty for the non-zero parameters is controlled by $m_{j}$, which represents a variable specific tuning parameter, generally chosen on the basis of computationally expensive methods (e.g. cross-validation). In their recent contribution, Ray and Bhattacharya (2018) introduce a purely data-driven, and less burdensome solution to the choice of the parameter $m_{j}$, proven to be robust to correlated designs. They suggest to specify the tuning parameter as $m_{j}=\left|\hat{b}_{j}\right|^{-2}$ such that the $j^{\text {th }}$ variable receives a penalization "ranked in inverse-squared order of the magnitude of the corresponding coefficient" (Ray and Bhattacharya, 2018), an approach similar to the Adaptive Lasso of Zou (2006). The Signal Adaptive Variable Selector (SAVS) algorithm can then be expressed as:

$$
b_{j}^{*}=\operatorname{sgn}\left(\hat{b}_{j}\right)\left\|X_{j}\right\|^{-2} \max \left\{\left|\hat{b}_{j}\right| \cdot\left\|X_{j}\right\|^{2}-m_{j}, 0\right\},
$$

where $\|\cdot\|$ represents the Euclidean norm of the vector $X_{j}$.

\section{D.3 Adaptive Metropolis-Hastings}

Posterior estimates of the parameters are obtained via simulation by means of the Adaptive Metropolis-Hastings algorithm proposed by Haario et al. (1999). Given that estimated parameters lie in bounded regions of the parameter space, we augment the algorithm with a rejection step to prevent numerical instability due to invalid parameter draws. The algorithm works as follows: given the $(d \times 1)$ vector of static parameters $\theta=\left(\varsigma^{\prime}, \kappa^{\prime}, \phi^{\prime}, \eta\right)^{\prime}$, we define $\theta^{j}$ as the draw of the parameters at the $\mathrm{j}^{\text {th }}$ iteration of the sampler, generated from the random walk kernel:

$$
\theta^{j}=\theta^{j-1}+\sigma_{j, s} \epsilon \quad \epsilon \sim \mathcal{N}\left(\mathbf{0}, \Sigma_{H}^{j}\right)
$$


where $\sigma_{j, s}$ is a scale parameter that contributes to the stability of the adaptive algorithm. $\Sigma_{H}^{j}$ is the covariance matrix of the last $\mathrm{H}$ draws, that is, the covariance matrix updated to reflect the variability of the last $\mathrm{H}$ iterations. Given these two elements, we postulate the following adaptive scheme: we compute the local acceptance rate $\tilde{\alpha}^{s}$ each $s$ iterations; if the acceptance rate is significantly greater (smaller) than the $25-35 \%$ target rate, we adjust the scale parameter according to a rescaling function $r\left(\tilde{\alpha}^{s}\right)$

$$
r\left(\tilde{\alpha}^{s}\right)= \begin{cases}\tanh \left(4 \tilde{\alpha}^{s}+0.24\right), & \tilde{\alpha}^{s}<0.25 \\ 1, & 0.25 \leq \tilde{\alpha}^{s} \leq 0.35 \\ 0.88+\tilde{\alpha}^{s 2}, & \tilde{\alpha}^{s}>0.35\end{cases}
$$

such that $\sigma_{j+1, s}=r\left(\tilde{\alpha}^{s}\right) \sigma_{j, s}$. Figure D1 plots the shape of the rescaling function against the admissible range of values for $\tilde{\alpha}^{s}$. Due to the asymmetry of the intervals before and

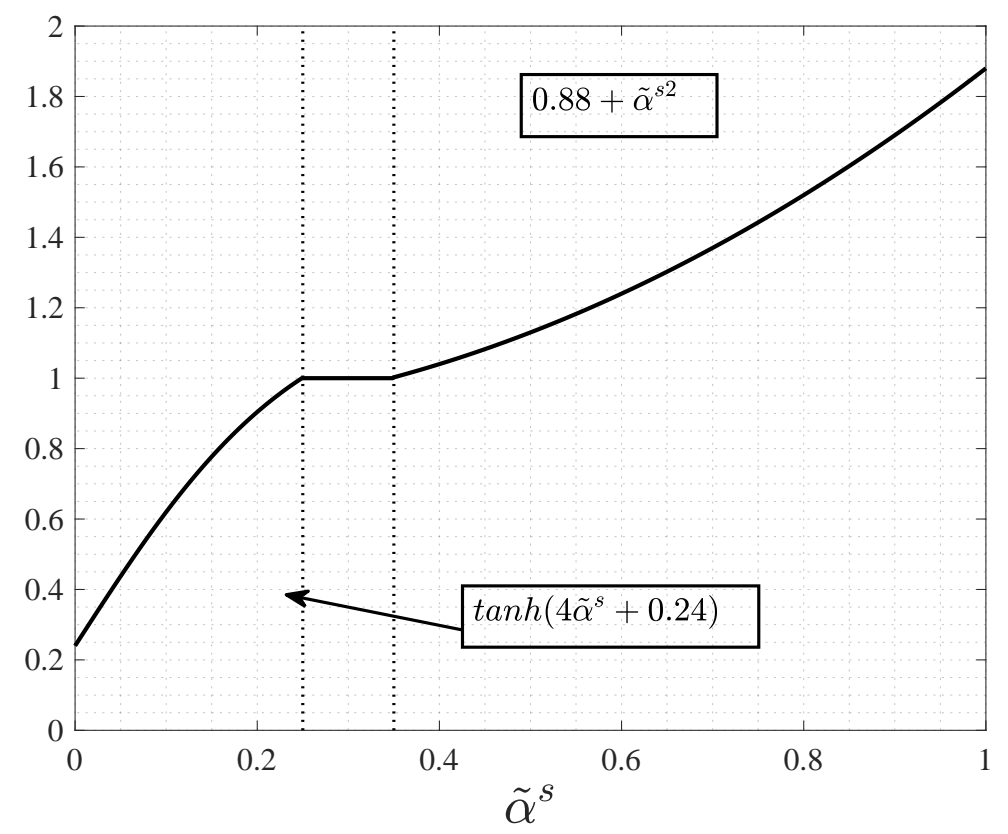

Figure D1: $r\left(\tilde{\alpha}^{s}\right)$ rescaling function

Note: The figure plots the rescaling function we apply to the variance of the candidate distribution to target an acceptance rate between $25 \%$ and $35 \%$.

after the 25-35\% acceptance region, the two branches of the reshaping function features different slopes and curvatures.

In addition, every $U \leq H$ iterations, we use the last $\mathrm{H}$ draws to recalibrate the 
covariance matrix of the proposal distribution: $\Sigma_{H}^{j}=\frac{\tilde{K}}{\sqrt{H-1}}$, where $\tilde{K}$ is the $(H \times d)$ centered matrix of the last $H$ draws, obtained as $K-\mathbb{E}[K]$; in this process we also reinitialize the scale parameter at the value of $\frac{2.38}{\sqrt{d}}$, as suggested by Gelman et al. (1996). According to the Metropolis-Hasting procedure, we accept $\theta^{j}$ with probability $p=\min \left\{1, \exp \left(f\left(\theta^{j}\right)-f\left(\theta^{j-1}\right)\right)\right\}$ where $f(\theta)=\log$-likelihood $\times$ priors. Discarded draws are replaced by the latest accepted draw. In order to prevent failures of the algorithm, we discard draws that do not lie in the bounded region of the parameter space, replacing them as previously specified. We set the number of iterations to 20000, of which we keep the last $40 \%$. We reduce dependence between consecutive draws by "thinning" each 2 realizations. Posterior distributions are eventually obtained from a sample of 4000 iterations. We adjust the scale parameter each hundred iterations $(s=100)$, while the adaptive step takes place every $U=1500$ iterations, considering $H=2500$ past iterations. ${ }^{35}$ Markov Chain properties have been checked by visual inspection, as suggested by Cowles and Carlin (1996). The algorithm results to be rather efficient, and a complete chain from the baseline model in Section 4 can be obtained in less than 3 minutes, whereas for the large data model, a complete chain can be obtained in about 7 minutes.

${ }^{35}$ The adaptive process starts when $j \geq H$, while the scale updating takes place from the $100^{\text {th }}$ iteration 


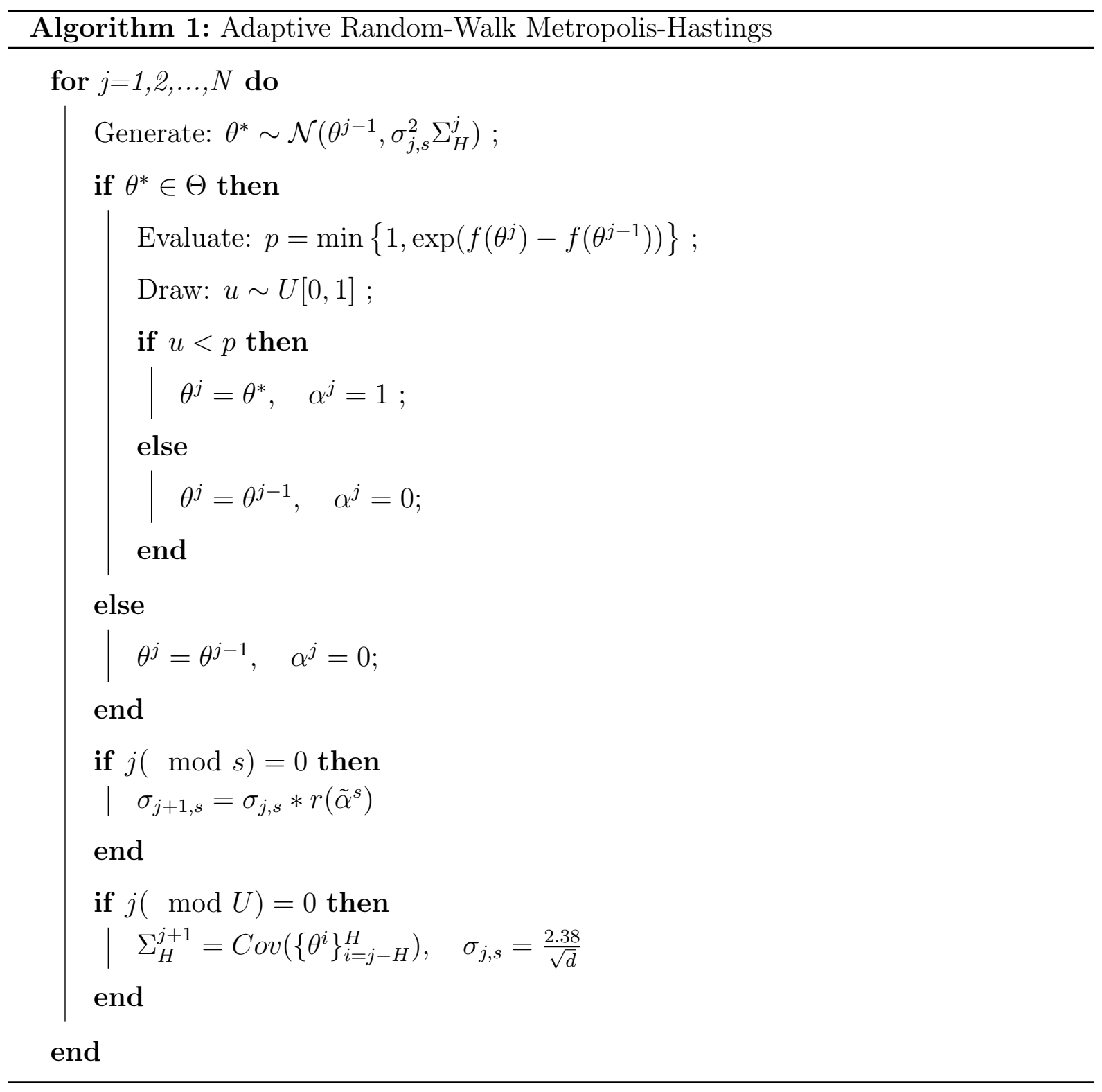

Note: the notation " $a(\bmod b)$ " represents the modulo operation, while " $-s$ " indicates the previous $s$ draws. 


\section{E Monte Carlo Exercise}

In this Section we outline a Monte Carlo exercise with the aim of illustrating the small-sample properties of the Skew-t model described in Section 3. We are interested in the reliability of the estimates of the asymmetry parameter and, in particular, whether the model is able to correctly disentangle the movements in the asymmetry parameter from the movements in the location and scale parameters.

We simulate $\mathrm{T}=250$ observations for the parameters of location, $\mu_{t}$, scale, $\sigma_{t}$, and asymmetry, $\varrho_{t}$, for every period $t$ from the $S k t_{\nu}\left(\mu_{t}, \sigma_{t}, \varrho_{t}\right)$ to obtain the series $\left\{Y_{t}\right\}_{t=1}^{T}$, then use to estimate the model discussed in Section 3 (excluding explanatory variables). Therefore, regardless of the DGP considered we always estimate a two component specification for all the three time-varying parameters. This approach mimics the true estimation process carried out on real data, to approximate the conditional distribution of the underlying GDP growth. We first consider ad-hoc specifications for the location and scale parameters $(\mathrm{AR}(2)$ and $\mathrm{AR}(1)$, respectively). Then, we turn to DGPs that replicate closely the dynamic properties of the time-varying parameters we estimate from the the data (and in particular replicate the correlation between location and scale parameter that we observe in the data). For the shape parameter, we consider a number of different DGPs, including no asymmetry, constant asymmetry, a single break in the asymmetry, and cyclical asymmetry.

In the first DGP, data are simulated from a specification featuring symmetric distributions, with independent, time-varying location and volatility, therefore aiming at checking that the model does not pick up any asymmetry when this is not a feature of the data. The second DGP considers the case in which the asymmetry parameter experiences a jump, from 0 to 0.5 after 100 observations, hence implying negatively skewed distributions in the second part of the sample. This case sheds light on the adaptiveness of the model, and provides a clear framework to illustrate the distinctive role played by the secular and transitory components. The third and fourth DGPs consider a specification for the location and scale parameter that replicate the basic features of the estimated location and scale parameters, e.g. a mildly negative correlation, whereas the shape parameter 
is constant, either at zero or at a positive value. ${ }^{36}$ In the last DGP, the asymmetry parameter varies over time, with cyclical fluctuations. To ensure that we replicate the cyclical features of the parameters, we simulate the three parameters from a $\operatorname{VAR}(1)$, with parameters estimated on the parameters obtained from the Skt-4DFI specification. For each DGP we perform $\mathrm{N}=500$ replications and we estimate the parameters of the two-component model using the estimation approach introduced in the main text, and detailed in Appendix D.

We simulate $\mu_{t}, \gamma_{t}=\log \left(\sigma_{t}\right)$, and $\delta_{t}=\operatorname{arctanh}\left(\varrho_{t}\right)$ from the following processes:

\section{DGP1: (No asymmetry)}

$$
\begin{aligned}
& \mu_{t}=0.125+1.2 \mu_{t-1}-0.25 \mu_{t-2}+\epsilon_{t}, \quad \epsilon_{t} \sim N(0,0.05) \\
& \gamma_{t}=0.95 \gamma_{t-1}+\epsilon_{t}, \quad \epsilon_{t} \sim N(0,0.025) ; \\
& \delta_{t}=0 .
\end{aligned}
$$

\section{DGP2: (Single break)}

$$
\begin{aligned}
& \mu_{t}=0.125+1.2 \mu_{t-1}-0.25 \mu_{t-2}+\epsilon_{t}, \quad \epsilon_{t} \sim N(0,0.05) ; \\
& \gamma_{t}=0.95 \gamma_{t-1}+\epsilon_{t}, \quad \epsilon_{t} \sim N(0,0.025) ; \\
& \delta_{t}=\left\{\begin{array}{l}
0, \quad t \leq 100 \\
0.5, \quad t>100
\end{array}\right.
\end{aligned}
$$

DGP3: (Correlated location, scale and no asymmetry)

$$
\left[\begin{array}{l}
\mu_{t} \\
\gamma_{t}
\end{array}\right]=\left[\begin{array}{c}
0.29 \\
-0.12
\end{array}\right]+\left[\begin{array}{ll}
0.89 & 0.01 \\
0.06 & 0.94
\end{array}\right]\left[\begin{array}{l}
\mu_{t-1} \\
\gamma_{t-1}
\end{array}\right]+\epsilon_{t}, \quad \epsilon_{t} \sim N(\mathbf{0}, \Omega)
$$

where

$$
\Omega=\left[\begin{array}{cc}
0.008 & -0.001 \\
-0.001 & 0.015
\end{array}\right]
$$

and $\delta_{t}=0, \forall t$.

\footnotetext{
${ }^{36}$ Specifically, we fit a $\operatorname{VAR}(1)$ to the location and log-scale parameters estimated from the data, and use these estimates for the DGPs.
} 
DGP4: (Correlated location, scale and constant asymmetry)

$$
\left[\begin{array}{l}
\mu_{t} \\
\gamma_{t}
\end{array}\right]=\left[\begin{array}{c}
0.29 \\
-0.12
\end{array}\right]+\left[\begin{array}{ll}
0.89 & 0.01 \\
0.06 & 0.94
\end{array}\right]\left[\begin{array}{c}
\mu_{t-1} \\
\gamma_{t-1}
\end{array}\right]+\epsilon_{t}, \quad \epsilon_{t} \sim N(\mathbf{0}, \Omega)
$$

where

$$
\Omega=\left[\begin{array}{cc}
0.008 & -0.001 \\
-0.001 & 0.015
\end{array}\right]
$$

and $\delta_{t}=0.5, \forall t$.

\section{DGP5: (Cyclical asymmetry)}

$$
\left[\begin{array}{l}
\mu_{t} \\
\gamma_{t} \\
\delta_{t}
\end{array}\right]=\left[\begin{array}{c}
0.40 \\
-0.38 \\
-0.33
\end{array}\right]+\left[\begin{array}{ccc}
0.85 & 0.03 & -0.06 \\
0.17 & 0.88 & 0.13 \\
0.14 & -0.09 & 0.95
\end{array}\right]\left[\begin{array}{c}
\mu_{t-1} \\
\gamma_{t-1} \\
\delta_{t-1}
\end{array}\right]+\epsilon_{t}, \quad \epsilon_{t} \sim N(\mathbf{0}, \Omega)
$$

where

$$
\Omega=\left[\begin{array}{ccc}
0.008 & -0.001 & -0.007 \\
-0.001 & 0.015 & 0.008 \\
-0.007 & 0.008 & 0.025
\end{array}\right]
$$

For all the DGPs, the model correctly picks up the time variation in the location and scale with great precision, and the degree of freedom are estimated without bias. These results are not reported in the interest of brevity, but are available upon request. Hence, in what follow we comment on the ability of the model to track the underlying asymmetry of the distribution. For the first four DGPs, we report the true asymmetry parameter and the 99, 95, 90 and 75 confidence bands for the estimated counterpart. For the fifth DGP we consider the median difference between the estimated and the simulated parameters. Figure E2 and E5 shows that when the distribution is symmetric, the estimated median parameter, and the associated confidence bands, remain close to zero with small variability. Therefore, the model clearly captures the symmetry of the underlying data generating process, and correctly disentangles the time variations of the volatility for changes in the asymmetry of the distribution in simple settings (DGP1), as well as when location and scale are correlated (DGP3). The filter is also able to detect the case with constant neg- 
ative skewness (DGP4), in spite of the dynamic correlation between location and scale. The model does not confound variations of the first two moments of the data with variation of the asymmetry (Figure E6). Interestingly, for all the cases where the asymmetry parameter is fixed at a positive value, the cyclical components are always estimated to be approximately zero, suggesting that no variation at all is captured. Whereas, the secular components show minimal variation, always around the true value. ${ }^{37}$ For this case we also investigate what happens when the initialization of the filter is away from the true parameter. The filter neatly discovers the true level of asymmetry relatively quickly (i.e. after roughly 20 observations), and the parameter sets around the true value.

In Figure E3 we report the results for the case of a single break in the asymmetry parameter. Until the jump takes place, the estimated asymmetry remains centered around zero, while it timely reacts to the jump occurring on the $100^{\text {th }}$ observation. Furthermore, due to the presence of a slow-moving trend component, the model fully captures the extent of the asymmetry in the second part of the sample in just 50 observations. Within this case, we also investigate to what extent the model is able to recognize the persistent nature of the shift in the asymmetry. Figure E4 reports the estimated secular and the cyclical components, respectively. The long-run components picks up the jump in a timely manner, and contributes to most of the variability of the estimated parameter. In addition, the first few observations after the jump are partly captured by the model as short-lived movements, revering to zero soon after.

Lastly, we report in Figure E7 the difference, and the associate confidence set, between the simulated and the estimated parameters. Despite co-movements in the location, scale and asymmetry parameters, the model clearly captures the cyclical variations of the latter, reported in red. The estimated parameter converges to the correct values after few observations, with small deviations, as suggested by the narrow bounds. Key for the identification of parameters' variation is that, as discussed in Section 4 , shifts in the shape parameter map into a time-varying correlation between the first and second moments of the data. Therefore, in spite of the (dynamic) interaction between the key parameters of the distribution, the model correctly identifies, in a timely manner, movements in the asymmetry of the distribution.

\footnotetext{
${ }^{37}$ These results are not reported but available upon request.
} 


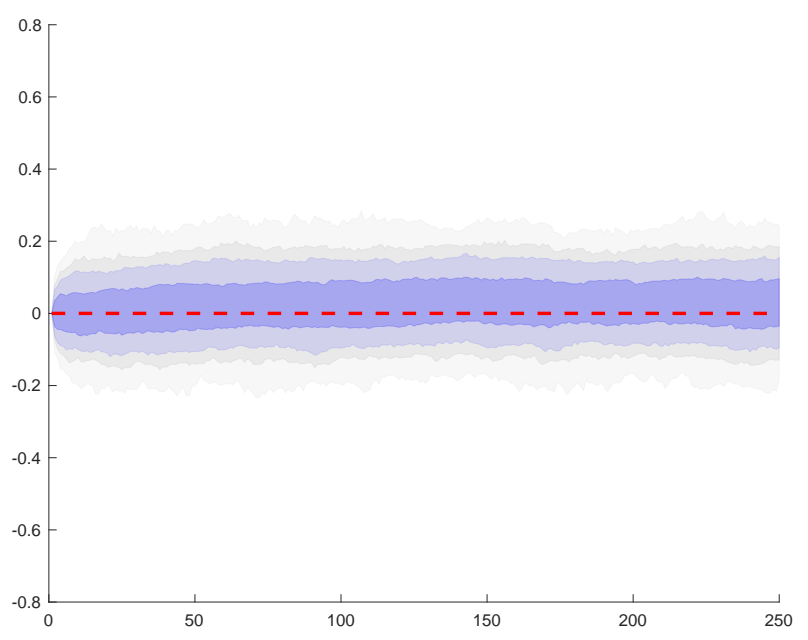

Figure E2: DGP1 - No asymmetry.

Note: The median simulated parameter is reported in red, while shades of blue represent the $99^{\text {th }}, 95^{\text {th }}$, $90^{\text {th }}, 75^{\text {th }}, 25^{\text {th }}, 10^{\text {th }}, 5^{\text {th }}$ and $1^{\text {st }}$ percentiles of the empirical distribution of the estimated parameter.

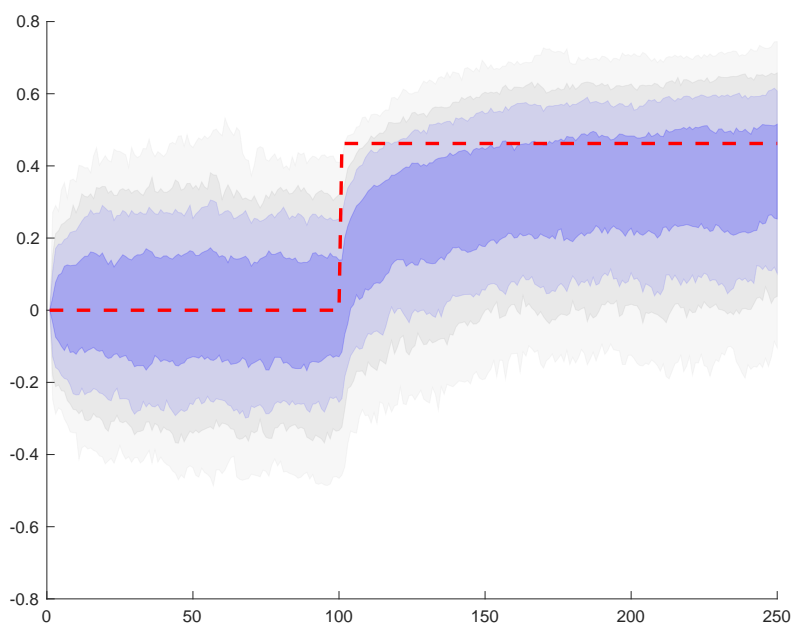

Figure E3: DGP2 - Single break in asymmetry.

Note: The median simulated parameter is reported in red, while shades of blue represent the $99^{\text {th }}, 95^{\text {th }}$, $90^{\text {th }}, 75^{\text {th }}, 25^{\text {th }}, 10^{\text {th }}, 5^{\text {th }}$ and $1^{\text {st }}$ percentiles of the empirical distribution of the estimated parameter. 


\section{Long-run}

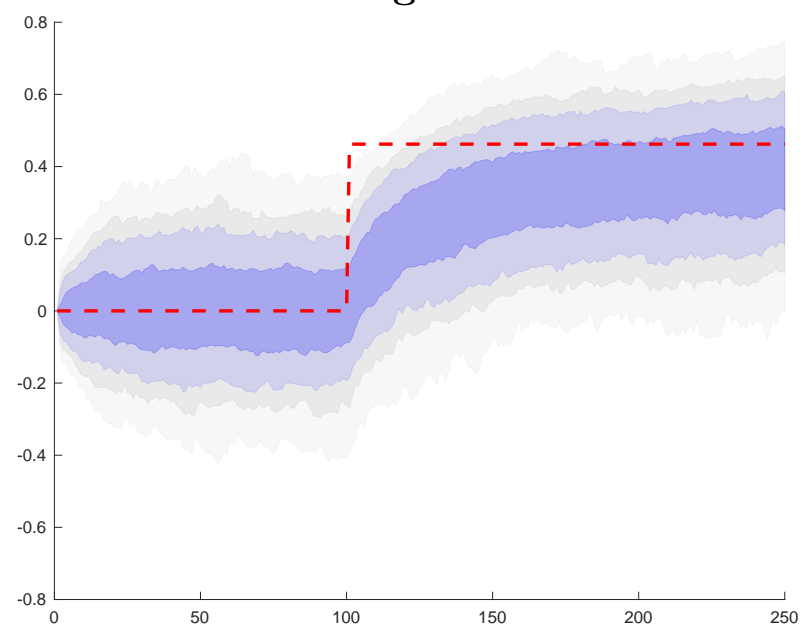

Short-run

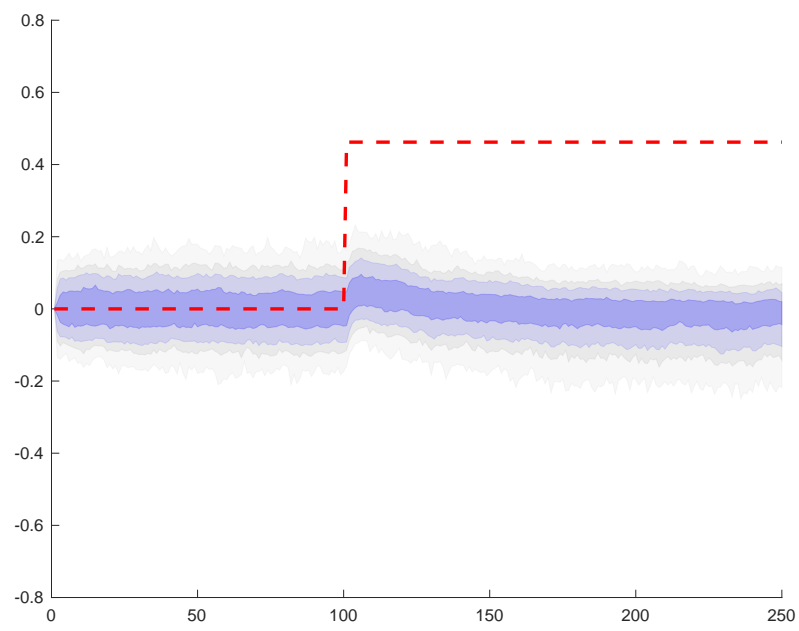

Figure E4: Secular and cyclical components for the DGP2 case.

Note: The median simulated parameter is reported in red, while shades of blue represent the $99^{\text {th }}, 95^{\text {th }}$, $90^{\text {th }}, 75^{\text {th }}, 25^{\text {th }}, 10^{\text {th }}, 5^{\text {th }}$ and $1^{\text {st }}$ percentiles of the empirical distribution of the estimated parameter.

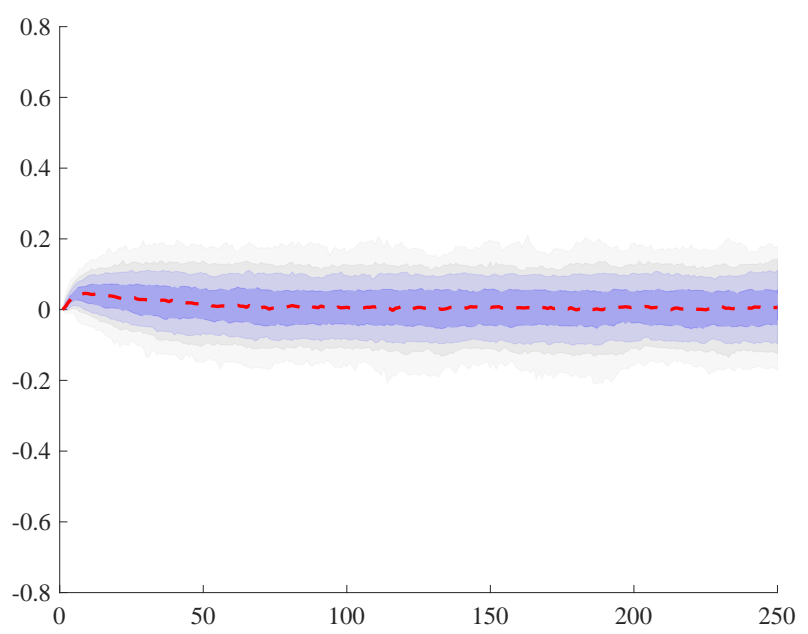

Figure E5: DGP3 - Correlated location, scale and no asymmetry.

Note: The median simulated parameter is reported in red, while shades of blue represent the $99^{\text {th }}, 95^{\text {th }}$, $90^{\text {th }}, 75^{\text {th }}, 25^{\text {th }}, 10^{\text {th }}, 5^{\text {th }}$ and $1^{\text {st }}$ percentiles of the empirical distribution of the estimated parameter. 


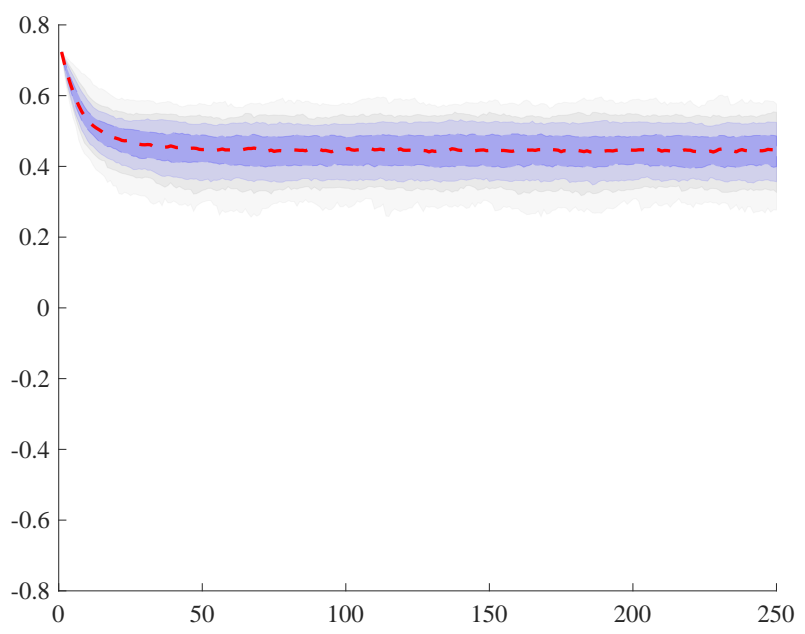

Figure E6: DGP4 - Correlated location, scale and constant negative skewness.

Note: The median simulated parameter is reported in red, while shades of blue represent the $99^{\text {th }}, 95^{\text {th }}$, $90^{\text {th }}, 75^{\text {th }}, 25^{\text {th }}, 10^{\text {th }}, 5^{\text {th }}$ and $1^{\text {st }}$ percentiles of the empirical distribution of the estimated parameter.

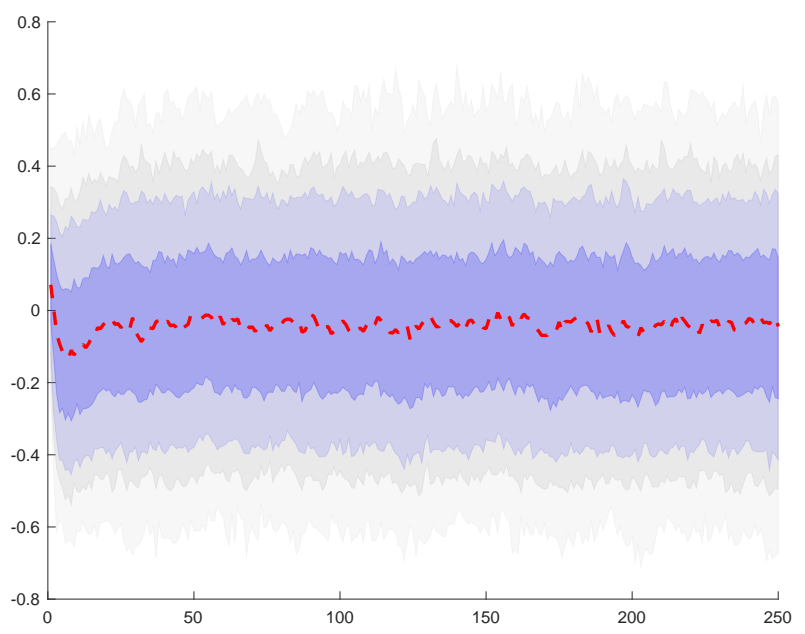

Figure E7: DGP5 - Cyclical asymmetry.

Note: The median difference between the simulated and the estimated parameters is reported in red, while shades of blue represent the $99^{\text {th }}, 95^{\text {th }}, 90^{\text {th }}, 75^{\text {th }}, 25^{\text {th }}, 10^{\text {th }}, 5^{\text {th }}$ and $1^{\text {st }}$ percentiles of the empirical distribution of such difference. 


\section{F Data}

In this Appendix we provide additional details on the data sources. We focus on (real) GDP growth in the US, and we measure financial conditions using the Chicago FED National Financial Condition Index (NFCI), and its subcomponents (Brave and Butters, 2011). The NFCI is a weekly index tracking the status of money markets, debt and equity markets, and the banking sector (comprehensive of the "shadow" banking sector). The contribution of these sectors maps into three subindices, each of which gauges financial conditions in terms of risk, leverage, and credit (refer to Brave and Butters, 2012, for further details). We use quarterly data on economic activity and financial conditions over the period 1973Q1 to 2018Q4, where the starting date for the analysis is dictated by the availability of the NFCI.

As new information is available, these indices are standardized. Thus, when an index takes a value of $1(-1)$, it signals that the financial conditions are one standard deviation tighter (looser) than their historical average. Consistently with the concept of financial tightening, the measure relating to the risk subcomponent positively contributes to the NFCI, reflecting increasing risk premia. In contrast, measures of leverage and credit receive negative weights in response to lower asset values and declining liquidity in the financial sector. The top panel of Figure F1 plots the NFCI against GDP growth, whereas the bottom panels report the NFCI subcomponents. The NFCI (and the three subcomponents) spikes during recessions, as indicated by the gray-shaded bands, and displays a clear negative correlation with GDP growth, suggesting that periods of financial overheating coincide with severe economic troughs, as documented by Adrian et al. (2019). The NFCI closely tracks the risk subcomponent, due to high weights being attached to some of the risk variables, such as the VIX index. This is consistent with the observation that volatility of the stock market is an accurate predictor of financial instability (see, e.g. Bekaert and Hoerova, 2014). The leverage component shows strong procyclicality, and tends to pick up on high values before other indices, consistently with the findings of Adrian and Shin (2010) and Jordà et al. (2013). Lastly, measures of credit spread and credit risk are contained in the risk and credit components (Krishnamurthy and Muir, 2017). 

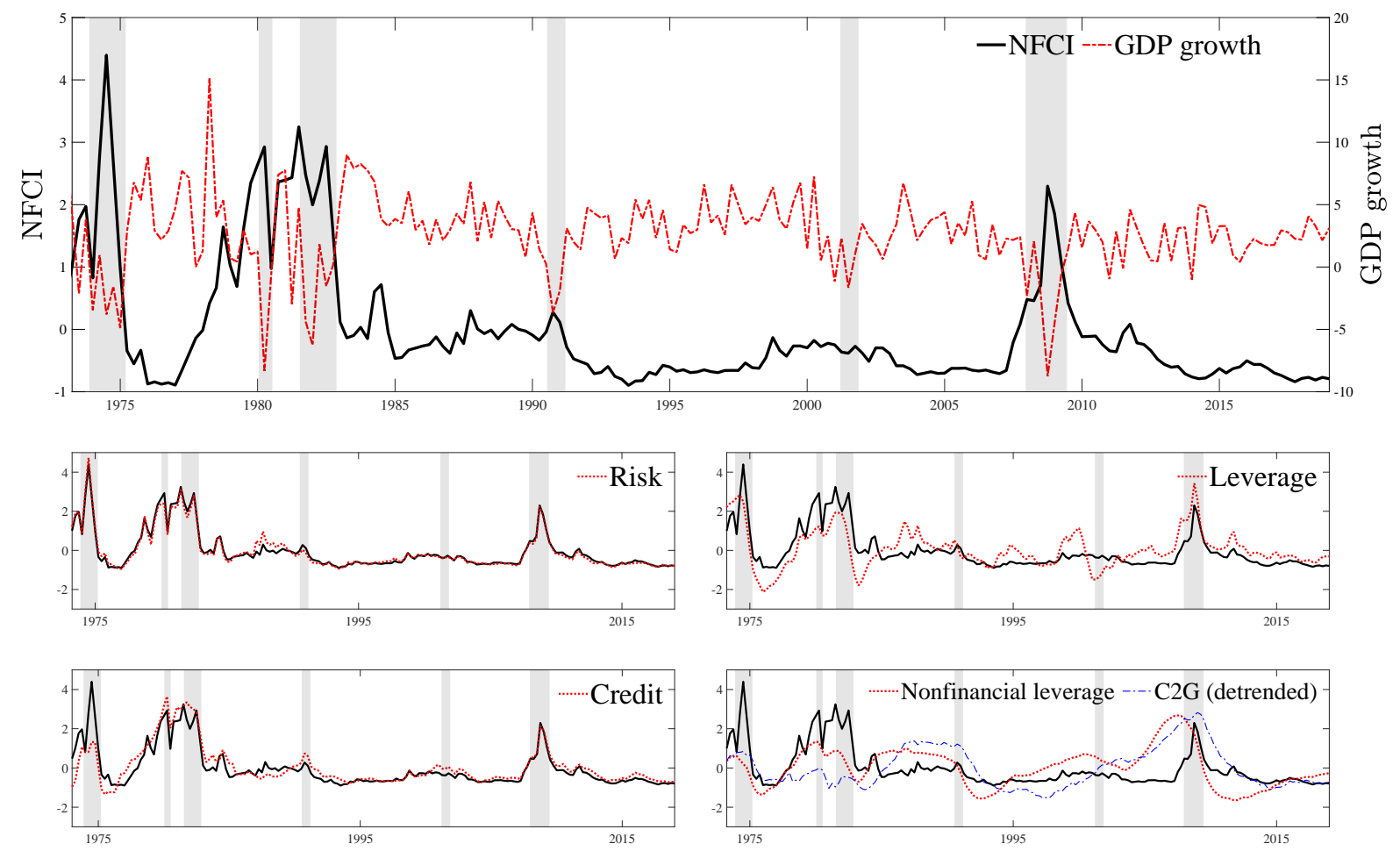

Figure F1: National Financial Condition Index and subcomponents

Note: The top panel illustrates the evolution of the NFCI and of GDP growth. Lower panels plot the risk, leverage, credit and nonfinancial leverage subcomponents, respectively. Shaded bands represent NBER recessions.

Alongside these subindices, the Chicago FED also produces the nonfinancial leverage (NFL) index (bottom right panel of Figure F1). This series tracks developments in the nonfinancial credit market using data on household and nonfinancial business leverage. Household data receive weights roughly 1.5 times higher than the latter. Mian and Sufi (2010) argue that the build up of financial instability leading to the Great Financial Crisis was mainly due to an "over-leveraged" household sector. Similarly, Jensen et al. (2020) observe that increasing households and firms leverage anticipates a deepening of business cycle skewness. A closer examination of the panel suggests that the massive deleveraging started in the early 2008 coincides with the beginning of the recession in the same year. This measure can thus be intended as an "early-warning" signal for economic downturns. In addition, this index is a clear leading indicator of the HP-filtered credit-to-GDP ratio measure (blue line in the bottom right panel of Figure F1), put forward as a leading signal of financial distress (Drehmann et al., 2010; Jordà et al., 2017). ${ }^{38}$

\footnotetext{
${ }^{38}$ Hasenzagl et al. (2020) extensively investigate the relation between the Nonfinancial leverage index and the Credit-to-GDP ratio index for forecasting purposes.
} 
Real-time data. In Sections 5 and 6 we evaluate the performance of our models, and compare them to a number of alternatives, both in an in- an out-of-sample forecasting exercise. For these exercises, we use real time data on GDP, provided by the Philadelphia FED's Real Time Data Research Center. This dataset contains GDP observations available at a particular vintage date, that is, GDP values available in the second week of the middle month of each quarter, as described in Croushore and Stark (2001). GDP growth undergoes substantial revisions, in particular over the first releases, and even more so around turning points (see, e.g. Croushore, 2011). Despite there is no consensus on what releases to use as "actual" data for forecast evaluation (Croushore, 2006), we evaluate models using the latest release. ${ }^{39}$

While real time data are available for GDP, the same is not true for the NFCI and its subcomponents. These are common factors in a broad panel of financial indicators, extracted using state-space methods. As such, these indicators are always revised at any point in time, when new information arrives. To this extent, we can only use a pseudo real-time dataset for the NFCI and its subcomponents. In Section 6, we use the disaggregated contributions of all the financial indicators which form the basis of the NFCI, as illustrated in Brave and Butters (2012). ${ }^{40}$ As GDP data are released about 45 days after the end of the reference quarter, we assume that it is at that point in time that the forecaster estimates the model and produces the forecasts. The weekly nature of these data allows us to include all the available information, by averaging all the weeks within the reference quarter, meaning that we can use all the information made available within the reference quarter. Despite still not being real-time, this method comes the closest to mimic the available information set at the time of the forecasts.

\footnotetext{
${ }^{39}$ This choice implies that the forecast error produced by our models also accounts for a "measurement error" component, induced by possible GDP measurement redefinitions, that took place over the considered forecast sample (for further discussion, see Stark and Croushore, 2002). The results of our forecast exercise would be qualitatively similar to the one reported if we were to target the 'advanced' (i.e. third) revision of GDP growth.

${ }^{40}$ We are grateful to the authors and the Chicago FED for making the full panel of weighted contribution of the financial indicators available for this work.
} 


\section{F.1 Main data sources and mnemonics}

Data on quarterly real economic activity come from the Federal Reserve Bank of St. Louis FRED dataset (mnemonic; GDPC1). The NFCI and the relative risk, leverage, nonfinancial leverage and credit subcomponents are downloaded from the same source (mnemonic: NFCI, NFCIRISK, NFCILEVERAGE, NFCINONFINLEVERAGE and NFCICREDIT). These latter are available at the weekly frequency, and they are converted into quarterly figure by taking the quarterly average. Overlapping weeks are accounted for in the averaging process: weekly values are computed in only one of the quarterly variables. $^{41}$

\section{F.2 Additional details on the disaggregated financial indicators}

We are grateful to Scot Brave and the Federal Reserve Bank of Chicago for sharing the weighted individual contribution to the NFCI. The dataset contains weekly time series of financial indicators that feed into the factor model generating both the NFCI and its subcomponens, as illustrated by Brave and Butters (2012). In Tables F1, F2, F3 and F4 we report all the indicators, their mnemonic, and the date they become available for the index. Figure F2 provides a graphical illustration of the time schedule of the availability of the predictors. The y-axis reports the years considered in our work in an ascending order (e.g. most recent times are closer to the origins).

\footnotetext{
${ }^{41}$ See https://fredhelp.stlouisfed.org/fred/data/understanding-the-data/ how-are-data-aggregated-when-periods-overlap/
} 
Table F1: Risk subindex components

\begin{tabular}{|c|c|c|}
\hline Mnemonic & Financial Indicator & Starting date \\
\hline $\mathrm{ABCP}$ & 1-mo. Asset-backed/Financial commercial paper spread & $05 / 01 / 2001$ \\
\hline ABSSPREAD & BofAML Home Equity ABS/MBS yield spread & $05 / 07 / 1991$ \\
\hline CBILL & 3-mo. Financial commercial paper/Treasury bill spread & 08/01/1971 \\
\hline CG & Commercial Paper Outstanding & $10 / 11 / 1995$ \\
\hline CMBS & BofAML 3-5 yr AAA CMBS OAS spread & $02 / 01 / 1998$ \\
\hline CPR & Counterparty Risk Index (formerly maintained by Credit Derivatives Research) & $13 / 09 / 2002$ \\
\hline CTABS & FTSE Russell US Global Markets ABS/5-yr Treasury yield spread & $01 / 02 / 1991$ \\
\hline CTERM & 3-mo./1-wk AA Financial commercial paper spread & $10 / 01 / 1997$ \\
\hline CTF & FTSE Russell US Global Markets Financial/Corporate Credit bond spread & $31 / 01 / 1997$ \\
\hline CTMBS & FTSE Russell US Global Markets MBS/10-year Treasury yield spread & $27 / 01 / 1989$ \\
\hline FAILS & Treasury Repo Delivery Fails Rate & $07 / 10 / 1994$ \\
\hline FAILSA & Agency Repo Delivery Failures Rate & $07 / 10 / 1994$ \\
\hline FAILSC & Corporate Securities Repo Delivery Failures Rate & $05 / 10 / 2001$ \\
\hline FAILSMBS & Agency MBS Repo Delivery Failures Rate & $07 / 10 / 1994$ \\
\hline GVL & FDIC Volatile Bank Liabilities & $01 / 07 / 1994$ \\
\hline LIBID & 3-mo. Eurodollar spread (LIBID-Treasury) & 08/01/1971 \\
\hline MLIQ10 & On-the-run vs. Off-the-run 10-yr Treasury liquidity premium & $04 / 01 / 1985$ \\
\hline MMF & Total Money Market Mutual Fund Assets/Total Long-term Fund Assets & $28 / 12 / 1984$ \\
\hline REPO & Fed Funds/Overnight Treasury Repo rate spread & $24 / 05 / 1991$ \\
\hline REPOA & Fed Funds/Overnight Agency Repo rate spread & $24 / 05 / 1991$ \\
\hline REPOGR & Repo Market Volume (Repurchases+Reverse Repurchases of primary dealers) & $07 / 10 / 1994$ \\
\hline REPOMORT & Fed Funds/Overnight MBS Repo rate spread & $24 / 05 / 1991$ \\
\hline RTERM & 3-mo./1-wk Treasury Repo spread & $24 / 05 / 1991$ \\
\hline SPR210 & 10-yr/2-yr Treasury yield spread & $20 / 08 / 1971$ \\
\hline SPR23M & 2-yr/3-mo. Treasury yield spread & 08/01/1971 \\
\hline SWAP10 & 10-yr Interest Rate Swap/Treasury yield spread & $03 / 04 / 1987$ \\
\hline SWAP2 & 2-yr Interest Rate Swap/Treasury yield spread & $03 / 04 / 1987$ \\
\hline SWAP3M & 3-mo. Overnight Indexed Swap (OIS)/Treasury yield spread & $19 / 09 / 2003$ \\
\hline TED & 3-mo. TED spread (LIBOR-Treasury) & 06/06/1980 \\
\hline TERM & 1-yr/1-mo. LIBOR spread & $10 / 01 / 1986$ \\
\hline USD & Advanced Foreign Economies Trade-weighted US Dollar Value Index & $12 / 01 / 1973$ \\
\hline VIX & CBOE Market Volatility Index VIX & 05/01/1990 \\
\hline VOL1 & 1-mo. BofAML Option Volatility Estimate Index & 08/04/1988 \\
\hline VOL3 & 3-mo. BofAML Swaption Volatility Estimate Index & $06 / 12 / 1996$ \\
\hline
\end{tabular}


Table F2: Leverage subindex components

\begin{tabular}{|c|c|c|}
\hline Mnemonic & Financial Indicator & Starting date \\
\hline ABSI & Nonmortgage ABS Issuance (Relative to 12-mo. MA) & $29 / 12 / 2000$ \\
\hline BDG & Broker-dealer Debit Balances in Margin Accounts & $29 / 01 / 1971$ \\
\hline BONDGR & New US Corporate Debt Issuance (Relative to 12-mo. MA) & $01 / 01 / 1988$ \\
\hline CITA & Commercial Bank C\&I Loans/Total Assets & $02 / 03 / 1973$ \\
\hline CMBSI & CMBS Issuance (Relative to 12-mo. MA) & $28 / 12 / 1990$ \\
\hline COMMODLIQ & COMEX Gold/NYMEX WTI Futures Market Depth & $04 / 01 / 2008$ \\
\hline CONTA & Commercial Bank Consumer Loans/Total Assets & $02 / 03 / 1973$ \\
\hline $\mathrm{CPH}$ & FRB Commercial Property Price Index & $02 / 04 / 1971$ \\
\hline D10 & 10-yr Constant Maturity Treasury yield & $08 / 01 / 1971$ \\
\hline DCOMM & Commercial Bank Total Unused C\&I Loan Commitments/Total Assets & $29 / 06 / 1990$ \\
\hline DNET & Net Notional Value of Credit Derivatives & $07 / 11 / 2008$ \\
\hline EQUITYLIQ & CME E-mini S\&P Futures Market Depth & $04 / 01 / 2008$ \\
\hline $\mathrm{FC}$ & Total Assets of Finance Companies/GDP & $02 / 04 / 1971$ \\
\hline FCORP & Total Assets of Funding Corporations/GDP & $02 / 04 / 1971$ \\
\hline FINS & S\&P 500 Financials/S\&P 500 Price Index (Relative to 2-yr MA) & $06 / 09 / 1991$ \\
\hline GSE & Total Agency and GSE Assets/GDP & $30 / 12 / 1983$ \\
\hline INS & Total Assets of Insurance Companies/GDP & $02 / 04 / 1971$ \\
\hline ITA & Fed funds and Reverse Repurchase Agreements/Total Assets of Commercial Banks & $30 / 03 / 1973$ \\
\hline LPH & CoreLogic National House Price Index & $02 / 04 / 1976$ \\
\hline MBONDGR & New State \& Local Government Debt Issues (Relative to 12-mo.h MA) & $27 / 02 / 2004$ \\
\hline MBSI & Total MBS Issuance (Relative to 12-mo. MA) & $29 / 12 / 2000$ \\
\hline MCAP & S\&P 500, NASDAQ, and NYSE Market Capitalization/GDP & $28 / 06 / 1985$ \\
\hline OEQ & S\&P 500, S\&P 500 mini, NASDAQ 100, NASDAQ mini Open Interest & $24 / 09 / 1999$ \\
\hline OINT & 3-mo. Eurodollar, 10-yr/3-mo. swap, 2-yr and 10-yr Treasury Open Interest & $23 / 06 / 1995$ \\
\hline PENS & Total Assets of Pension Funds/GDP & $02 / 04 / 1971$ \\
\hline RATELIQ & CME Eurodollar/CBOT T-Note Futures Market Depth & $01 / 02 / 2008$ \\
\hline REIT & Total REIT Assets/GDP & $02 / 04 / 1971$ \\
\hline RTA & Commercial Bank Real Estate Loans/Total Assets & $02 / 03 / 1973$ \\
\hline SBD & Total Assets of Broker-dealers/GDP & $02 / 04 / 1971$ \\
\hline STA & Commercial Bank Securities in Bank Credit/Total Assets & $02 / 03 / 1973$ \\
\hline STKGR & New US Corporate Equity Issuance (Relative to 12-mo. MA) & $01 / 01 / 1988$ \\
\hline STLOC & Federal, state, and local debt outstanding/GDP & $02 / 04 / 1971$ \\
\hline TABS & Total Assets of ABS issuers/GDP & $30 / 12 / 1983$ \\
\hline W500 & Wilshire 5000 Stock Price Index & $29 / 01 / 1971$ \\
\hline
\end{tabular}

Table F3: Nonfinancial Leverage subindex components

\begin{tabular}{llc}
\hline \hline Mnemonic & Financial Indicator & Starting date \\
\hline HH & Household debt outstanding/PCE Durables and Residential Investment & $02 / 04 / 1971$ \\
NFC & Nonfinancial business debt outstanding/GDP & $02 / 04 / 1971$ \\
\hline \hline
\end{tabular}


Table F4: Credit subindex components

\begin{tabular}{|c|c|c|}
\hline Mnemonic & Financial Indicator & Starting date \\
\hline $\mathrm{A} 2 \mathrm{P} 2$ & 1-mo. Nonfinancial commercial paper A2P2/AA credit spread & $10 / 01 / 1997$ \\
\hline BAA & Moody's Baa corporate bond/10-yr Treasury yield spread & $03 / 01 / 1986$ \\
\hline CARSPREAD & UM Household Survey: Auto Credit Conditions Good/Bad spread & $24 / 02 / 1978$ \\
\hline CBCAR & Commercial Bank 48-mo. New Car Loan/2-yr Treasury yield spread & $05 / 05 / 1972$ \\
\hline CBPER & Commercial Bank 24-mo. Personal Loan/2-yr Treasury yield spread & $05 / 05 / 1972$ \\
\hline CCDQ & S\&P US Bankcard Credit Card: 3-mo. Delinquency Rate & $28 / 02 / 1992$ \\
\hline CCG & Consumer Credit Outstanding & $29 / 01 / 1971$ \\
\hline CCINC & S\&P US Bankcard Credit Card: Excess Rate Spread & $31 / 01 / 1992$ \\
\hline CILARGE & FRB Senior Loan Officer Survey: Tightening Standards on Large C\&I Loans & $13 / 07 / 1990$ \\
\hline CISMALL & FRB Senior Loan Officer Survey: Tightening Standards on Small C\&I Loans & $13 / 07 / 1990$ \\
\hline $\mathrm{CRE}$ & FRB Senior Loan Officer Survey: Tightening Standards on CRE Loans & $12 / 10 / 1990$ \\
\hline CRG & S\&P US Bankcard Credit Card: Receivables Outstanding & $28 / 02 / 1992$ \\
\hline CWILL & FRB Senior Loan Officer Survey: Willingness to Lend to Consumers & $15 / 01 / 1971$ \\
\hline $\mathrm{DBC}$ & ABA Value of Delinquent Bank Card Credit Loans/Total Loans & $26 / 02 / 1999$ \\
\hline DCLOSE & ABA Value of Delinquent Consumer Loans/Total Loans & $26 / 02 / 1999$ \\
\hline DHE & ABA Value of Delinquent Home Equity Loans/Total Loans & $26 / 02 / 1999$ \\
\hline DOTH & ABA Value of Delinquent Noncard Revolving Credit Loans/Total Loans & $26 / 02 / 1999$ \\
\hline DURSPREAD & UM Household Survey: Durable Goods Credit Conditions Good/Bad spread & $27 / 01 / 1978$ \\
\hline FG & Finance Company Owned \& Managed Receivables & $29 / 01 / 1971$ \\
\hline HOUSSPREAD & UM Household Survey: Mortgage Credit Conditions Good/Bad spread & $24 / 02 / 1978$ \\
\hline HY & BofAML High Yield/Moody's Baa corporate bond yield spread & $07 / 11 / 1986$ \\
\hline JINC & 30-yr Jumbo/Conforming fixed rate mortgage spread & $12 / 06 / 1998$ \\
\hline LHY & Markit High Yield (HY) 5-yr Senior CDS Index & $07 / 01 / 2005$ \\
\hline LIG & Markit Investment Grade (IG) 5-yr Senior CDS Index & $01 / 10 / 2004$ \\
\hline MBOND & 20-yr Treasury/State \& Local Government 20-yr GO bond spread & 08/01/1971 \\
\hline MDQ & MBA Serious Delinquencies & $30 / 06 / 1972$ \\
\hline $\mathrm{MG}$ & Money Stock: MZM & $01 / 03 / 1974$ \\
\hline MINC & 30-yr Conforming Mortgage/10-yr Treasury yield spread & $02 / 04 / 1971$ \\
\hline MSWAP & Bond Market Association Municipal Swap/20-yr Treasury yield spread & $07 / 07 / 1989$ \\
\hline NACMM & NACM Survey of Credit Managers: Credit Manager's Index & $15 / 02 / 2002$ \\
\hline NCL & Commercial Bank Noncurrent/Total Loans & $28 / 06 / 1985$ \\
\hline RRE & FRB Senior Loan Officer Survey: Tightening Standards on RRE Loans & $12 / 10 / 1990$ \\
\hline SMALL & NFIB Survey: Credit Harder to Get & $02 / 11 / 1973$ \\
\hline SPCILARGE & FRB Senior Loan Officer Survey: Increasing spreads on Large C\&I Loans & $13 / 07 / 1990$ \\
\hline SPCISMALL & FRB Senior Loan Officer Survey: Increasing spreads on Small C\&I Loans & $13 / 07 / 1990$ \\
\hline
\end{tabular}




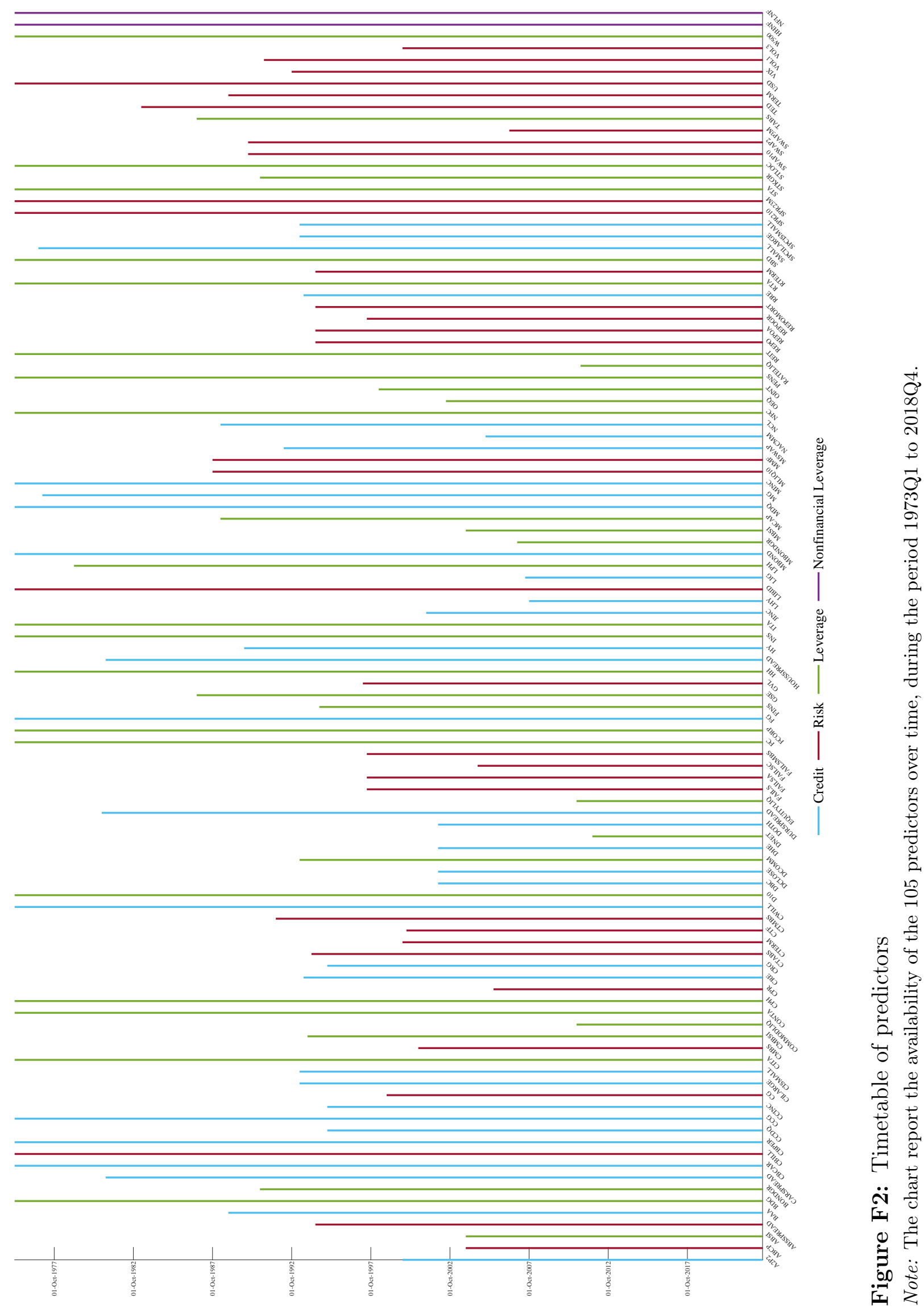




\section{G Additional plots and tables}

Table G5: Static parameters

\begin{tabular}{|c|c|c|c|c|c|c|c|c|}
\hline & $\mu_{y}$ & $\mu_{\sigma}$ & $\phi_{y, 1}$ & $\phi_{y, 2}$ & $\phi_{\mu, 1}$ & $\phi_{\mu, 2}$ & $\phi_{\tilde{\gamma}}$ & $\phi_{\tilde{\delta}}$ \\
\hline$A R(\mathscr{Q})$ & $\begin{array}{c}1.504 \\
{[1.400,1.622]}\end{array}$ & $\begin{array}{c}0.014 \\
{[0.013,0.016]}\end{array}$ & $\begin{array}{c}0.337 \\
{[0.303,0.383]}\end{array}$ & $\begin{array}{c}0.210 \\
{[0.171,0.249]}\end{array}$ & & & $\begin{array}{c}0.958 \\
0.954 .0 .960]\end{array}$ & \\
\hline Skt no-X & & & & & $\begin{array}{c}0.984 \\
{[0.892,1.073]}\end{array}$ & $\begin{array}{c}-0.192 \\
{[-0.293,-0.100]}\end{array}$ & $\begin{array}{c}0.833 \\
{[0.778,0.877]}\end{array}$ & $\begin{array}{c}0.785 \\
{[0.738,0.828]}\end{array}$ \\
\hline Skt NFCI & & & & & $\begin{array}{c}0.949 \\
{[0.862,1.034]}\end{array}$ & $\begin{array}{c}-0.176 \\
{[-0.271,-0.070]}\end{array}$ & $\begin{array}{c}0.675 \\
{[0.618,0.728]}\end{array}$ & $\begin{array}{c}0.703 \\
{[0.627,0.772]}\end{array}$ \\
\hline \multirow[t]{2}{*}{ Skt $4 D F I$} & & & & & $\begin{array}{c}1.048 \\
{[1.002,1.092]}\end{array}$ & $\begin{array}{c}-0.206 \\
{[-0.257,-0.156]}\end{array}$ & $\begin{array}{c}0.501 \\
{[0.434,0.569]}\end{array}$ & $\begin{array}{c}0.773 \\
{[0.720,0.813]}\end{array}$ \\
\hline & $\varsigma_{\mu}$ & $\kappa_{\mu}$ & $\varsigma_{\gamma}$ & $\kappa_{\gamma}$ & $\varsigma_{\delta}$ & $\kappa_{\delta}$ & $\chi$ & $\eta$ \\
\hline$A R(\mathbb{Q})$ & & & & $\begin{array}{c}0.108 \\
{[0.095,0.121]}\end{array}$ & & & $\begin{array}{c}0.210 \\
{[0.123,0.303]}\end{array}$ & \\
\hline Skt no-X & $\begin{array}{c}0.023 \\
{[0.019,0.028]}\end{array}$ & $\begin{array}{c}0.077 \\
{[0.062,0.097]}\end{array}$ & $\begin{array}{c}0.029 \\
{[0.023,0.036]}\end{array}$ & $\begin{array}{c}0.096 \\
{[0.080,0.118]}\end{array}$ & $\begin{array}{c}0.022 \\
{[0.018,0.026]}\end{array}$ & $\begin{array}{c}0.095 \\
{[0.081,0.110]}\end{array}$ & $\begin{array}{c}0.265 \\
{[0.169,0.354]}\end{array}$ & $\begin{array}{c}0.201 \\
{[0.171,0.233]}\end{array}$ \\
\hline Skt NFCI & $\begin{array}{c}0.025 \\
{[0.020,0.033]}\end{array}$ & $\begin{array}{c}0.074 \\
{[0.061,0.091]}\end{array}$ & $\begin{array}{c}0.026 \\
{[0.020,0.034]}\end{array}$ & $\begin{array}{c}0.071 \\
{[0.058,0.086]}\end{array}$ & $\begin{array}{c}0.026 \\
{[0.022,0.032]}\end{array}$ & $\begin{array}{c}0.067 \\
{[0.057,0.079]}\end{array}$ & $\begin{array}{c}0.293 \\
{[0.215,0.366]}\end{array}$ & $\begin{array}{c}0.173 \\
{[0.146,0.203]}\end{array}$ \\
\hline Skt $4 D F I$ & $\begin{array}{c}0.023 \\
{[0.019,0.028]}\end{array}$ & $\begin{array}{c}0.072 \\
{[0.059,0.085]}\end{array}$ & $\begin{array}{c}0.025 \\
{[0.020,0.031]}\end{array}$ & $\begin{array}{c}0.066 \\
{[0.056,0.075]}\end{array}$ & $\begin{array}{c}0.021 \\
{[0.018,0.024]}\end{array}$ & $\begin{array}{c}0.075 \\
{[0.063,0.086]}\end{array}$ & $\begin{array}{c}0.109 \\
{[0.068,0.148]}\end{array}$ & $\begin{array}{c}0.151 \\
{[0.130,0.175]}\end{array}$ \\
\hline
\end{tabular}

Note: The table reports the estimates of the static parameters for all the models: the Gaussian $A R(2)$, the $S k t$ no- $X$ without predictors, with lags of the NFCI (Skt NFCI) and with lags of the subcomponents of the index (Skt $4 D F I)$. Confidence intervals at the $68 \%$ level are in brackets.

Table G6: Predictor loadings

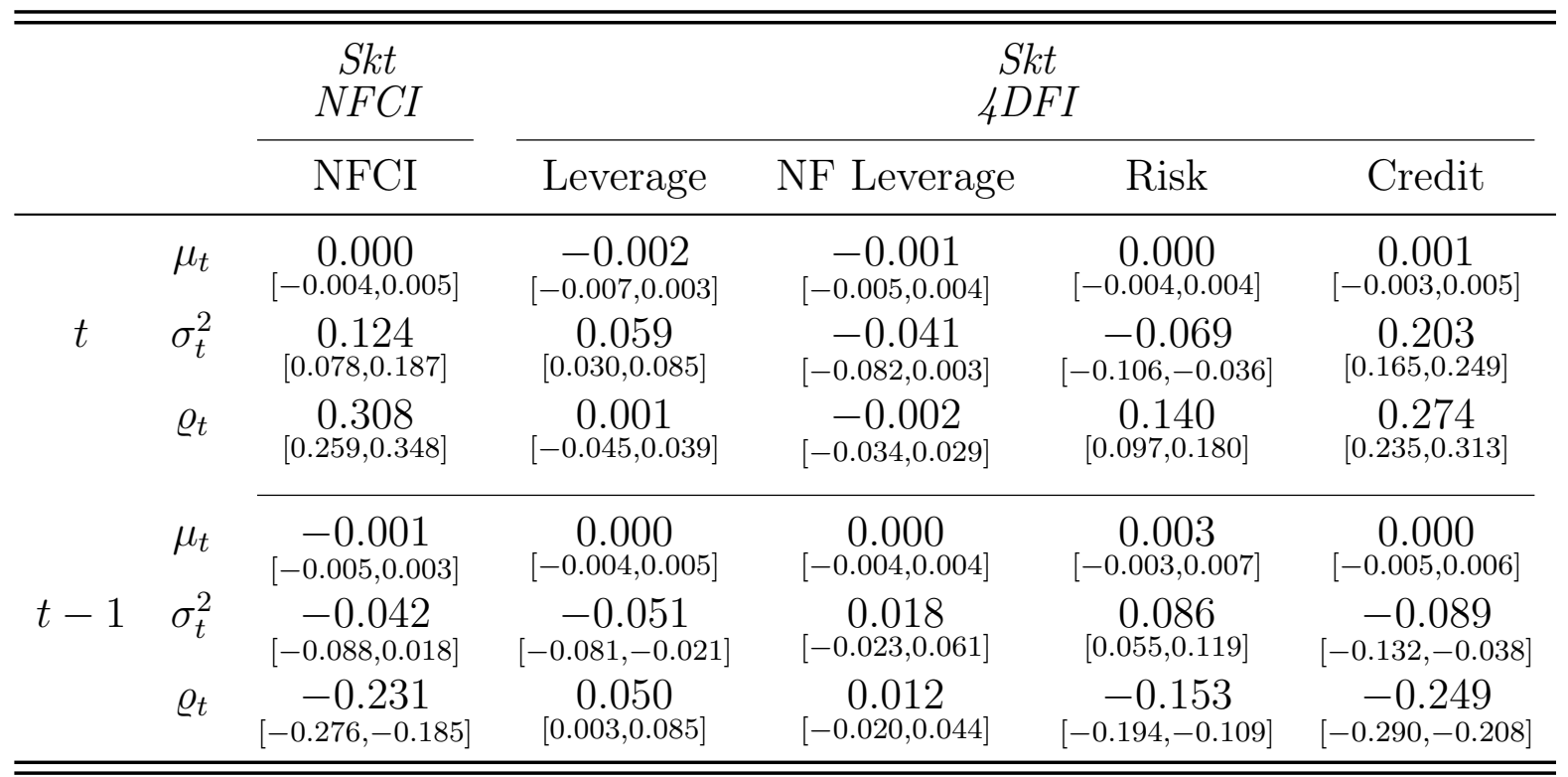

Note: $68 \%$ confidence intervals are reported in brackets. 
Table G7: Forecast performance - One quarter ahead

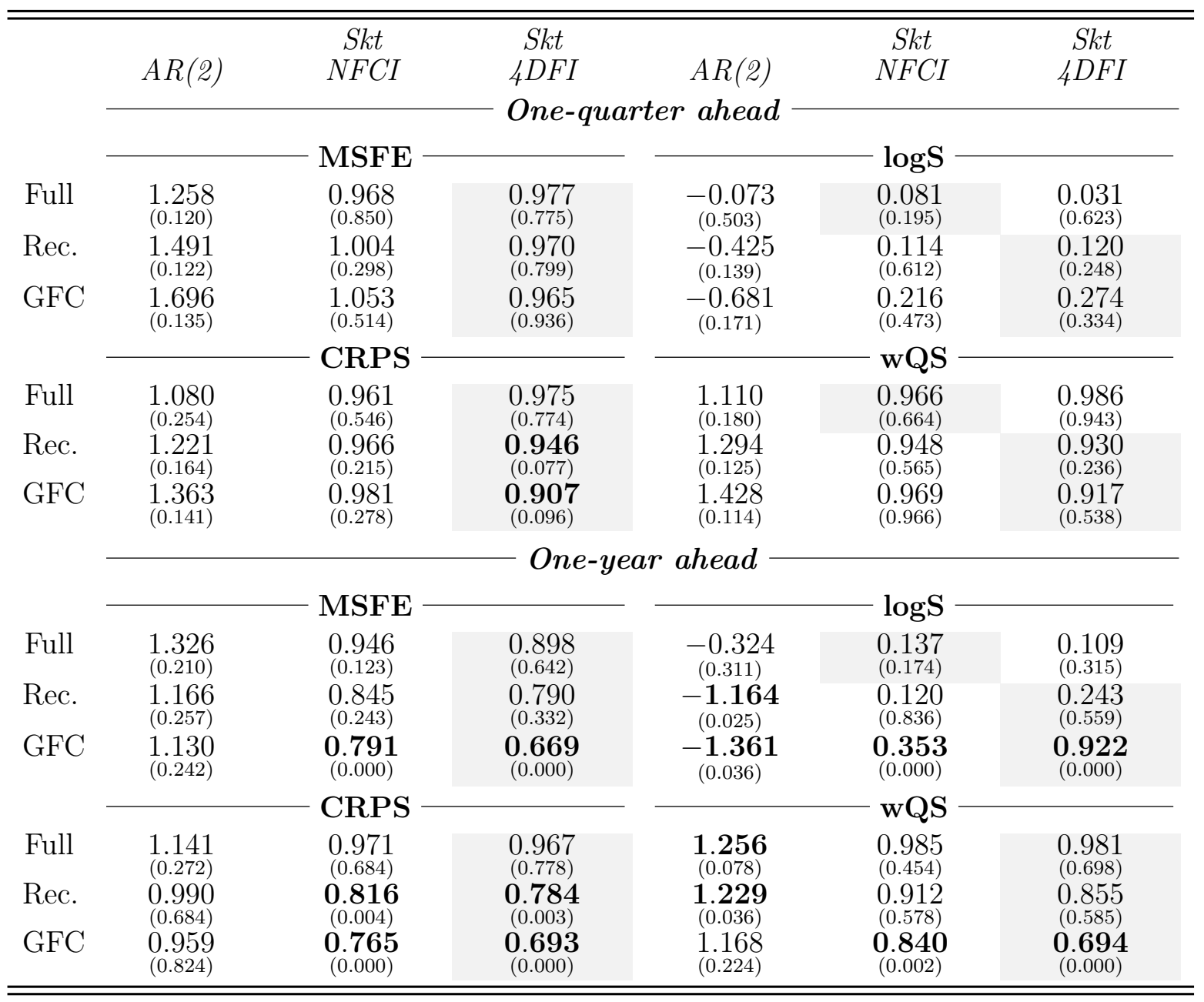

Note: The table reports the average forecast metrics relative to Adrian et al. (2019). We use ratios for the MSFE, CRSP and wQS, and differences for the $\operatorname{logS}$. Ratios smaller than 1, and positive values of the log-score differences indicate that the column-specific model performs better than Adrian et al. (2019). The p-value for Giacomini and White (2006) test are in parentheses. Values in bold are significant at the $10 \%$ level; gray shaded cells highlight the best score. 
Table G8: Density calibration tests

\begin{tabular}{|c|c|c|c|c|c|c|}
\hline \multirow[b]{3}{*}{ Dist. } & $A R(2)$ & $A B G$ & $\begin{array}{c}\text { Skt } \\
4 D F I\end{array}$ & $A R(2)$ & $A B G$ & $\begin{array}{c}S k t \\
4 D F I\end{array}$ \\
\hline & \multicolumn{3}{|c|}{ One-quarter ahead } & \multicolumn{3}{|c|}{ One-year ahead } \\
\hline & 1.178 & 1.911 & 0.906 & 2.399 & 2.050 & 1.300 \\
\hline Left tail & 1.018 & 1.439 & 0.866 & 2.399 & 2.050 & 1.300 \\
\hline
\end{tabular}

Note: The table reports the test statistics for the Rossi and Sekhposyan (2019) tests, based on the Kolmogorov-Smirnov type tests. The left tail score is computed over the support [0,0.25]. Values in bold indicate the rejection of the null hypothesis of correct specification of the density forecast, at the $10 \%$ confidence level. Critical values are obtained by 1000 bootstrap simulations. Gray shaded cells indicate the lowest value of the statistic.

Table G9: Forecast performance - Parameter uncertainty

\begin{tabular}{cccccc}
\hline \hline & \multicolumn{2}{c}{ One-quarter ahead } & & \multicolumn{2}{c}{ One-year ahead } \\
\cline { 2 - 3 } \cline { 5 - 6 } Full & MSFE & logS & & MSFE & logS \\
& 1.010 & 0.019 & & 0.914 & 0.099 \\
Rec. & $(0.671)$ & $(0.565)$ & & $(0.415)$ & $(0.373)$ \\
GFC & 1.001 & 0.033 & & 0.878 & 0.495 \\
& $(0.988)$ & $(0.588)$ & & $(0.349)$ & $(0.000)$ \\
& 1.068 & -0.024 & & 0.874 & 0.333 \\
& $(0.181)$ & $(0.663)$ & & $(0.518)$ & $(0.029)$ \\
Full & CRPS & wQS & & CRSP & wQS \\
& 0.998 & 0.999 & & 1.004 & 0.942 \\
Rec. & $(0.849)$ & $(0.616)$ & & $(0.345)$ & $(0.413)$ \\
GFC & 0.984 & 0.994 & & 0.971 & 0.880 \\
& $(0.469)$ & $(0.578)$ & & $(0.551)$ & $(0.011)$ \\
& 1.046 & 1.044 & & 0.988 & 0.909 \\
\hline \hline
\end{tabular}

Note: In this table we compare the forecast metrics of the baseline model, Skt $4 F D I$, against a version of the same model that does not account for parameter uncertainty (w/o P.U.). The table reports the average forecast metrics relative to the $w / o$ P.U. model. We use ratios for the MSFE, CRSP and wQS, and differences for the logS. Ratios smaller than 1, and positive values of the log-score differences indicate that the baseline model (which allows for uncertainty) performs better than the model without parameters uncertainty. The p-value for Giacomini and White (2006) test are in parentheses. 
Table G10: Density calibration tests - Parameter uncertainty

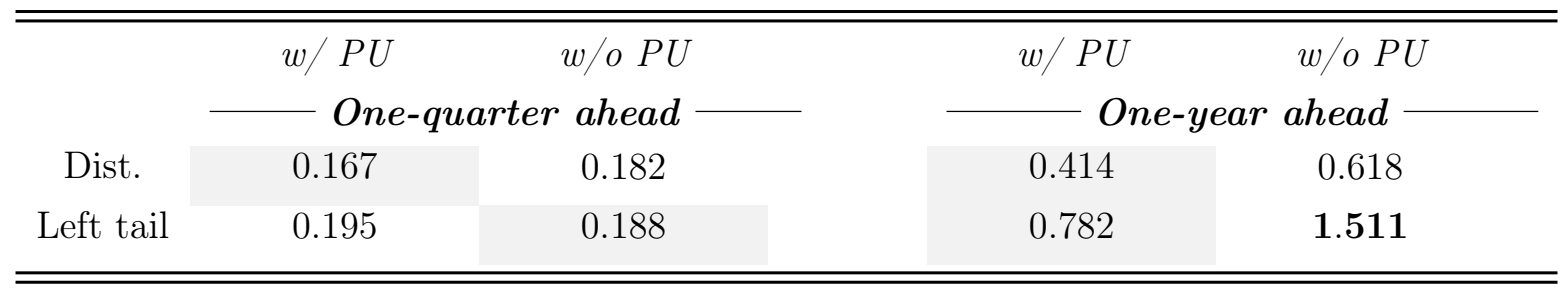

Note: The table reports the test statistics for the Rossi and Sekhposyan (2019) tests, based on the Cramér-von Mises type tests. The left tail score is computed over the support [0, 0.25]. Values in bold indicate the rejection of the null hypothesis of correct specification of the density forecast, at the $10 \%$ confidence level. Critical values are obtained by 1000 bootstrap simulations. Gray shaded cells indicate lowest value of the statistic.

Table G11: Downside risk scores

\begin{tabular}{|c|c|c|c|c|c|c|}
\hline & $\begin{array}{c}\text { Skt } \\
n o-X\end{array}$ & $\begin{array}{c}\text { Skt } \\
4 D F I\end{array}$ & $\begin{array}{c}S k t \\
n o-X\end{array}$ & $\begin{array}{c}S k t \\
4 D F I\end{array}$ & $\begin{array}{c}\text { Skt } \\
n o-X\end{array}$ & $\begin{array}{c}S k t \\
4 D F I\end{array}$ \\
\hline & \multicolumn{2}{|c|}{ FZG } & \multirow{2}{*}{\multicolumn{2}{|c|}{$\begin{array}{l}-\mathrm{ALS}- \\
\text { One-quarter ahead }\end{array}$}} & \multicolumn{2}{|c|}{- TLF } \\
\hline & & & & & & \\
\hline Full & $\begin{array}{l}0.502 \\
(0.356)\end{array}$ & $\begin{array}{l}0.530 \\
(0.323)\end{array}$ & $\begin{array}{l}0.820 \\
(0.206)\end{array}$ & $\begin{array}{l}0.813 \\
(0.174)\end{array}$ & $\begin{array}{l}0.825 \\
(0.293)\end{array}$ & $\begin{array}{l}0.782 \\
(0.229)\end{array}$ \\
\hline Rec. & $\begin{array}{l}0.297 \\
(0.155)\end{array}$ & $\begin{array}{l}0.317 \\
(0.176)\end{array}$ & $\begin{array}{l}0.566 \\
(0.116)\end{array}$ & $\begin{array}{l}0.541 \\
(0.125)\end{array}$ & $\begin{array}{l}0.640 \\
(0.111)\end{array}$ & $\begin{array}{l}0.562 \\
(0.142)\end{array}$ \\
\hline \multirow[t]{2}{*}{ GFC } & $\begin{array}{l}0.254 \\
(0.330)\end{array}$ & $\begin{array}{l}0.192 \\
(0.337)\end{array}$ & $\begin{array}{l}0.558 \\
(0.283)\end{array}$ & $\begin{array}{l}0.464 \\
(0.288)\end{array}$ & $\begin{array}{l}0.654 \\
(0.263)\end{array}$ & $\begin{array}{l}0.507 \\
(0.229)\end{array}$ \\
\hline & \multicolumn{6}{|c|}{ One-year ahead } \\
\hline Full & $\begin{array}{l}0.394 \\
(0.335)\end{array}$ & $\begin{array}{l}0.121 \\
(0.303)\end{array}$ & $\begin{array}{l}0.674 \\
(0.240)\end{array}$ & $\begin{array}{l}0.596 \\
(0.302)\end{array}$ & $\begin{array}{l}0.828 \\
(0.307)\end{array}$ & $\begin{array}{l}0.596 \\
(0.300)\end{array}$ \\
\hline Rec. & $\begin{array}{c}\mathbf{0 . 2 2 5} \\
(0.027)\end{array}$ & $\begin{array}{c}\mathbf{0 . 2 8 6} \\
(0.076)\end{array}$ & $\begin{array}{c}\mathbf{0 . 5 4 2} \\
(0.082)\end{array}$ & $\begin{array}{l}0.553 \\
(0.448)\end{array}$ & $\begin{array}{c}\mathbf{0 . 5 8 9} \\
(0.015)\end{array}$ & $\begin{array}{c}\mathbf{0 . 4 3 6} \\
(0.019)\end{array}$ \\
\hline GFC & $\begin{array}{c}\mathbf{0 . 3 9 4} \\
(0.092)\end{array}$ & $\begin{array}{l}0.121 \\
(0.172)\end{array}$ & $\begin{array}{c}\mathbf{0 . 4 7 4} \\
(0.056)\end{array}$ & $\begin{array}{l}0.294 \\
(0.187)\end{array}$ & $\begin{array}{l}0.618 \\
(0.122)\end{array}$ & $\begin{array}{l}0.297 \\
(0.198)\end{array}$ \\
\hline
\end{tabular}

Note: The table reports the average downside risk test scores, expressed as ratios relative to the Gaussian model. Ratios smaller than 1 indicate that the column-specific model performs better than the benchmark. p-values for Giacomini and White (2006) test are reported in parentheses. Values in bold are significant at the 10\% level; gray shaded cells highlight the best score. FZG: Fissler et al. (2016) loss function; ALS: Taylor (2019) loss function; TLF: Giacomini and Komunjer (2005) tick loss function. 


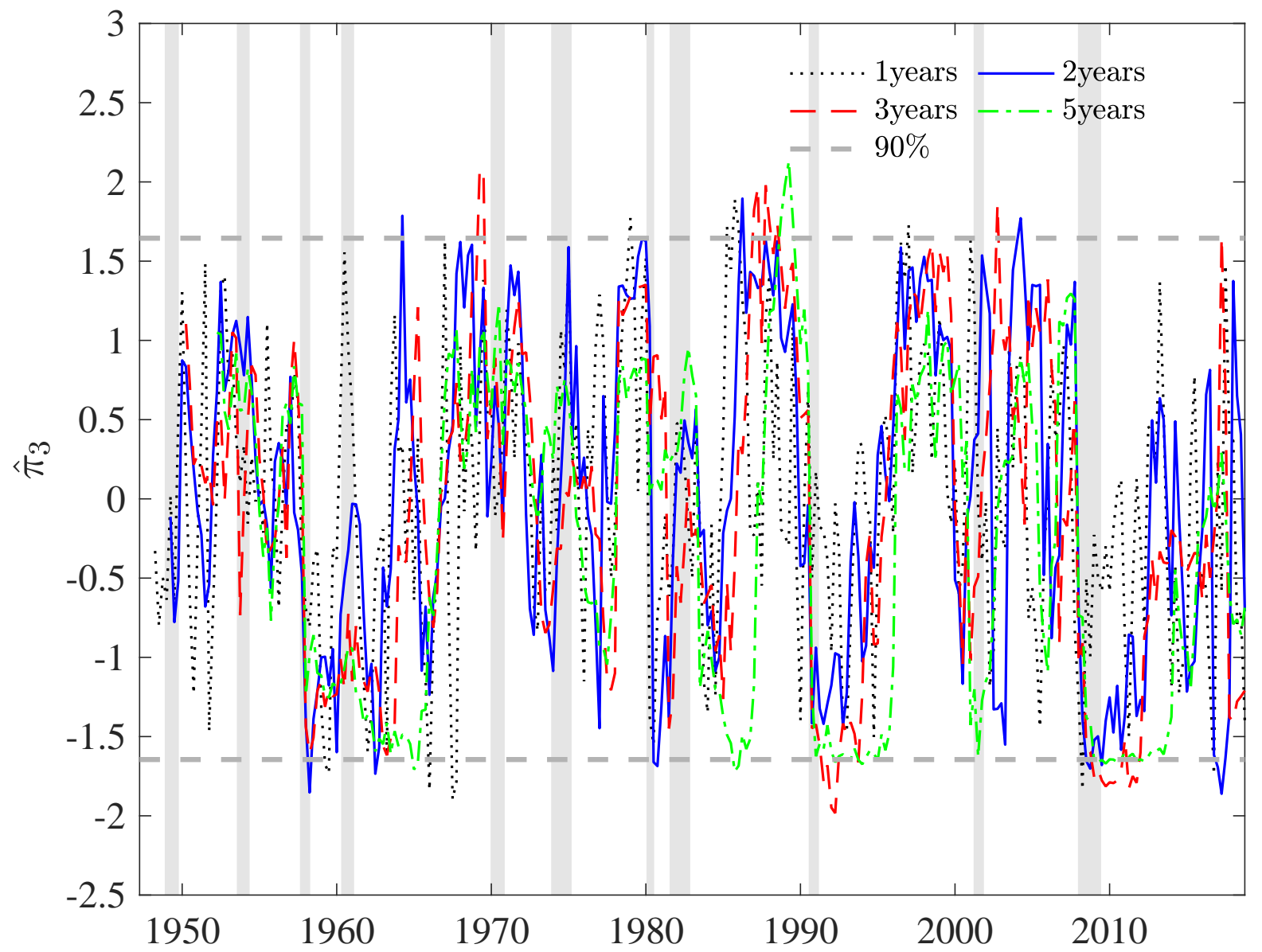

Figure G1: Bai and Ng (2005) test for skewness

Note: We report the Bai and Ng (2005) test for skewness' test statistic, for different rolling windows sizes of 1, 2, 3 and 5 years. The gray lines represent $90 \%$ (dotted) critical values. Shaded bands represent NBER recessions. 
Skt
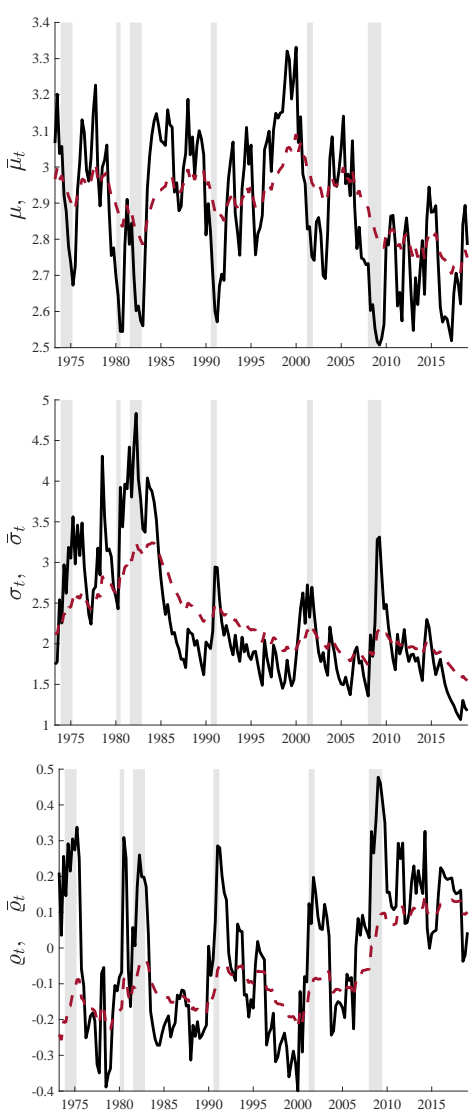

Skt $-N F C I$
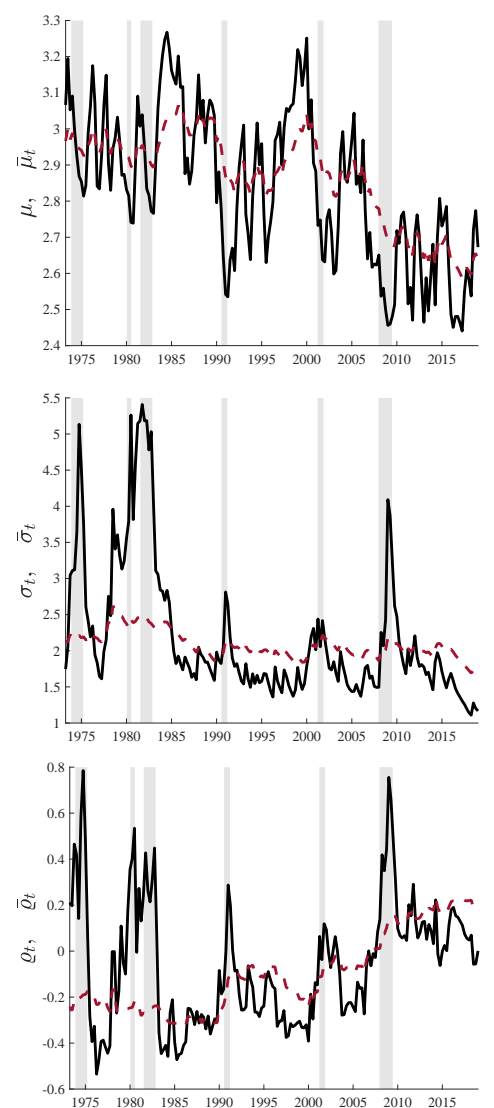

Skt $-4 D F I$
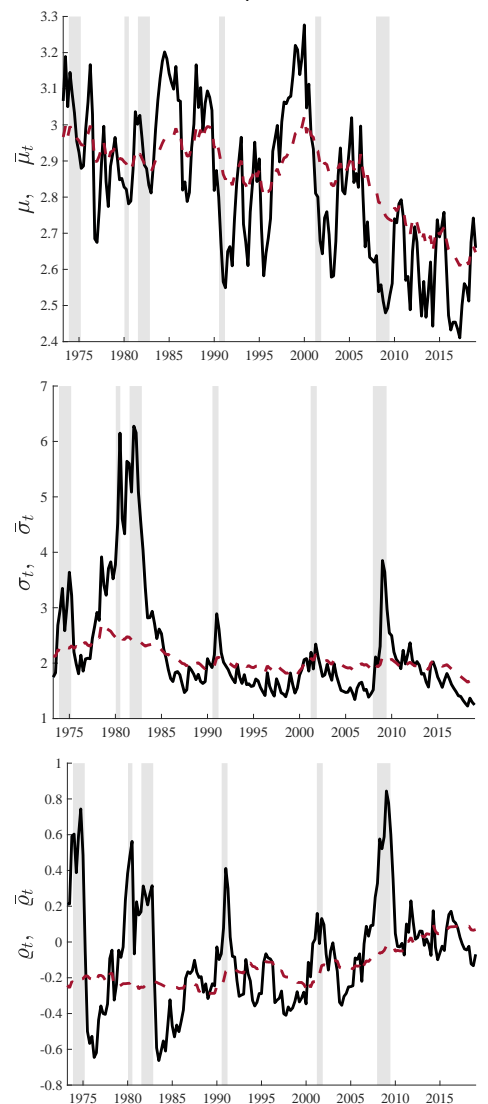

Figure G2: Time-varying parameters

Note: The plots illustrate the estimated time-varying parameters (black) for the three model specifications. Long-run components are reported in red (right scale). Shaded bands represent NBER recessions. 
$S k t$
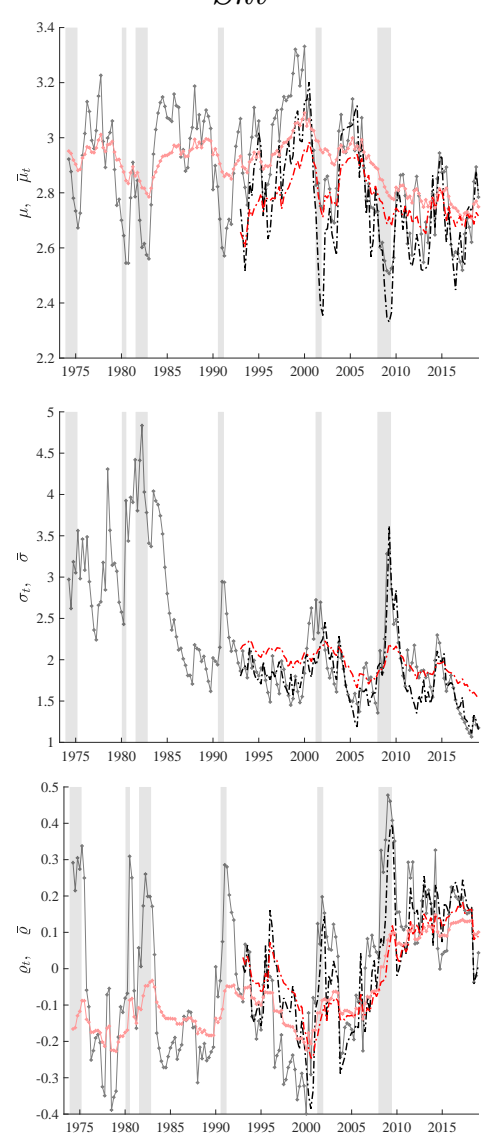

Skt $-N F C I$
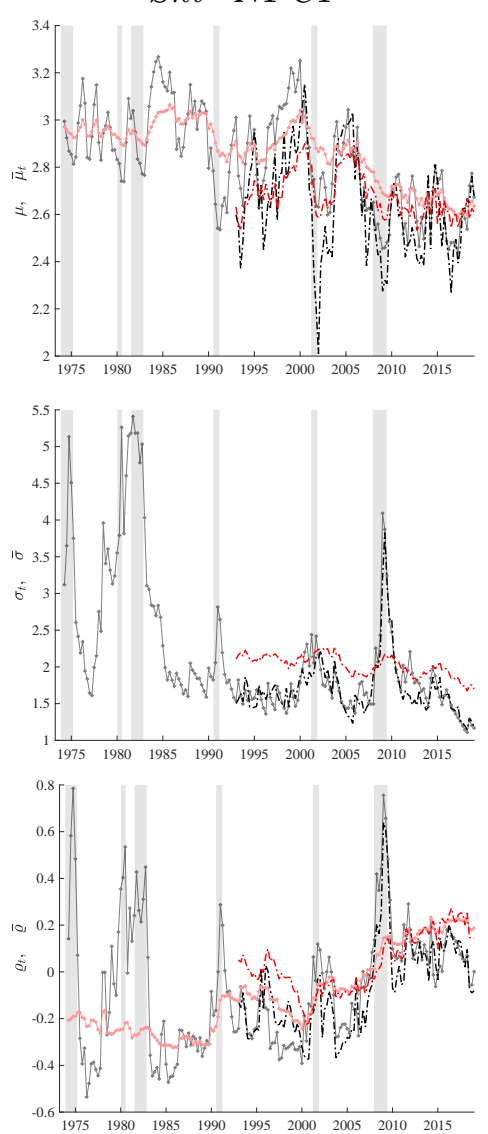

$S k t-4 D F I$
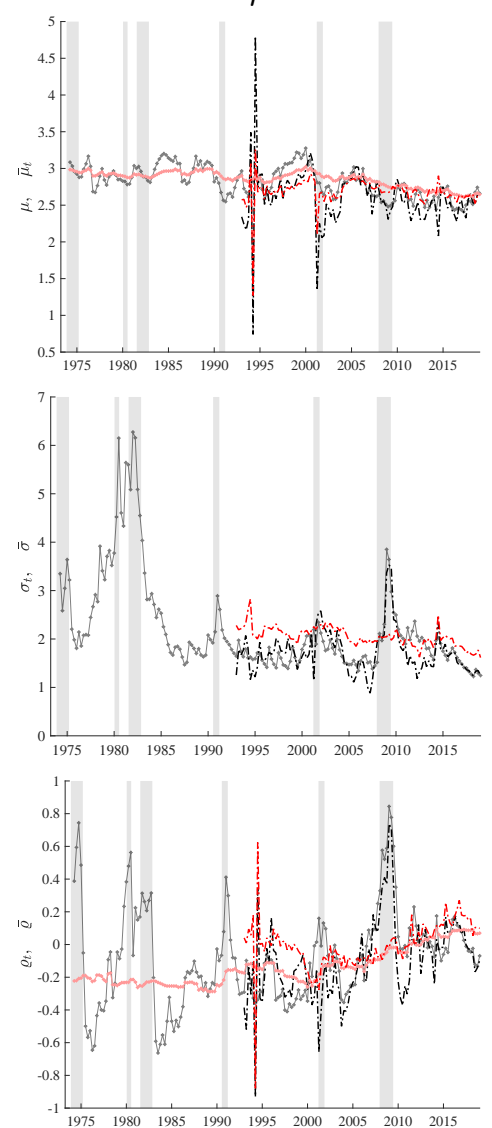

Figure G3: Time-varying parameters

Note: The plots compare the in sample (solid gray) and out of sample (dotted black) parameters. Longrun components are reported in scales of red (right scale). Shaded bands represent NBER recessions.

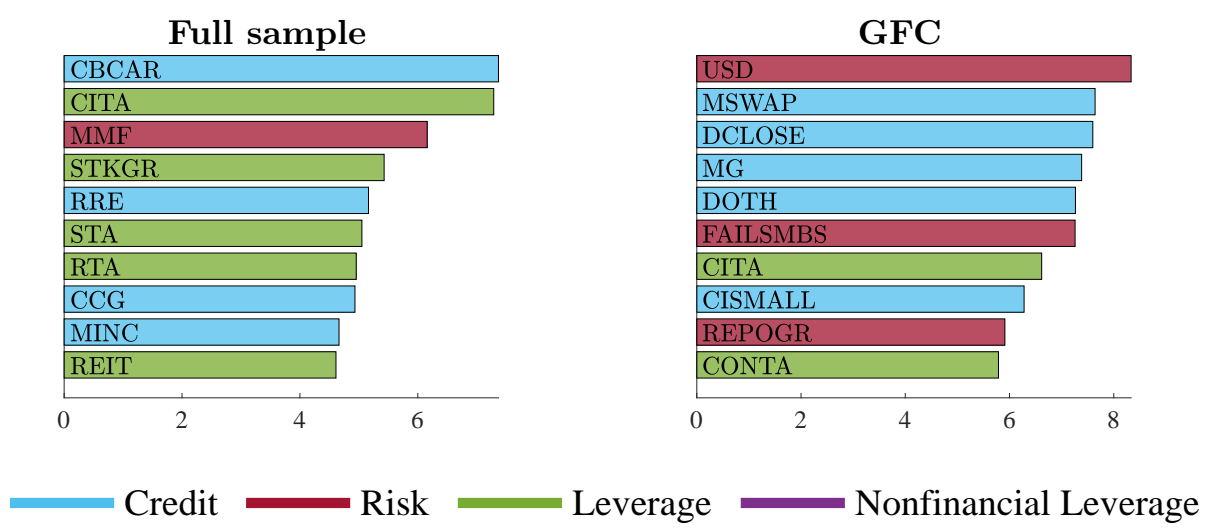

Figure G4: Top 10 predictors for $\mu_{t}$

Note: The bar plots report the top 10 predictors for the location parameter. The $x$-axis reports average posterior probability of inclusion, expressed in percentage terms. 
-

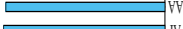

$\longrightarrow$ dFMS

—aSP

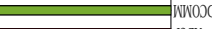

$\square$ aNogi मㄱ zart HOdAy Wyมี $=\frac{\mathrm{XI \Lambda}}{\mathrm{XIS}}$

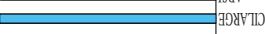
 壮 ¿ ४อ0 TTFISID ${ }^{9 \mathrm{~A}}$ $\square_{H \mathrm{X}}^{\mathrm{KH}}$ WEAHS $\square$

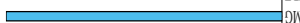

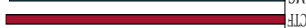
aㅐ LNO ${ }_{-}^{\mathrm{HLOCO}}$ בonts $\Longrightarrow$ $\square$ ○(a) 을 do Sañ ISAII) : : : : $\vdots$ $\vdots:$ : : : : : $\vdots$ i . : : ingys ałมdds -

:

on

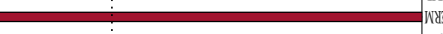

dץว :

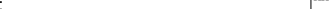

: ¿ (1931 כNII $\longleftarrow$ @

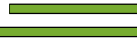
ए (2)

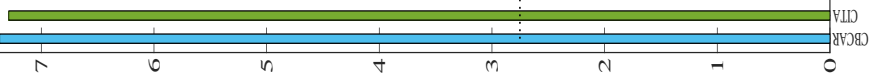




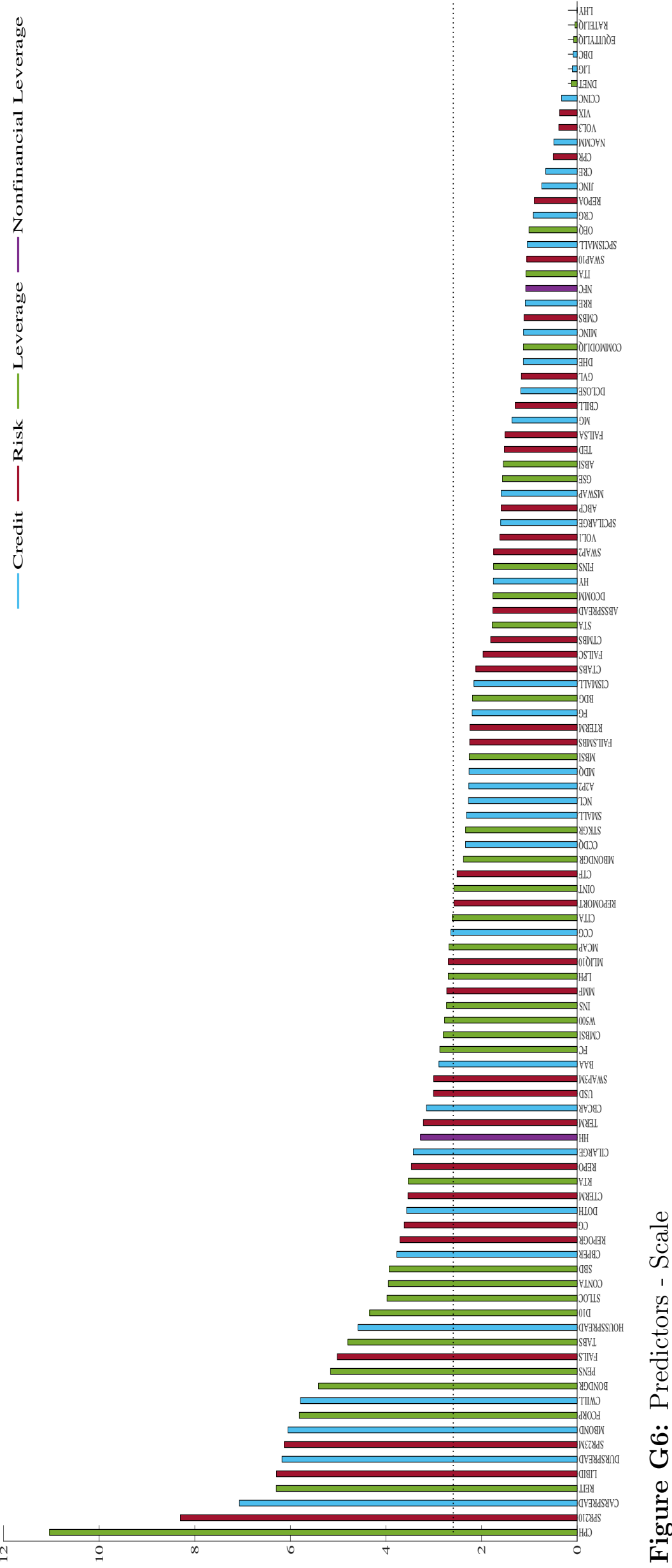




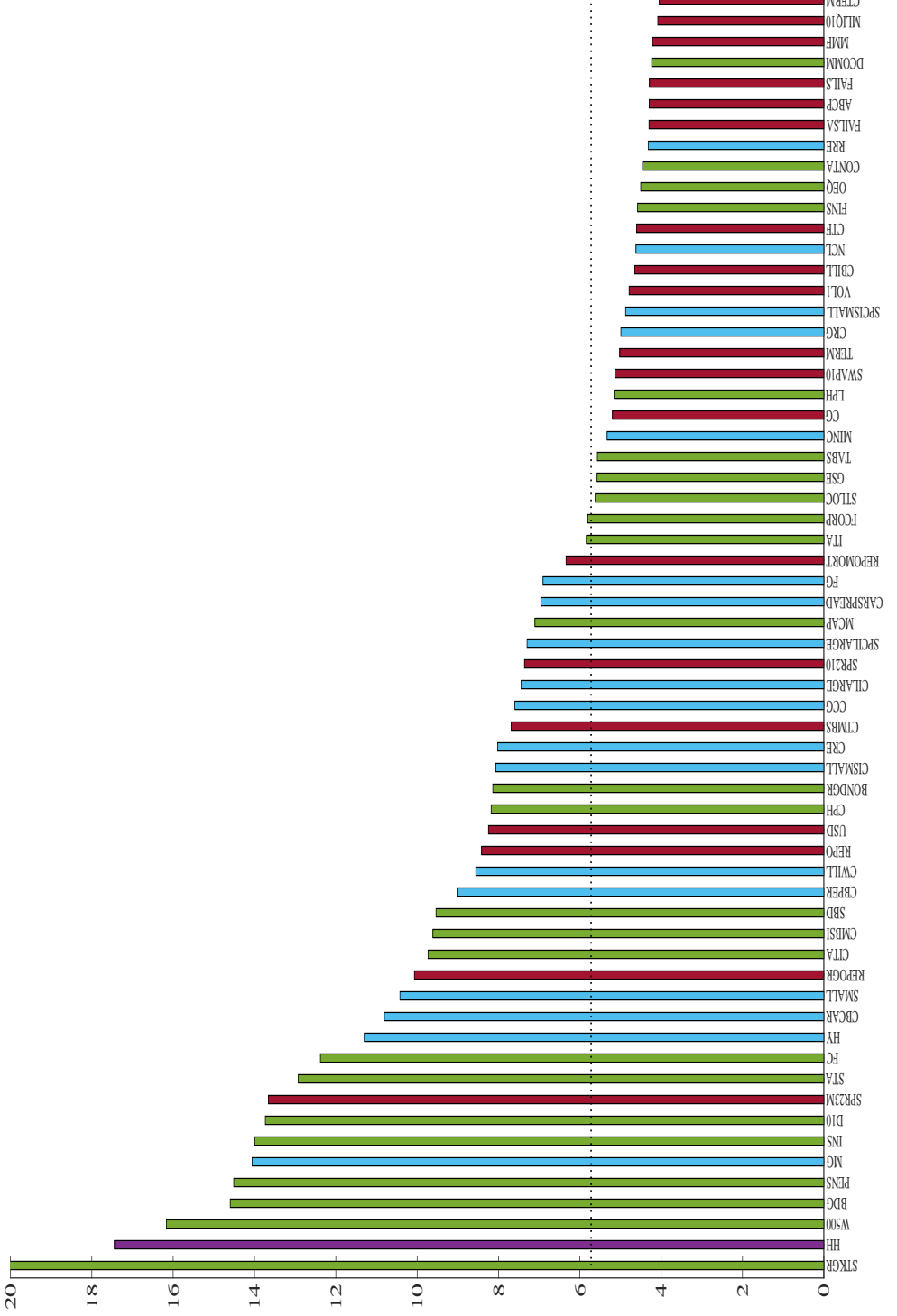




\section{References}

Adrian, T., N. Boyarchenko, and D. Giannone (2019): "Vulnerable Growth," American Economic Review, 109, 1263-89.

Adrian, T. AND H. S. SHIN (2010): "Liquidity and leverage," Journal of Financial Intermediation, 19, 418-437.

Azzalini, A. And A. Capitanio (2003): "Distributions generated by perturbation of symmetry with emphasis on a multivariate skew t-distribution," Journal of the Royal Statistical Society: Series B (Statistical Methodology), 65, 367-389.

Bekaert, G. And M. Hoerova (2014): "The VIX, the variance premium and stock market volatility," Journal of Econometrics, 183, 181-192.

Blasques, F., S. J. Koopman, And A. LuCas (2014): "Stationarity and ergodicity of univariate generalized autoregressive score processes," Electronic Journal of Statistics, 8, 1088-1112.

BollersleV, T. (1990): "Modelling the coherence in short-run nominal exchange rates: a multivariate generalized ARCH model," The Review of Economics and Statistics, 498-505.

Brave, S. And R. A. Butters (2012): "Diagnosing the Financial System: Financial Conditions and Financial Stress," International Journal of Central Banking, 8, 191239.

Brave, S. A. AND R. Butters (2011): "Monitoring financial stability: A financial conditions index approach," Economic Perspectives, 35, 22.

Calvori, F., D. Creal, S. J. Koopman, and A. Lucas (2017): "Testing for parameter instability across different modeling frameworks," Journal of Financial Econometrics, $15,223-246$.

Carvalho, C. M., N. G. Polson, And J. G. Scott (2010): "The horseshoe estimator for sparse signals," Biometrika, 97, 465-480. 
Cogley, T. And T. J. SARgent (2005): "Drifts and volatilities: monetary policies and outcomes in the post WWII US," Review of Economic Dynamics, 8, 262-302.

Cowles, M. K. And B. P. Carlin (1996): "Markov Chain Monte Carlo Convergence Diagnostics: A Comparative Review," Journal of the American Statistical Association, 91, 883-904.

Creal, D., S. J. Koopman, And A. LuCAs (2013): "Generalized autoregressive score models with applications," Journal of Applied Econometrics, 28, 777-795.

Croushore, D. (2006): "Forecasting with real-time macroeconomic data," Handbook of Economic Forecasting, 1, 961-982.

(2011): "Frontiers of real-time data analysis," Journal of Economic Literature, 49, $72-100$.

Croushore, D. And T. Stark (2001): "A real-time data set for macroeconomists," Journal of Econometrics, 105, 111-130.

DoAn, T., R. LitTerman, And C. Sims (1984): "Forecasting and conditional projection using realistic prior distributions," Econometric Reviews, 3, 1-100.

Drehmann, M., C. E. Borio, L. Gambacorta, G. Jimenez, and C. Trucharte (2010): "Countercyclical capital buffers: exploring options," Working Paper 317, Bank for International Settlement.

Escanciano, J. C. And I. N. Lobato (2009): "An automatic portmanteau test for serial correlation," Journal of Econometrics, 151, 140-149.

Gelman, A., G. O. Roberts, W. R. Gilks, et Al. (1996): "Efficient Metropolis jumping rules," Bayesian Statistics, 5, 42.

Gómez, H. W., F. J. Torres, And H. Bolfarine (2007): "Large-sample inference for the epsilon-skew-t distribution," Communications in Statistics - Theory and Methods, $36,73-81$.

HaArio, H., E. Saksman, And J. TAmminen (1999): "Adaptive proposal distribution for random walk Metropolis algorithm," Computational Statistics, 14, 375-396. 
Harvey, A. And M. Streibel (1998): "Testing for a slowly changing level with special reference to stochastic volatility," Journal of Econometrics, 87, 167-189.

Harvey, A. And S. Thiele (2016): "Testing against changing correlation," Journal of Empirical Finance, 38, 575-589.

Harvey, A. C. (2013): Dynamic models for volatility and heavy tails: with applications to financial and economic time series, vol. 52, Cambridge University Press.

Hasenzagl, T., L. Reichlin, and G. Ricco (2020): "Financial Variables as Predictors of Real Growth Vulnerability," Discussion Paper DP14322, CEPR.

Jensen, H., I. Petrella, S. H. Ravn, And E. Santoro (2020): "Leverage and Deepening Business-Cycle Skewness," American Economic Journal: Macroeconomics, $12,245-81$.

Jordà, Ò., M. Schularick, And A. M. TAYlor (2013): "When credit bites back," Journal of Money, Credit and Banking, 45, 3-28.

- (2017): "Macrofinancial history and the new business cycle facts," NBER Macroeconomics Annual Report, 31, 213-263.

JuÁrez, M. A. ANd M. F. Steel (2010): "Model-based clustering of non-Gaussian panel data based on skew-t distributions," Journal of Business 65 Economic Statistics, $28,52-66$.

Krishnamurthy, A. And T. Muir (2017): "How credit cycles across a financial crisis," Working Paper 23850, National Bureau of Economic Research.

MAKAlic, E. AND D. F. Schmidt (2015): "A simple sampler for the horseshoe estimator," IEEE Signal Processing Letters, 23, 179-182.

McConnell, M. M. And G. Perez-Quiros (2000): "Output fluctuations in the United States: What has changed since the early 1980's?" American Economic Review, 90, 1464-1476.

Mian, A. And A. Sufi (2010): "Household Leverage and the Recession of 2007-09," IMF Economic Review, 58, 74-117. 
NyBlOM, J. (1989): "Testing for the constancy of parameters over time," Journal of the American Statistical Association, 84, 223-230.

Plagborg-Møller, M., L. Reichlin, G. Ricco, and T. Hasenzagl (2020): "When is Growth at Risk?" Conference draft, Brooking Paper on Economic Activity.

Ray, P. And A. Bhattacharya (2018): "Signal Adaptive Variable Selector for the Horseshoe Prior," arXiv preprint arXiv:1810.09004.

Sims, C. A. AND T. ZHA (1998): "Bayesian methods for dynamic multivariate models," International Economic Review, 949-968.

Spiegelhalter, D. J., N. G. Best, B. P. Carlin, and A. Van Der Linde (2002): "Bayesian measures of model complexity and fit," Journal of the Royal Statistical Society: Series B (Statistical Methodology), 64, 583-639.

Stark, T. And D. Croushore (2002): "Forecasting with a real-time data set for macroeconomists," Journal of Macroeconomics, 24, 507-531.

Stock, J. H. And M. W. Watson (2002): "Has the business cycle changed and why?" NBER Macroeconomics Annual Report, 17, 159-218.

Zou, H. (2006): "The adaptive lasso and its oracle properties," Journal of the American Statistical Association, 101, 1418-1429. 


\section{RECENTLY PUBLISHED “TEMI” (*)}

N.1301 - A quantitative analysis of distortions in managerial forecasts, by Yueran Ma, Tiziano Ropele, David Sraer and David Thesmar (November 2020).

N.1302 - Bargaining power and the Phillips curve: a micro-macro analysis, by Marco J. Lombardi, Marianna Riggi and Eliana Viviano (November 2020).

N. 1303 - The effects of structural reforms: Evidence from Italy, by Emanuela Ciapanna, Sauro Mocetti and Alessandro Notarpietro (November 2020).

N. 1304 - Consumption and Wealth: New Evidence from Italy, by Riccardo De Bonis, Danilo Liberati, John Muellbauer and Concetta Rondinelli (November 2020).

N. 1305 - Do details matter? An analysis of the Italian personal income tax, by Martino Tasso (November 2020).

N.1306 - Effects of eligibility for central bank purchases on corporate bond spreads, by Taneli Mäkinen, Fan Li, Andrea Mercatanti and Andrea Silvestrini (November 2020).

N. 1307 - On the design of grant assignment rules, by Francesca Modena, Santiago Pereda Fernandez and Giulia Martina Tanzi (December 2020).

N. 1308 - Monetary policy strategies in the New Normal: a model-based analysis for the euro area, by Fabio Busetti, Stefano Neri, Alessandro Notarpietro and Massimiliano Pisani (December 2020).

N.1309 - Rare disasters, the natural interest rate and monetary policy, by Alessandro Cantelmo (December 2020).

N.1310 - The market stabilization role of central bank asset purchases: high-frequency evidence from the COVID-19 crisis, by Marco Bernardini and Annalisa De Nicola (December 2020).

N. 1311 - Equity tail risk in the treasury bond market, by Dario Ruzzi and Mirco Rubin (December 2020).

N. 1312 - Scars of youth non-employment and labour market conditions, by Giulia Martina Tanzi (December 2020).

N. 1313 - The COVID-19 shock and a fiscal-monetary policy mix in a monetary union, by Anna Bartocci, Alessandro Notarpietro and Massimiliano Pisani (December 2020).

N.1314 - Working horizon and labour supply: the effect of raising the full retirement age on middle-aged individuals, by Francesca Carta and Marta De Philippis (February 2021).

N. 1315 - Bank credit and market-based finance for corporations: the effects of minibond issuances, by Steven Ongena, Sara Pinoli, Paola Rossi and Alessandro Scopelliti (February 2021).

N. 1316 - Is inflation targeting a strategy past its sell-by date?, by Alberto Locarno and Alessandra Locarno (February 2021).

N.1317 - Declining natural interest rate in the US: the pension system matters, by Jacopo Bonchi and Giacomo Caracciolo (February 2021).

N. 1318 - Can we measure inflation expectations using Twitter?, by Cristina Angelico, Juri Marcucci, Marcello Miccoli and Filippo Quarta (February 2021).

N. 1319 - Identifying deposits'outflows in real-time, by Edoardo Rainone (February 2021).

N.1320 - Whatever it takes to save the planet? Central banks and unconventional green policy, by Alessandro Ferrari and Valerio Nispi Landi (February 2021).

(*) Requests for copies should be sent to:

Banca d'Italia - Servizio Studi di struttura economica e finanziaria - Divisione Biblioteca e Archivio storico - Via Nazionale, 91 - 00184 Rome - (fax 003906 47922059). They are available on the Internet www.bancaditalia.it. 
ALBANESE G., M. CIOFFI and P. TOMMASINO, Legislators' behaviour and electoral rules: evidence from an Italian reform, European Journal of Political Economy, v. 59, pp. 423-444, WP 1135 (September 2017).

Aprigliano V., G. ARDizzI and L. MONTEFORTE, Using the payment system data to forecast the economic activity, International Journal of Central Banking, v. 15, 4, pp. 55-80, WP 1098 (February 2017).

ARnAudo D., G. MiCUCCI, M. RIGON and P. Rossi, Should I stay or should I go? Firms' mobility across banks in the aftermath of the financial crisis, Italian Economic Journal / Rivista italiana degli economisti, v. 5, 1, pp. 17-37, WP 1086 (October 2016).

BASSO G., F. D'AMURI and G. PERI, Immigrants, labor market dynamics and adjustment to shocks in the euro area, IMF Economic Review, v. 67, 3, pp. 528-572, WP 1195 (November 2018).

BAtini N., G. MELINA and S. VILla, Fiscal buffers, private debt, and recession: the good, the bad and the ugly, Journal of Macroeconomics, v. 62, WP 1186 (July 2018).

Burlon L., A. NotARPIETRO and M. PISANI, Macroeconomic effects of an open-ended asset purchase programme, Journal of Policy Modeling, v. 41, 6, pp. 1144-1159, WP 1185 (July 2018).

BUSETTI F. and M. CAIVANO, Low frequency drivers of the real interest rate: empirical evidence for advanced economies, International Finance, v. 22, 2, pp. 171-185, WP 1132 (September 2017).

CAPpelletti G., G. GuAZZAROtTI and P. TOMmasino, Tax deferral and mutual fund inflows: evidence from a quasi-natural experiment, Fiscal Studies, v. 40, 2, pp. 211-237, WP 938 (November 2013).

CARDANi R., A. PACCAGNINI and S. VILLA, Forecasting with instabilities: an application to DSGE models with financial frictions, Journal of Macroeconomics, v. 61, WP 1234 (September 2019).

Chiades P., L. Greco, V. Mengotto, L. Moretti and P. VAlbonesi, Fiscal consolidation by intergovernmental transfers cuts? The unpleasant effect on expenditure arrears, Economic Modelling, v. 77, pp. 266-275, WP 1076 (July 2016).

CIANI E., F. DAVID and G. DE BLASIO, Local responses to labor demand shocks: a re-assessment of the case of Italy, Regional Science and Urban Economics, v. 75, pp. 1-21, WP 1112 (April 2017).

CIANI E. and P. FISHER, Dif-in-dif estimators of multiplicative treatment effects, Journal of Econometric Methods, v. 8. 1, pp. 1-10, WP 985 (November 2014).

CIAPANNA E. and M. TABOGA, Bayesian analysis of coefficient instability in dynamic regressions, Econometrics, MDPI, Open Access Journal, v. 7, 3, pp.1-32, WP 836 (November 2011).

Coletta M., R. De Bonis and S. Piermattei, Household debt in OECD countries: the role of supply-side and demand-side factors, Social Indicators Research, v. 143, 3, pp. 1185-1217, WP 989 (November 2014).

Cova P., P. PAgAno and M. PISANI, Domestic and international effects of the Eurosystem Expanded Asset Purchase Programme, IMF Economic Review, v. 67, 2, pp. 315-348, WP 1036 (October 2015).

ERCOLANI V. and J. VALLE E AZEVEDO, How can the government spending multiplier be small at the zero lower bound?, Macroeconomic Dynamics, v. 23, 8. pp. 3457-2482, WP 1174 (April 2018).

FERrERo G., M. GROSS and S. NERI, On secular stagnation and low interest rates: demography matters, International Finance, v. 22, 3, pp. 262-278, WP 1137 (September 2017).

FoA G., L. GAmBACORTA, L. Guiso and P. E. Mistrulli, The supply side of household finance, Review of Financial Studies, v.32, 10, pp. 3762-3798, WP 1044 (November 2015).

GerAli A. and S. NERI, Natural rates across the Atlantic, Journal of Macroeconomics, v. 62, article 103019, WP 1140 (September 2017).

GIORDANO C., M. MARINUCCI and A. SILVESTRINI, The macro determinants of firms' and households' investment: evidence from Italy, Economic Modelling, v. 78, pp. 118-133, WP 1167 (March 2018).

GOMEllini M., D. PELlEGRINO and F. GIFFONI, Human capital and urban growth in Italy, 1981-2001, Review of Urban \& Regional Development Studies, v. 31, 2, pp. 77-101, WP 1127 (July 2017).

LiBERATI D. and M. LOBERTO, Taxation and housing markets with search frictions, Journal of Housing Economics, v. 46, article 101632, WP 1105 (March 2017).

MAGRI S., Are lenders using risk-based pricing in the Italian consumer loan market? The effect of the 2008 crisis, Journal of Credit Risk, v. 15, 1, pp. 27-65, WP 1164 (January 2018).

Mercatanti A., T. MAKINEN and A. SiLVESTRINI, The role of financial factors for european corporate investment, Journal of International Money and Finance, v. 96, pp. 246-258, WP 1148 (October 2017). 
Miglietta A., C. Picillo and M. PIETRUnTI, The impact of margin policies on the Italian repo market, The North American Journal of Economics and Finance, v. 50, WP 1028 (October 2015).

MONTEFORTE L. and V. RAPONI, Short-term forecasts of economic activity: are fortnightly factors useful?, Journal of Forecasting, v. 38, 3, pp. 207-221, WP 1177 (June 2018).

Neri S. and A. NotArpietro, Collateral constraints, the zero lower bound, and the debt-deflation mechanism, Economics Letters, v. 174, pp. 144-148, WP 1040 (November 2015).

PANCRAZI R. and M. PIETRUNTI, Natural expectations and home equity extraction, Journal of Housing Economics, v. 46, 4, WP 984 (November 2014).

Pereda FERnANDEZ S., Teachers and cheaters. Just an anagram?, Journal of Human Capital, v. 13, 4, pp. 635-669, WP 1047 (January 2016).

RigGi M., Capital destruction, jobless recoveries, and the discipline device role of unemployment, Macroeconomic Dynamics, v. 23, 2, pp. 590-624, WP 871 (July 2012).

AlessANDRi P. and M. BOTTERO, Bank lending in uncertain times, R European Economic Review, V. 128, WP 1109 (April 2017).

Antunes A. and V. ERCOlAnI, Public debt expansions and the dynamics of the household borrowing constraint, Review of Economic Dynamics, v. 37, pp. 1-32, WP 1268 (March 2020).

ARDUINI T., E. PATACCHINI and E. RAINONE, Treatment effects with heterogeneous externalities, Journal of Business \& Economic Statistics, , v. 38, 4, pp. 826-838, WP 974 (October 2014).

Bottero M., F. MeZZANOTTI and S. LENZU, Sovereign debt exposure and the Bank Lending Channel: impact on credit supply and the real economy, Journal of International Economics, v. 126, article 103328, WP 1032 (October 2015).

BRIPI F., D. LOSCHIAVO and D. REVELLI, Services trade and credit frictions: evidence with matched bankfirm data, The World Economy, v. 43, 5, pp. 1216-1252, WP 1110 (April 2017).

BRONZINI R., G. CARAMELLINO and S. MAGRI, Venture capitalists at work: a Diff-in-Diff approach at latestages of the screening process, Journal of Business Venturing, v. 35, 3, WP 1131 (September 2017).

BronzINI R., S. MocetTI and M. MONGARDINI, The economic effects of big events: evidence from the Great Jubilee 2000 in Rome, Journal of Regional Science, v. 60, 4, pp. 801-822, WP 1208 (February 2019).

COIBION O., Y. GORODNICHENKO and T. ROPELE, Inflation expectations and firms' decisions: new causal evidence, Quarterly Journal of Economics, v. 135, 1, pp. 165-219, WP 1219 (April 2019).

CORSELlO F. and V. NiSPI LANDI, Labor market and financial shocks: a time-varying analysis, Journal of Money, Credit and Banking, v. 52, 4, pp. 777-801, WP 1179 (June 2018).

COVA P. and F. NATOLI, The risk-taking channel of international financial flows, Journal of International Money and Finance, v. 102, WP 1152 (December 2017).

D'Alessio G., Measurement errors in survey data and the estimation of poverty and inequality indices, Statistica Applicata - Italian Journal of Applied Statistics, v. 32, 3, WP 1116 (June 2017).

Del Prete S. and S. FEDERICO, Do links between banks matter for bilateral trade? Evidence from financial crises, Review of World Economic, v. 156, 4, pp. 859 - 885, WP 1217 (April 2019).

D'IGNAZIO A. and C. MENON, The causal effect of credit Guarantees for SMEs: evidence from Italy, The Scandinavian Journal of Economics, v. 122, 1, pp. 191-218, WP 900 (February 2013).

ERCOLANI V. and F. NATOLI, Forecasting US recessions: the role of economic uncertainty, Economics Letters, v. 193, WP 1299 (October 2020).

MAKINEN T., L. SARNO and G. ZINNA, Risky bank guarantees, Journal of Financial Economics, v. 136, 2, pp. 490522, WP 1232 (July 2019).

MOdEnA F., E. RETTORE and G. M. TANZI, The effect of grants on university dropout rates: evidence from the Italian case, Journal of Human Capital, v. 14, 3, pp. 343-370, WP 1193 (September 2018).

NiSPI LANDI V., Capital controls spillovers, Journal of International Money and Finance, v. 109, WP 1184 (July 2018).

PERICOLI M., On risk factors of the stock-bond correlation, International Finance, v. 23, 3, pp. 392-416, WP 1198 (November 2018). 
RAINONE E., The network nature of OTC interest rates, Journal of Financial Markets, v.47, article 100525, WP 1022 (July 2015).

RAINONE E. and F. VACIRCA, Estimating the money market microstructure with negative and zero interest rates, Quantitative Finance, v. 20, 2, pp. 207-234, WP 1059 (March 2016).

RIZZICA L., Raising aspirations and higher education. Evidence from the UK's widening participation policy, Journal of Labor Economics, v. 38, 1, pp. 183-214, WP 1188 (September 2018).

SANTIONI, R., F. SCHIANTARELLI and P. STRAHAN, Internal capital markets in times of crisis: the benefit of group affiliation, Review of Finance, v. 24, 4, pp. 773-811, WP 1146 (October 2017).

SChiantarelli F., M. Stacchini and P. Strahan, Bank Quality, judicial efficiency and loan repayment delays in Italy, Journal of Finance, v. 75, 4, pp. 2139-2178, WP 1072 (July 2016).

\section{FORTHCOMING}

Accetturo A., A. LAmorgese, S. Mocetti and D. Pellegrino, Housing Price elasticity and growth: evidence from Italian cities, Journal of Economic Geography, WP 1267 (March 2020).

AlBAnese G., E. CIANI and G. DE BLASIO, Anything new in town? The local effects of urban regeneration policies in Italy, Regional Science and Urban Economics, WP 1214 (April 2019).

Albanese G., G. DE BlAsio and A. LOCATELLI, Does EU regional policy promote local TFP growth? Evidence from the Italian Mezzogiorno, Papers in Regional Science, WP 1253 (December 2019).

ANZUINI A. and L. Rossi, Fiscal policy in the US: a new measure of uncertainty and its effects on the American economy, Empirical Economics, WP 1197 (November 2018).

Bologna P., A. Miglietta and A. Segura, Contagion in the CoCos market? A case study of two stress events, International Journal of Central Banking, WP 1201 (November 2018).

Cova P., P. PAgAnO, A. NotARPIETRO and M. PisAni, Secular stagnation, R\&D, public investment and monetary policy: a global-model perspective, Macroeconomic Dynamics, WP 1156 (December 2017).

DE PHILIPPIS M., Multitask agents and incentives: the case of teaching and research for university professors, Economic Journal, WP 1156 (December 2015).

Del Prete S. and M. L. SteFAni, Women as "Gold Dust": gender diversity in top boards and the performance of Italian banks, Economic Notes, Monte dei Paschi di Siena, WP 1014 (June 2015).

Fidora M., C. GIORDANO and M. SchMitz, Real exchange rate misalignments in the Euro Area, Open Economies Review, WP 1042 (January 2018).

HERTWECK M., V. LEWIS and S. VILLA, Going the extra mile: effort by workers and job-seekers, Journal of Money, Credit and Banking, WP 1277 (June 2020).

Li F., A. MercatAnti, T. MAKINEN and A. SilveSTRINI, A regression discontinuity design for ordinal running variables: evaluating central bank purchases of corporate bonds, Annals of Applied Statistics, WP 1213 (March 2019).

LOSCHIAVO D., Household debt and income inequality: evidence from Italian survey data, Review of Income and Wealth, WP 1095 (January 2017).

METELli L. and F. NATOLI, The international transmission of US tax shocks: a proxy-SVAR approach, IMF Economic Review, WP 1223 (June 2019).

Mocetti S., G. RomA and E. RuBOLINO, Knocking on parents' doors: regulation and intergenerational mobility, Journal of Human Resources, WP 1182 (July 2018).

NisPi LANDI V. and A. SCHIAVONE, The effectiveness of capital controls, Open Economies Review, WP 1200 (November 2018).

PeReda Fernandez S., Copula-based random effects models for clustered data, Journal of Business \& Economic Statistics, WP 1092 (January 2017).

PERICOLI M. and M. TABOGA, Nearly exact Bayesian estimation of non-linear no-arbitrage term-structure models, Journal of Financial Econometrics, WP 1189 (September 2018). 